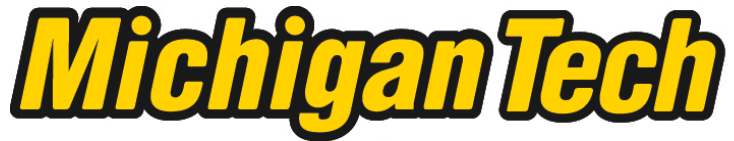 \\ Michigan Technological University Create the Future Digital Commons @ Michigan Tech
}

2010

\section{Mathematical analysis for perceived annoyance of impulsive sounds in terms of physical factors}

Gayatri S. Kadlaskar

Michigan Technological University

Follow this and additional works at: https://digitalcommons.mtu.edu/etds

Part of the Mechanical Engineering Commons

Copyright 2010 Gayatri S. Kadlaskar

\section{Recommended Citation}

Kadlaskar, Gayatri S., "Mathematical analysis for perceived annoyance of impulsive sounds in terms of physical factors", Master's report, Michigan Technological University, 2010.

https://doi.org/10.37099/mtu.dc.etds/559

Follow this and additional works at: https://digitalcommons.mtu.edu/etds

Part of the Mechanical Engineering Commons 


\title{
MATHEMATICAL ANALYSIS FOR PERCEIVED ANNOYANCE OF IMPULSIVE SOUNDS IN TERMS OF PHYSICAL FACTORS
}

\author{
By \\ GAYATRI S. KADLASKAR
}

\begin{abstract}
A REPORT
Submitted in partial fulfillment of the requirements

For the degree of

MASTER OF SCIENCE IN MECHANICAL ENGINEERING
\end{abstract}

MICHIGAN TECHNOLOGICAL UNIVERSITY

2010

Copyright $\odot$ Gayatri S. Kadlaskar 2010 
This thesis, "Mathematical Analysis for Perceived Annoyance of Impulsive Sounds In Terms Of Physical Factors", is hereby approved in partial fulfillment of the requirements for the Degree of MASTER OF SCIENCE in Mechanical Engineering.

\section{DEPARTMENT:}

Mechanical Engineering-Engineering Mechanics

Signatures:

Report Advisor

Dr. Mohan D. Rao

Department Chair

Dr. William W. Predebon

Date 


\section{Abstract}

From the customer satisfaction point of view, sound quality of any product has become one of the important factors these days. The primary objective of this research is to determine factors which affect the acceptability of impulse noise. Though the analysis is based on a sample impulse sound file of a Commercial printer, the results can be applied to other similar impulsive noise.

It is assumed that impulsive noise can be tuned to meet the accepTable criteria. Thus it is necessary to find the most significant factors which can be controlled physically. This analysis is based on a single impulse. A sample impulsive sound file is tweaked for different amplitudes, background noise, attack time, release time and the spectral content. A two level factorial design of experiments (DOE) is applied to study the significant effects and interactions. For each impulse file modified as per the DOE, the magnitude of perceived annoyance is calculated from the objective metric developed recently at Michigan Technological University. This metric is based on psychoacoustic criteria such as loudness, sharpness, roughness and loudness based impulsiveness. Software called 'Artemis V11.2' developed by HEAD Acoustics is used to calculate these psychoacoustic terms. As a result of two level factorial analyses, a new objective model of perceived annoyance is developed in terms of above mentioned physical parameters such as amplitudes, background noise, impulse attack time, impulse release time and the spectral content. Also the effects of the significant individual factors as well as two level interactions are also studied. The results show that all the mentioned five factors affect annoyance level of an impulsive sound significantly. Thus annoyance level 
can be reduced under the criteria by optimizing the levels. Also, an additional analysis is done to study the effect of these five significant parameters on the individual psychoacoustic metrics. 


\section{Acknowledgments}

I would like to dedicate this work to my parents, grandparents and my sweet younger sister for their unconditional love and support. This project wouldn't have been possible without the support of my advisor, colleagues, family and friends. I would like to take this opportunity to thank all of them.

During the whole course of my graduate study, my adviser Dr. Rao has always been kind and supportive towards me. He provided me with the great technical support throughout last three years of my graduate study. He has always offered me different challenging projects in the field of Noise, Vibration and Harshness. He has always encouraged me to work through my ups and downs.

This project was made possible because of the generous financial and technical support I received from Xerox Corporation. Mr. Jasper Wong and Mr. Jeffrey Shelton were the two points of contact for this research. They have always provided me with all the technical help I needed on this project. Also, I would like to thank them for backing me in this project to maintain my timeline constraints.

Russ Ruhnow of HEAD Acoustics has provided very prompt technical support for Artemis software. He was supportive to provide help in acquiring new modules for this project by going out of his way. I would like to acknowledge the help and guidance of Andrew Willemsen at MTU to get me started with the project and answering my unending questions.

I would like to thank Dr. Friedrich for providing me guidance throughout my Master's Degree. I would also like to thank Dr. Paulin Buaka and David Nickel from 
Cummins Emission Solution, Stoughton, WI for mentoring me throughout my internship. Through their guidance I have gained practical experience and skill-set required to approach any engineering problem.

Finally, I would like to appreciate my friends at Houghton for being there with me through thick and thin. Without their support and cooking I wouldn't have survived the long winters. 


\section{List of Contents}

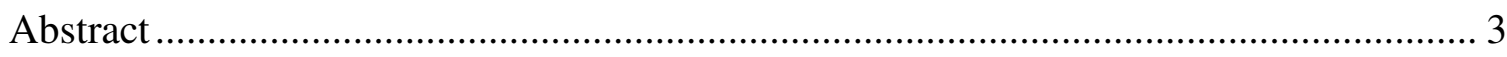

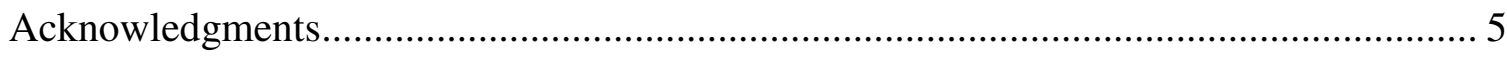

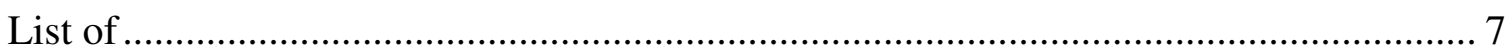

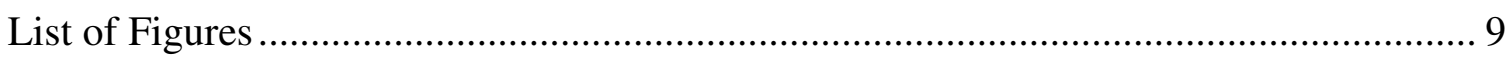

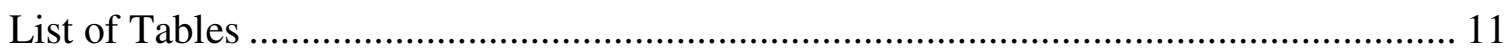

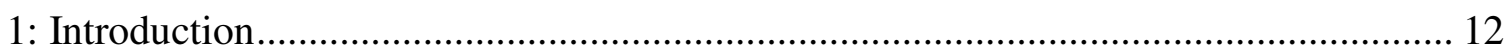

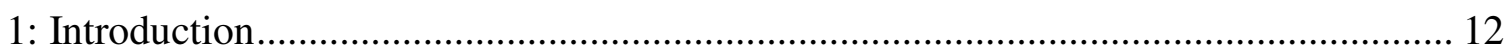

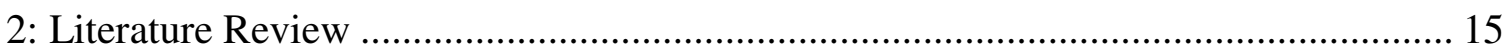

2.1: Research on Sound Quality Measurement.......................................................... 15

2.2: Research on Sound Quality of Impulsive Sounds ........................................... 17

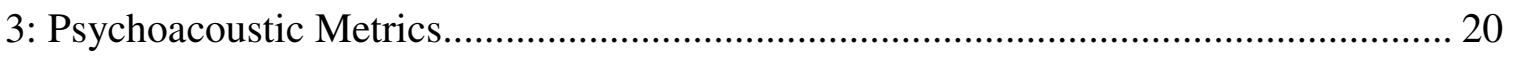

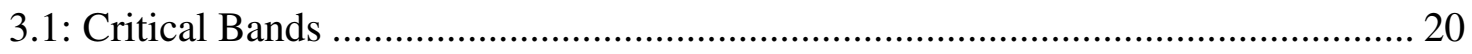

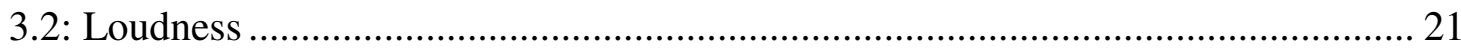

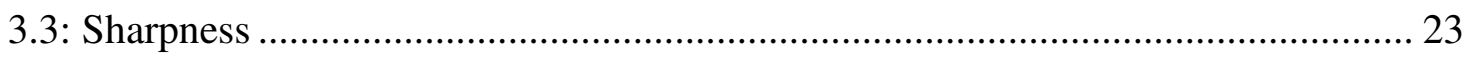

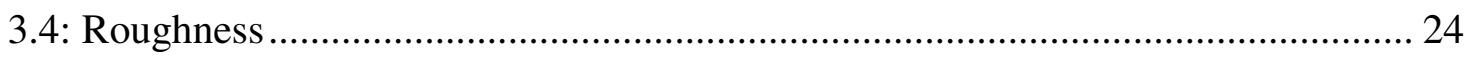

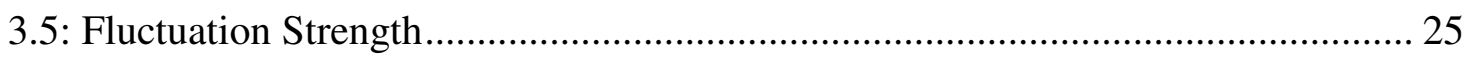

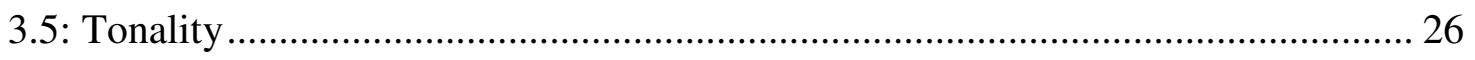

3.6: Loudness Based Impulsiveness ....................................................................... 27

4: Objective Metric for Perceived Annoyance............................................................. 30

5: Physical Parameters of an Impulse and their Effect on Annoyance ............................. 34

5.1: Physical Parameters of a single impulse ........................................................ 34

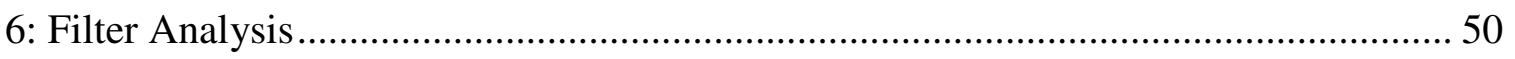

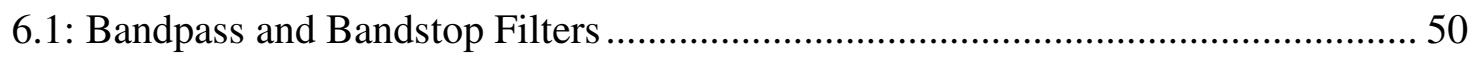

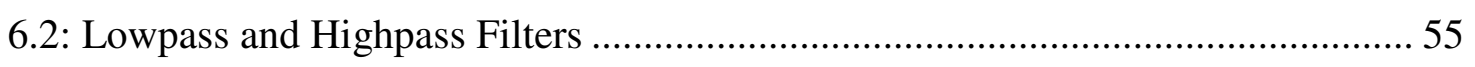

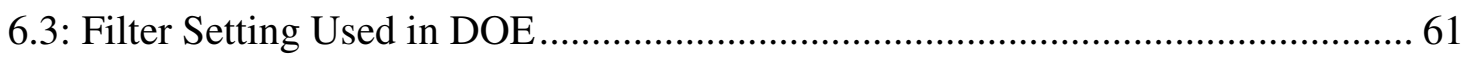

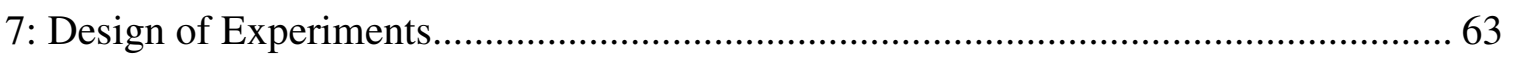

7.1: Development of Prediction Model by $2^{5}$ Full Factorial Design ........................... 63

7.2: Confirmatory tests for checking the model................................................. 73

7.3: Coefficient of Determination and PRESS ..................................................... 76 


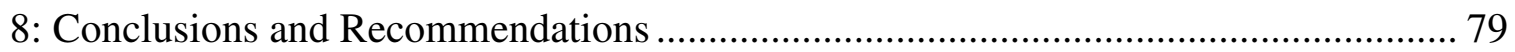

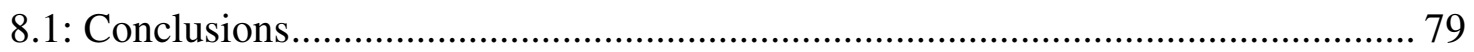

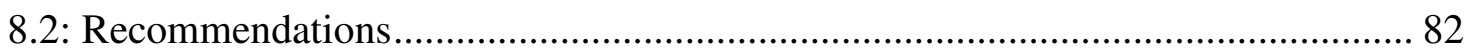

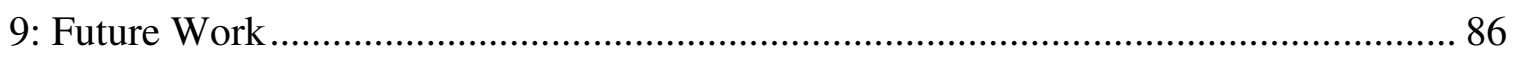

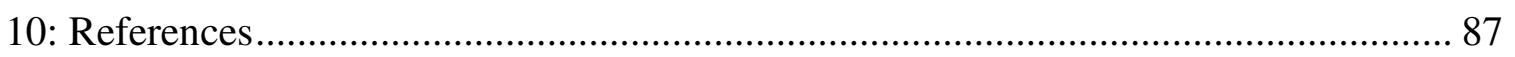

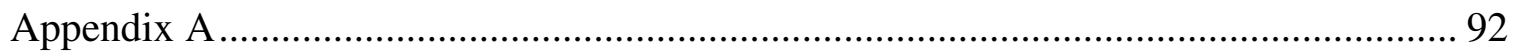

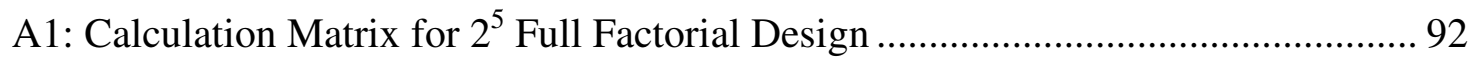

A2: Computed Values for Loudness N5, Sharpness S50, Roughness R5, Impulsiveness

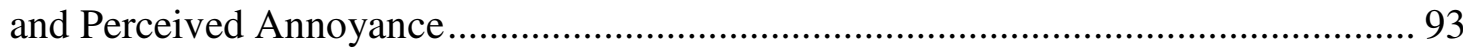

A3: Coefficients for Loudness N5, Sharpness S50, Roughness R5, Impulsiveness and Perceived Annoyance Mathematical Model ........................................................... 96

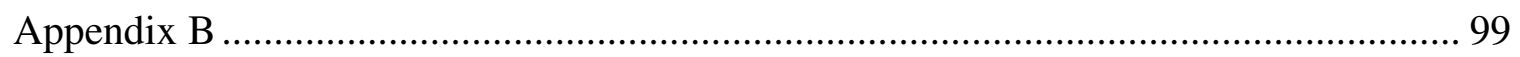

Matlab Code for Loudness Based Impulsiveness Metric [_] ................................... 99

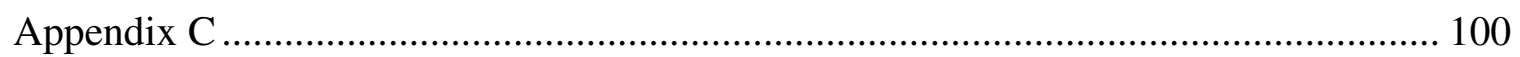

Permission for using Copyright Material.............................................................. 100 


\section{List of Figures}

Figure 1: Selected Loudness Vs Time Settings in Artemis 11.2 …………………….... 23

Figure 2: Selected Sharpness Vs Time Settings in Artemis 11.2 ……………………... 24

Figure 3: Selected Fluctuation Strength Vs Time Settings in Artemis 11.2 .................... 26

Figure 4: Selected Tonality Vs Time Settings in Artemis 11.2 ……………………..... 27

Figure 5: Frequency Content of strip_05 ..................................................................... 35

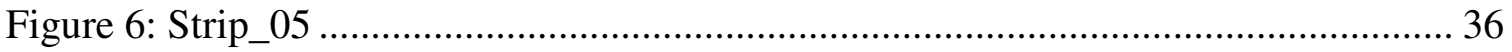

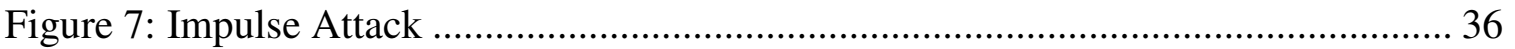

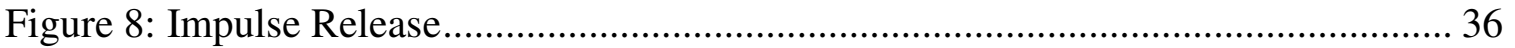

Figure 9: Effect of Variation in Amplitude of an Impulse on Perceived Annoyance....... 38

Figure 10: Effect of Variation in Amplitude of an Impulse on Loudness N5 ………....... 39

Figure 11: Effect of Variation in Amplitude of an Impulse on Loudness N5 .................. 39

Figure 12: Effect of Variation in Amplitude of an Impulse on Roughness R5 ……........ 39

Figure 13: Effect of Variation in Amplitude of an Impulse on Impulsiveness.................. 39

Figure 14: Background Noise file Properties (back_02) ................................................. 40

Figure 15: Effect of Variation in Background Noise Amplitude of an Impulse on

Perceived Annoyance................................................................................... 41

Figure 16: Effect of Variation in Background Noise Amplitude of an Impulse on Loudness N5 ..................................................................................... 42

Figure 17: Effect of Variation in Background Noise Amplitude of an Impulse on

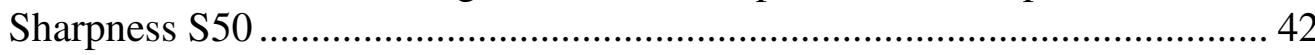

Figure 18: Effect of Variation in Background Noise Amplitude of an Impulse on Roughness R5 ………..................................................................... 42

Figure 19: Effect of Variation in Background Noise Amplitude of an Impulse on

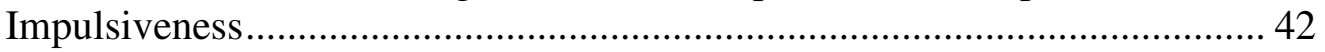

Figure 20: Effect of Variation in Attack Time of an Impulse on Perceived Annoyance.. 43

Figure 21: Effect of Variation in Attack Time of an Impulse on Loudness N5 ............... 44

Figure 22: Effect of Variation in Attack Time of an Impulse on Sharpness S50 ............. 44

Figure 23: Effect of Variation in Attack Time of an Impulse on Roughness R5 ............. 44

Figure 24: Effect of Variation in Attack Time of an Impulse on Impulsiveness.............. 44

Figure 25: Effect of Variation in Release Time of an Impulse on Perceived Annoyance 46

Figure 26: Effect of Variation in Release Time of an Impulse on Loudness N5 .............. 47

Figure 27: Effect of Variation in Release Time of an Impulse on Sharpness S50 ........... 47

Figure 28: Effect of Variation in Release Time of an Impulse on Roughness R5 ............ 47

Figure 29: Effect of Variation in Release Time of an Impulse on Impulsiveness ............ 47

Figure 30: Effect of Low Pass Filter on Perceived Annoyance......................................... 48

Figure 31: Effect of Low Pass Filter on Loudness N5 .................................................... 49

Figure 32: Effect of Low Pass Filter on Sharpness S50 …………………................... 49

Figure 33: Effect of Low Pass Filter on Roughness R5 .................................................. 49

Figure 34: Effect of Low Pass Filter on Impulsiveness ..................................................... 49

Figure 35: Effect of Various Filter Orders as Various Frequency Bands on Annoyance-

BP and BS Butterworth Filters ................................................................. 52 
Figure 36: Effect of Various Filter Orders as Various Frequency Bands on AnnoyanceBP and BS Bessel Filters

Figure 37: Effect of Various Filter Orders as Various Frequency Bands on AnnoyanceBP and BS Tschebycheff0.5dB Filters

Figure 38: Effect of Various Filter Orders as Various Frequency Bands on AnnoyanceBP and BS Tschebycheff3dB Filters

Figure 39: Effect of Various Filter Types at Various Frequency Bands on AnnoyanceBandpass order 4 Filters.

Figure 40: Effect of Various Filter Orders at Various Frequency Bands on AnnoyanceBandpass Tschebycheff 0.5dB Filter

Figure 41: Effect of Various Filter Orders as Various Frequency Bands on Annoyance-

LP and HP Butterworth Filters 56

Figure 42: Effect of Various Filter Orders at Various Frequency Bands on AnnoyanceLowpass Butterworth Filter ..... 57

Figure 43: Effect of Various Filter Orders as Various Frequency Bands on Annoyance-

LP and HP Bessel Filters 57

Figure 44: Effect of Various Filter Orders at Various Frequency Bands on AnnoyanceLowpass Bessel Filter 58

Figure 45: Effect of Various Filter Orders as Various Frequency Bands on Annoyance-

LP and HP Tschebycheff $0.5 \mathrm{~dB}$ Filters

Figure 46: Effect of Various Filter Orders at Various Frequency Bands on AnnoyanceLowpass Tschebycheff $0.5 \mathrm{~dB}$ Filter

Figure 47: Effect of Various Filter Orders as Various Frequency Bands on AnnoyanceLP and HP Tschebycheff $3 \mathrm{~dB}$ Filters

Figure 48: Effect of Various Filter Orders at Various Frequency Bands on AnnoyanceLowpass Tschebycheff $3 \mathrm{~dB}$ Filter

Figure 49: Effect of Various Filter Types at Various Frequency Bands on AnnoyanceLowpass order 4 Filters 61

Figure 50: Model Residuals Vs Run Order (3s dead time filter setting 1) ....................... 75

Figure 51: Model Residuals Vs Predicted Annoyance (3s dead time filter setting 1)...... 75

Figure 53: Model Residuals Vs Amplitude (3s dead time filter setting 1) ....................... 75 Figure 54: Model Residuals Vs Background Noise (3s dead time filter setting 1) .......... 76 Figure 55: Model Residuals Vs Attack Time (3s dead time filter setting 1) .................... 76 Figure 56: Model Residuals Vs Release Time (3s dead time filter setting 1) ................... 76 Figure 57: Model Residuals Vs Filter Level (3s dead time filter setting 1) ..................... 76 


\section{List of Tables}

Table 1: Critical Frequency Bands for Human Ear ........................................................ 21

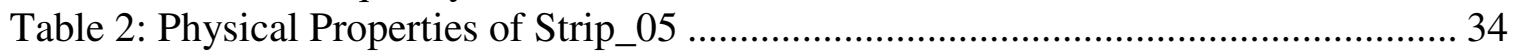

Table 3: Effect of Variation in Amplitude of an Impulse on Perceived Annoyance ........ 37

Table 4: Effect of Variation in Background Noise Amplitude of an Impulse on Perceived

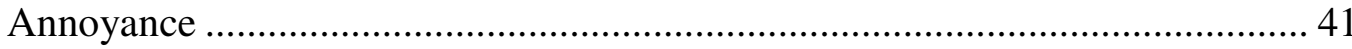

Table 5: Effect of Variation in Attack Time of an Impulse on Perceived Annoyance ..... 43

Table 6: Effect of Variation in Release Time of an Impulse on Perceived Annoyance ... 46

Table 7: Effect of Variation in Frequency Content of an Impulse on Perceived

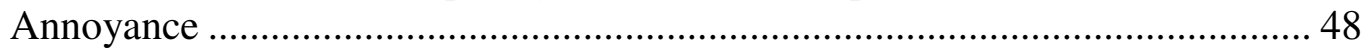

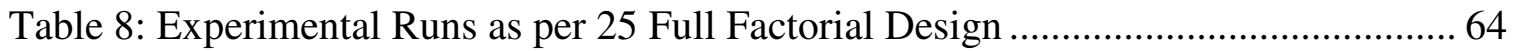

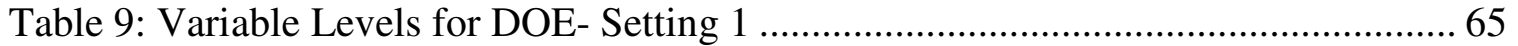

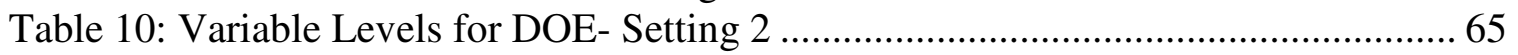

Table 11: Psychoacoustic Response values for file: 0.2s dead time filter setting 2 ........ 66

Table 12: Coefficients for Significant Factors in Predicted Model for annoyance, loudness, roughness, sharpness and impulsiveness for file: $0.2 \mathrm{~s}$ dead time filter

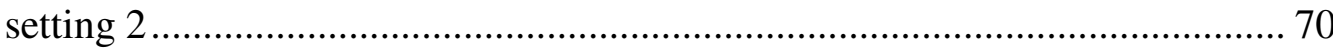

Table 13: Psychoacoustic Response values for file: 3 s dead time filter setting 1 .......... 72

Table 14: Coefficients for Significant Factors in Predicted Model for annoyance, loudness, roughness, sharpness and impulsiveness for file: $3 \mathrm{~s}$ dead time filter

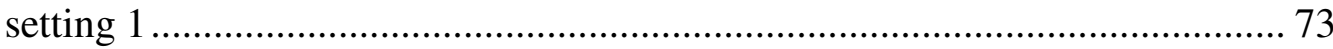

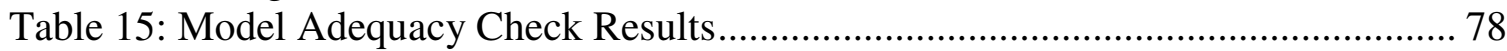

Table 17: Psychoacoustic Response values for file: 1s dead time filter setting 1 ..........93

Table 18: Psychoacoustic Response values for file: 1 s dead time filter setting 2 .......... 94

Table 19: Psychoacoustic Response values for file: 3s dead time filter setting 2 .......... 95

Table 20: Coefficients for Significant Factors in Predicted Model for annoyance, loudness, roughness, sharpness and impulsiveness for file: 1s dead time filter setting 1

Table 21: Coefficients for Significant Factors in Predicted Model for annoyance, loudness, roughness, sharpness and impulsiveness for file: 1s dead time filter setting 2

Table 22: Coefficients for Significant Factors in Predicted Model for annoyance, loudness, roughness, sharpness and impulsiveness for file: $3 \mathrm{~s}$ dead time filter setting 2 


\section{1: Introduction}

Sound Quality of a product is an important factor during its evaluation. As any machine is a mechanical system, it produces different sounds while in operating condition. For various ranges of products, not only the sound pressure level but also the quality of the unwanted sound (noise) creates a big impact on what attracts or repels the customer. Thus, it is very important to tune these sounds to meet the acceptability criteria of the customers. It has been observed that impulsive sounds from printers are one of the concerns in many offices [1]. Thus it is necessary to quantify the annoyance due to these impulsive sounds from printers.

The sound quality evaluation is primarily based on how a human ear perceives the sound; pleasant or annoying. Objective parameters such as sound pressure level of the sound in $\mathrm{dBA}$ are not sufficient to evaluate the sound quality accurately $[2,3]$. Thus, it is very important to study different psychoacoustic metrics. Psychoacoustics deals with the relationship between physical characteristics of sound and its perceptual attributes [4]. It analyses subjective attributes of sound, such as loudness, sharpness, roughness, fluctuation strength and tonality; and how they relate to physically measurable quantities such as sound level, frequency, duration and spectrum of the sound.

Until now, a lot of research [5 through 27] has been carried out to develop different metrics, which would quantify sound quality in terms of individual psychoacoustics attributes such as loudness, sharpness, roughness, fluctuation strength and tonality. Recently a new objective metric [28] for perceived annoyance of impulsive sound has been developed at Michigan Technological University by Andrew Willemsen 
under Dr. Mohan Rao. In [28], the perceived annoyance of an impulsive sound is characterized in terms of loudness, sharpness, roughness and impulsiveness. An objective relation of physical parameters of an impulsive sound such as amplitude, frequency content, and duration with respect to its perceived annoyance has not yet been clearly developed. In this project a mathematical model for the perceived annoyance in terms of the above mentioned physical factors which can be externally tweaked is presented. By using this model an impulsive sound can be tuned under acceptable annoyance values.

In order to tune the printer's impulsive noise within acceptable range, different impulsive sounds from Xerox Corp.'s printers were studied to rate annoyance level as part of this project. The primary objective behind this project is to determine the various factors that might influence the sound quality of an impulsive noise for a printer.

For the scope of this project, the analysis is limited to only single impulse rather than multiple impulses. It is assumed that the objective metric for perceived annoyance with psychoacoustic attributes is best applicable to technical impulsive sounds [28]. Thus it was decided to use real life sample impulse files from a Xerox printer for the analysis. The data were recorded at Xerox using a binaural HEAD system. Out of all the available impulses, a sample impulse file which sounded most annoying was selected for the study. Every recorded file has two channels one representing each ear. The channel with higher sound pressure level was selected for the analysis.

This analysis is done on the first impulse in a recorded signal called 'strip_05'. Physical parameters of 'strip_05' are shown in Table 2. The selected impulse is modified for varying amplitudes, background noise levels, attack and release times and filter settings. Initially the effect of individual variable on the perceived annoyance and other 
fundamental psychoacoustic attributes is studied. The change in attack and release durations for an impulse is done by stretching or shrinking the time signal using Artemis 11.2 time editing module [29]. The effect of spectral content in an impulsive signal is studied by applying different filters to the signal.

A planned $2^{5}$ full factorial experiment is designed to study the effect of 5 factors (amplitude, background noise, attack time, release time and spectral content) on the annoyance and other fundamental psychoacoustic attributes [30]. This approach is taken to identify significance of the physical factors which are considered under this analysis.

The mathematical models in terms of amplitude, background noise, attack time, release time and spectral content are developed for annoyance, loudness $\left(5^{\text {th }}\right.$ percentile), roughness $\left(5^{\text {th }}\right.$ percentile), sharpness (median value) and loudness based impulsiveness. With the help of these mathematical models it is possible to identify critical parameters to tweak in order to tune the impulsive sounds under the acceptable criteria. The results are presented in Chapter 9. 


\section{2: Literature Review}

This Chapter summarizes some previously done studies and findings on quantification of sound quality relevant to the current project.

\section{1: Research on Sound Quality Measurement}

Sound quality of a product is one of the important factors from the customer satisfaction point of view. In some cases, sound coming out of the product may be perceived as annoying. Now, as perception of annoyance is subjective to each human being, it becomes very important to quantify the annoyance objectively. Many studies have focused on development of a sound quality metric for a specific device or with more general applications [_10-21, 31]. Most of them talk about non transient sounds. Altinsoy, Kanka, and Belak [19] and Sobhi and Ladegaard [20] developed objective measures of annoyance for sounds emitted by household appliances. Altinsoy, Kanka, and Belak found that the annoyance of vacuum cleaner noise depended on loudness, sharpness, roughness, fluctuation strength, tone-to-noise ratio, and prominence ratio. Sottek and Genuit [12] developed a 'Hearing Model' for evaluation of sound quality of a fan noise. According to them Tonal components and modulated sounds are often the causes of customer complaints. Thus, Applying the Hearing Model to sound quality tasks allowed them to evaluate the spectral and temporal patterns of a sound apart from it's Aweighted sound pressure level and loudness. Likewise many past studies have shown that, it is possible to model the annoyance perceived by human ear with fundamental 
psychoacoustic metrics such as loudness, sharpness, roughness, fluctuation strength, tonality etc [10-20, 31, 32]. Several other studies have been conducted which resulted in development of nonlinear relationships between psychoacoustic metrics and sound quality. One such study by Widmann $[5,31]$ resulted in the development of the measure known as psychoacoustic annoyance. This measure uses 5th percentile loudness, sharpness, fluctuation strength, and roughness to predict annoyance. This metric is applicable to both synthetic and technical sounds. Similarly Aures [5, 21] modeled sensory pleasantness based on relative values of loudness, sharpness, roughness, and tonality. This model found the relationship between these psychoacoustic metrics and pleasantness to be exponential, and predicted relative perceived pleasantness.

Most of these models were developed using regression analysis theory. For this technique, jury evaluation experiments were conducted to subjectively rate the sound quality of a sample set of sounds. Mathematical models for different psychoacoustic metrics were designed by regression to predict these subjective ratings. Nykänen and Sirkka [15] developed sound quality metrics for automobile power windows using the same technique predicting the perceived annoyance. This study found that product quality could be predicted by loudness of the sound filtered by a lowpass filter $(0-1500 \mathrm{~Hz})$, sharpness as determined from a weighting of the sound pressure level, and relative RPM deviation of the power window motor. Also they proposed that the perceived annoyance could be predicted from just the lowpass filtered loudness and the sound pressure level based sharpness. This annoyance model accounted for $98 \%$ of the variability in the subjective annoyance ratings. In the current project also frequency content of impulsive sound under study is varied using lowpass filter at different cutoff frequencies. 


\section{2: Research on Sound Quality of Impulsive Sounds}

Most of the above mentioned studies have focused on non transient general sound. In the past few studies have tried to predict annoyance due to impulsive sounds as a function of psychoacoustic attributes [33-37].

Recently at Michigan Technological University Willemsen and Rao [28] developed an objective metric for prediction of perceived annoyance of an impulsive wave. Though this research is done for the printer's impulsive sounds, the annoyance model is applicable to any technical or generic impulsive sound. In [28], perceived annoyance is expressed in terms of loudness $\left(5^{\text {th }}\right.$ percentile), sharpness (median value), roughness $\left(5^{\text {th }}\right.$ percentile) and loudness based impulsiveness measure. The model is developed using simple and multiple regression method based on the results obtained from jury annoyance evaluation data for some sample impulsive sounds. The annoyance model developed in [28] is used to generate perceived annoyance data for the current project.

The annoyance model developed in [28] includes a term called impulsiveness which is used to define sound quality of an impulsive noise. Till now two methods for quantifying impulsiveness have been standardized. The first of these methods, specific to IT equipment applications, is the ISO 7779 impulsive parameter [36]. The ISO 7779 procedure for measuring impulsiveness requires determination of the A-weighted sound pressure level of a sound with no time weighting and with impulse time weighting. The impulse time weighting integrates over 35 milliseconds while rising to a peak value. Once the peak is reached, the level slowly decays with an integration time of 1500 milliseconds. This method is not used for the development of annoyance metric in [28] 
because of the following reasons: The impulse time-weighting does not allow for the detection of closely spaced impulses due to the slow post-peak decay time. Also it does not accurately reflect the degree of impulse detection by human hearing.

The second standardized method for impulsiveness is described as the NORDTEST Method NT ACOU 112 [37] and explained by Pedersen [32]. This standardized method determines a predicted prominence of the impulses in a sound.

Willemsen and Rao [28] developed a new measure for quantification of impulsiveness which proves to be more accurate than above two methods. The measure is based on the time varying loudness of the impulsive file. This impulsiveness metric sums together the magnitudes of each loudness impulse in the sound recording. The impulsiveness equation generated at the end of this [28] study is used to calculate impulsiveness in the current project.

The focus of the current research is to formulate the effect of various physical parameters of an impulse on its perceived annoyance. Few similar studies on this topic have been done in the past. Dfi Dell, Pearsonsm, Grignetti and Green [35] studied the effects of duration, inter-signal interval, repetition and the frequency on the perceived noisiness of an impulsive signal. This research concluded that the variations in the phase spectra of the impulsive signals do not have significant impact on the noisiness of that signal. They may sound different but they may not be subjectively perceived with different annoyance levels. Boullet, Parizeau and Meunier [39] designed a model of loudness applicable to impulsive sounds to study the effects of duration, frequency and temporal pattern of the signal on loudness. In this research five pure tones of different durations were used to mimic the impulsive sound of short attack, zero sustain and 
exponential decay. In this research [39], it was found that, loudness of such impulse increases with increase in duration. It also states that for impulses with duration less than $500 \mathrm{~ms}$, frequency does not affect the loudness of the signal. In this current project, which focuses on the printer impulses, it is found that frequency is one of the major factors in determining the loudness and annoyance of the noise. 


\section{3: Psychoacoustic Metrics}

\section{1: Critical Bands}

Till now a lot of research has been done on human hearing and how a human ear responds to a sound stimulus [2, 4-7, 40]. Human ear combines sound stimuli situated close to each other in frequency domain in a single frequency band. These bands are called as critical bands. For a given frequency or a tone, the critical band is the smallest band of frequencies around which it activates the same part of the basilar membrane. Zwicker divided the audible range into 24 critical bands with a scale called 'Critical band rate' $[2,5,9]$. It is measured in the units of 'Barks'. The following Table gives the critical bands with the corresponding bandwidths. 
Table 1: Critical Frequency Bands for Human Ear

\begin{tabular}{|c|c|c|c|c|c|c|c|c|}
\hline $\begin{array}{c}\text { Critical } \\
\text { Band } \\
\text { Rate } \\
\mathbf{Z} \text { (Bark) }\end{array}$ & $\begin{array}{c}\text { Frequency } \\
(\mathrm{Hz})\end{array}$ & $\begin{array}{c}\text { Critical } \\
\text { bandwidth }\end{array}$ & $\begin{array}{c}\text { Critical } \\
\text { Band } \\
\text { Rate } \\
\mathbf{Z} \text { (Bark) }\end{array}$ & $\begin{array}{c}\text { Frequency } \\
(\mathrm{Hz})\end{array}$ & $\begin{array}{c}\text { Critical } \\
\text { bandwidth }\end{array}$ & $\begin{array}{c}\text { Critical } \\
\text { Band } \\
\text { Rate } \\
\mathbf{Z}(\text { Bark) }\end{array}$ & $\begin{array}{c}\text { Frequency } \\
(\mathrm{Hz})\end{array}$ & $\begin{array}{c}\text { Critical } \\
\text { bandwidth }\end{array}$ \\
\hline $\mathbf{0}$ & 0 & & $\mathbf{8}$ & 920 & & $\mathbf{1 6}$ & 3150 & $\Delta \mathrm{f}(\mathrm{Hz})$ \\
\hline & & 100 & & & 160 & & & 550 \\
\hline $\mathbf{1}$ & 100 & & $\mathbf{9}$ & 1080 & & $\mathbf{1 7}$ & 3700 & \\
\hline & & 100 & & & 190 & & & 700 \\
\hline $\mathbf{2}$ & 200 & & $\mathbf{1 0}$ & 1270 & & $\mathbf{1 8}$ & 4400 & \\
\hline & & 100 & & & 210 & & & 900 \\
\hline $\mathbf{3}$ & 300 & & $\mathbf{1 1}$ & 1480 & & $\mathbf{1 9}$ & 5300 & \\
\hline & & 100 & & & 240 & & & 1100 \\
\hline $\mathbf{4}$ & 400 & & $\mathbf{1 2}$ & 1720 & & $\mathbf{2 0}$ & 6400 & \\
\hline & & 110 & & & 280 & & & 1300 \\
\hline $\mathbf{5}$ & 510 & & $\mathbf{1 3}$ & 2000 & & $\mathbf{2 1}$ & 7700 & \\
\hline & & 120 & & & 320 & & & 1800 \\
\hline $\mathbf{6}$ & 630 & & $\mathbf{1 4}$ & 2320 & & $\mathbf{2 2}$ & 9500 & \\
\hline & & 140 & & & 380 & & & 2500 \\
\hline $\mathbf{7}$ & 770 & & $\mathbf{1 5}$ & 2700 & & $\mathbf{2 3}$ & 12000 & \\
\hline & & 150 & & & 450 & & & 3500 \\
\hline & & & & & & $\mathbf{2 4}$ & 15500 & \\
\hline
\end{tabular}

\section{2: Loudness}

Loudness is the subjective perception of acoustic signal amplitude by human ear. It is the term used to describe the estimate of sound intensity as per human sensation. The unit used for loudness in is the phon or sone. At $1000 \mathrm{~Hz}$, value of loudness in phon is equal to $\mathrm{dB}$ from the equal loudness contours. Human ear reacts differently to different frequencies. Equal loudness contour is a curve with represents SPL over a frequency range for which the listener perceives the sound at same loudness level. The subjective perceptual estimate of loudness does not directly correspond to SPL. To visualize the amplitude of loudness on a linear scale, the unit of loudness "sone" was developed. 1 sone is defined as equal to the subjective loudness of a 40 phon sound. Thus a tone of frequency $1000 \mathrm{~Hz}$ with a sound pressure level of $40 \mathrm{~dB}$ is defined as equal to 1 sone. It 
is observed that the relation between loudness and the sound power or sound pressure level is not linear. Doubling of sound power increases the sound pressure level by $3 \mathrm{~dB}$ but only produces a barely noticeable increase in loudness (not a doubling). A $10 \mathrm{~dB}$ increase in SPL would approximately result in twice the subjective loudness $[4,9,40]$.

Two sound signals with same amplitude or level but with different frequency contents would evoke different sensation of loudness in humans. The loudness perception of acoustic stimuli is dependent on the spectral content as well.

When the loudness of a sound wave is plotted against the critical bands, it is called as specific loudness. It is expressed in the units of "sone/bark". The overall loudness $\mathrm{N}$ is the integration of specific loudness over critical band rate $[4,9]$. It is given by,

$$
N=\int_{0}^{2 A B a r k} n^{s}(z) d z
$$

Equation (3.2.1)

Zwicker has established a procedure to calculate loudness and sound pressure level which now has been standardized by ISO norm (ISO $532 \mathrm{~B}$ ). The same method is described in the German standard as well (Deutsche Norm, DIN 45631) [2, 5, 8, 22-24]. According to this method, initially a specific loudness pattern is determined from one third octave stationary sound and then loudness and sound pressure level can be calculated. The following equation gives the relation between loudness and sound pressure level according to DIN 45631 method.

$$
L_{N}=\left\{\begin{array}{c}
40+33.22 . \lg \left(\frac{N}{\text { sone }}\right) \text { for } N \geq 1 \text { sone } \\
40 .\left(\frac{N}{\text { sone }}+0.0005\right)^{0.35} \text { for } N<1 \text { sone }
\end{array}\right.
$$


As the impulsive noise is a transient sound file, a time dependent method for calculation of loudness is necessary. As the calculation of time dependant loudness is standardized only in the draft standard DIN 45631/A1, this method is selected for loudness calculations from various algorithms available in Artemis 11.2. The parameter settings for loudness calculation are shown in Figure (1).

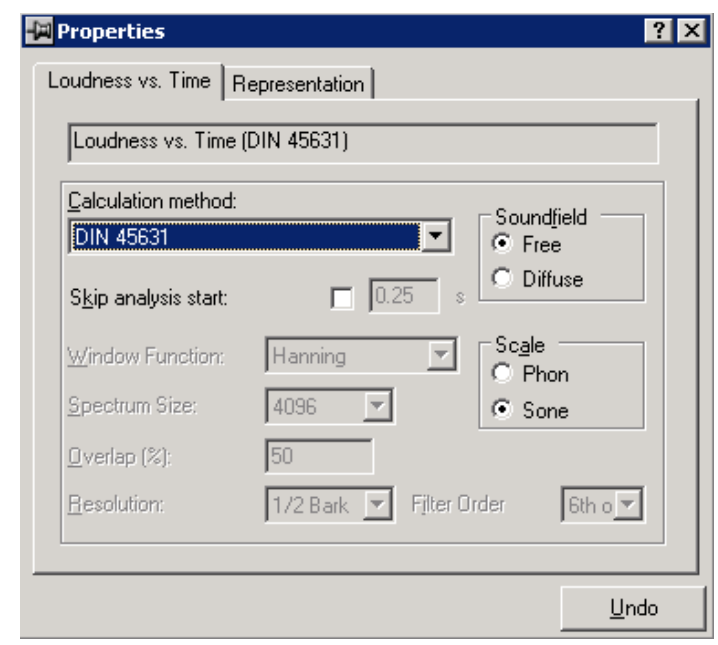

Figure 1: Selected Loudness Vs Time Settings in Artemis 11.2

\section{3: Sharpness}

Sharpness is another fundamental psychoacoustic attribute which is related to high frequency content in the sound. If the sound contains lot of high frequencies, that sound is perceived as sharp and annoying [28]. The sharpness calculations are based on specific loudness computations. Sharpness can primarily be calculated using either of the two algorithms: 1) Aures and 2) Von Bismarck [8, 25, 26].

Von Bismarck algorithm [26] is based on the distribution of the specific loudness throughout the critical band rate. This method applies best to the sounds with equal loudness. Aures algorithm [25] is pretty similar to von Bismarck's algorithm. But in 
addition to that an influence of loudness is taken into account while calculating the sharpness value. As impulsive sounds are transient signal, Aures method is chosen as it would take the loudness value calculated as per DIN 45631/A1 [24] into an account while evaluating time varying sharpness. The parameter settings for sharpness in Artemis 11.2 are shown in Figure (2).

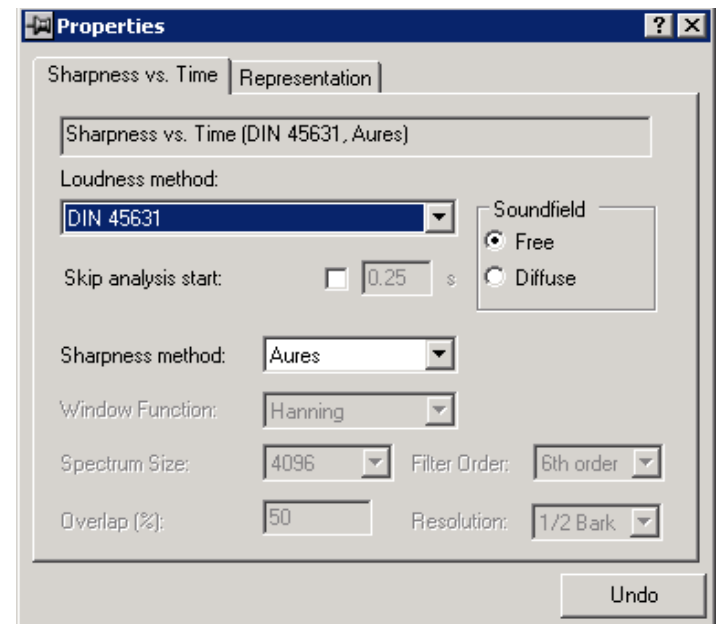

Figure 2: Selected Sharpness Vs Time Settings in Artemis 11.2

\section{4: Roughness}

Roughness is one of the important attribute in subjective judgment of sound quality. With increasing roughness, the same sound is perceived as more annoying. The sensation of roughness occurs during the existence of time varying envelop over a critical band, when a tone varies in the amplitude or frequency. When the frequency modulation is between $20-300 \mathrm{~Hz}$, sound is perceived as rough [9, 28]. Above $300 \mathrm{~Hz}$, the center frequencies and side bands of amplitude modulated tones are heard as individual tones. The sensation of roughness is dependent on the center frequency, modulation frequency and modulation depth. Roughness increases with increasing modulation depth and decreases with very low or high modulation frequencies. 
A unit of roughness is asper. 1 asper roughness is defined as a sine tone of $1 \mathrm{kHz}$ with level of $60 \mathrm{~dB}$, amplitude modulated at a frequency of $70 \mathrm{~Hz}$ and with a modulation depth of 1. To sum it up roughness sensation can occur if two tonal components are produced within a same critical bandwidth of human hearing.

For the current research roughness is calculated with 'roughness vs time' algorithm using Artemis 11.2 developed by HEAD Acoustics [9]. This algorithm calculated the partial roughness from the modulation depth of partial bands and then sums them up to calculate the total roughness value. The only limitation of this algorithm is, it tries to overestimate the value of roughness than the actual perception.

\section{5: Fluctuation Strength}

The hearing sensation caused by very low frequency modulations is called as fluctuation strength. This means that the perception of fluctuations can be described as modulations in sounds which occur slowly enough that human hearing can track the temporal changes in the level of the sound. [9,28]. Fluctuation strength is maximum at modulation frequencies of $4 \mathrm{~Hz}$. The unit of fluctuation strength is vacil. 1 vacil roughness is defined as a sine tone of $1 \mathrm{kHz}$ with level of $60 \mathrm{~dB}$, amplitude modulated at a frequency of $4 \mathrm{~Hz}$ and with a modulation depth of 1.

It has been proved that the interpretation of sound quality with fluctuation strength strongly depends on the type of the sound to be analyzed. If the listener is interested in the information conveyed by sound, modulated sounds with high fluctuation strength are not annoying. But if the sound is undesirable, then fluctuations are perceived as more annoying independent of its volume or loudness [9]. As printer impulsive sound 
can be termed as desired sound, fluctuation strength might not have any effect on the annoyance level.

Like roughness, fluctuation strength is calculated with 'fluctuation strength vs time' algorithm using Artemis 11.2 developed by HEAD Acoustics. This algorithm calculated the partial fluctuation strength from the modulation depth of partial bands and then sums them up to calculate the total fluctuation strength value. The parameter settings for fluctuation strength in Artemis 11.2 are shown in Figure (3).

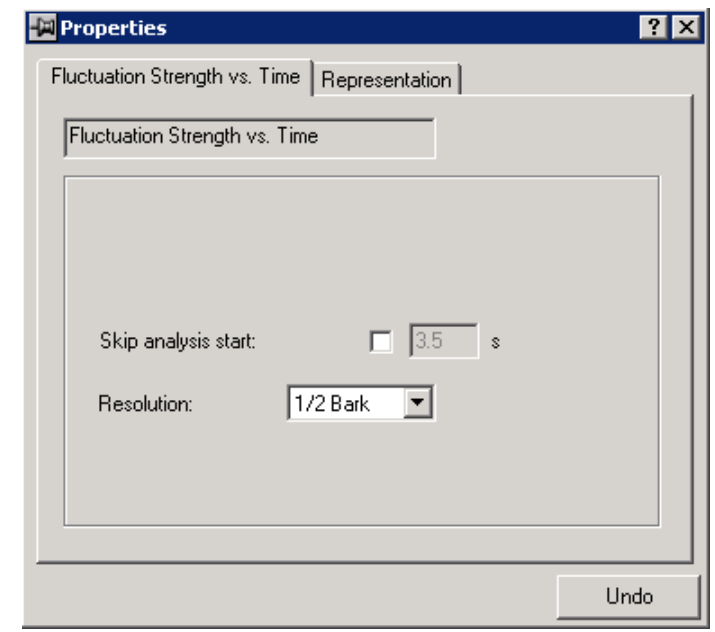

Figure 3: Selected Fluctuation Strength Vs Time Settings in Artemis 11.2

\section{5: Tonality}

Tonality of a sound describes whether a sound is composed of mainly tonal components or broadband noise. Contribution of these tonal components towards tonality depends on their frequency. The unit of tonality is 'tu' and is defined for $1 \mathrm{KHz}$ sine tone with a level of $60 \mathrm{~dB}[9]$.

The tonality is calculated based on a method developed by E. Terhardt and W. Aures[26,27]. Tonality calculated using this algorithm accounts for the dependency on the bandwidth, frequency of the tonal component and ratio of loudness of the signal with 
its tonal component. This research is based on all tonality calculations done using this algorithm with Artemis 11.2. The parameter settings for fluctuation strength in Artemis 11.2 are shown in Figure (4).

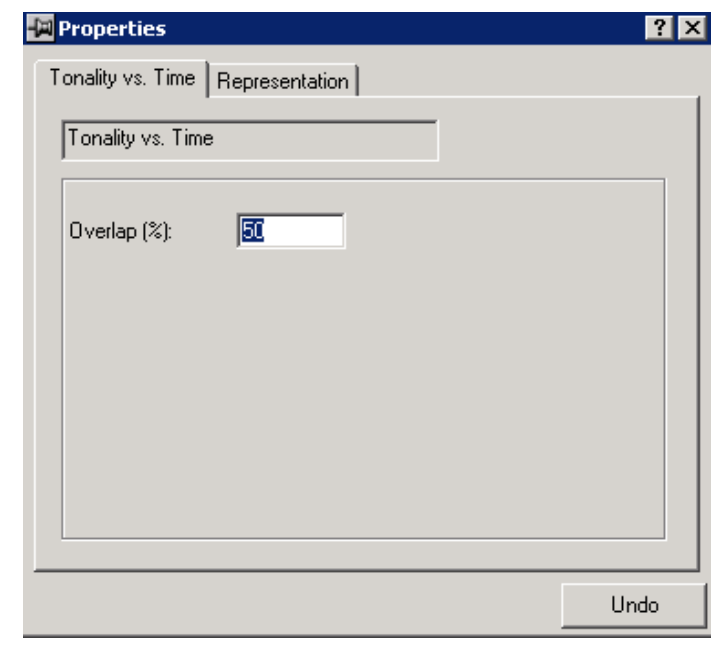

Figure 4: Selected Tonality Vs Time Settings in Artemis 11.2

\section{6: Loudness Based Impulsiveness}

Impulsiveness is a property pertaining to magnitude of an impulsive content in an event. A human hear is very sensitive to impulsive sound files. Thus it becomes necessity to quantify the effect due to any impulsive event while determining the quality of the sound. At Michigan Technological University, a new measure for impulsiveness has been developed which predicts impulsiveness very close to human hearing [28]. This measure is used in the objective metric for determination of perceived annoyance of impulsive sounds. This measure is based on the time varying loudness of the impulsive file. This metric sums together the magnitudes of each loudness impulse in the sound recording. It is achieved by running an impulse detection algorithm which detects the magnitude of loudness data points of each impulse over the background noise level. All these loudness 
magnitudes are then summed together. Thus impulsiveness metric increases in value with increase in the amplitude of the impulse and the number of the impulses.

Now, as this metric is focused on the impulsive sounds, it does not take into account any slow transient signals. To evaluate loudness of background noise in the impulsive file, the moving average background level over the entire length of the signal is computed. Now the computed loudness of the background level of the signal is subtracted from the loudness of total signal. As a result only the magnitude of impulsive content in the sound is obtained.

The calculation of the background loudness signal is given by

$N_{b}(t)=\left\{\begin{array}{cl}P_{95}\left[N_{0}, \ldots N_{2+i_{t}}\right], & t<0.5 \\ P_{95}\left[N_{i_{t-0.5}}, \ldots, N_{i_{t+0.5}}\right], & 0.5 \leq t \leq T-0.5 \\ P_{95}\left[N_{i_{2 t-T}}, \ldots, N_{i_{T}}\right], & t>T-0.5\end{array}\right.$

Equation (3.6.1)

Where

$N_{b}(t)=$ background loudness signal as a function of time $t$

$N_{i}=$ loudness magnitude at data index i

$i_{t}=$ data index corresponding to time $t$

$T=$ total length of time of original loudness signal

$P_{95}\left[N_{a}, \ldots, N_{b}\right]=95^{\text {th }}$ percentile of the ordered loudness data values between indices $a$ and $b$.

Using this background loudness signal, the summation used to calculate loudness-based impulsiveness is given by

$I_{N}=\frac{1}{M} \sum_{i=1}^{M}\left[\left(N_{i}-N_{b, i}\right)\right]$ 
Where $M$ is the total number of data points in the loudness versus time signal. The $1 / M$ term is used for normalization of the impulsiveness in terms of the length of the analyzed sound recording.

Following are the properties of this newly developed loudness based impulsiveness metric [28].

- The measure increases in value due to the presence of sudden, short-term transient sound events (impulses). The perception of impulsiveness varies linearly with respect to the magnitude of the impulses in the sound.

- The measure has a value of zero for completely stationary, non-transient noises.

- The measure does not increase in value due to the presence of slow transient sound events.

- The measure increases in value for every increase in the number of audible impulses present in the sound.

- The measure increases in value as the magnitude of any impulse within the sound increases.

- The measure is independent of the overall level, duration, spectral content and time resolution of the sound. 


\section{4: Objective Metric for Perceived Annoyance}

This research is based on the objective metric developed recently for perceived annoyance. This metric for annoyance quantifies the overall sound quality of the impulse noise in terms of different fundamental psychoacoustics metrics [28].

As annoyance due to any noise is a subjective term, the most of the methods developed till now focus on the jury testing. In these methods subjects are exposed to different sounds and then they are asked to evaluate the annoyance on some defined scale. These jury based tests are very time consuming and costly. Also they introduce some variability in the experimentation. Thus the recent research at Michigan Technological University focused on development of an objective metrics for perceived annoyance. By application of this annoyance metric, the need of jury testing can be eliminated.

In this study [28], fifteen different impulsive sounds (both generic and technical) were rated for their annoyance rating by jury testing. The annoyance rating scale was set to 0 to 100,100 being the state of maximum annoyance and 0 being the state of minimum annoyance. Initially it was predicted that perceived annoyance should be a function of loudness, roughness, sharpness, fluctuation strength, tonality and loudness based impulsiveness. The effects of these variables individually on the annoyance were studied. It was concluded that perceived annoyance can be best predicted by following fundamental psychoacoustic metrics: loudness $\left(5^{\text {th }}\right.$ percentile), sharpness (median value), 
roughness $\left(5^{\text {th }}\right.$ percentile) and newly developed loudness based impulsiveness. An annoyance model based on these attributes is developed by multiple stepwise regression theory. It was found out that fluctuation strength and tonality are not very much significant while modeling a fit for perceived annoyance. The model developed is given below:

$$
\widehat{A}=27.73+1.24 * I_{N}+0.86 * N_{5} * S_{56}+1.81 * R_{5}
$$

Equation (4.1)

Where,

$\hat{A}=$ predicted scale value of perceived annoyance (based on 0 to 100 scale from jury evaluation experiment)

$I_{N}=$ loudness-based impulsiveness metric

$N_{5}=5^{\text {th }}$ percentile of loudness in units of sone

$S_{50}=$ median of sharpness in units of acum

$R_{5}=5^{\text {th }}$ percentile of roughness in units of asper

This model is interpreted as follows [28]

- A 1 sone increase in $5^{\text {th }}$ percentile loudness, given the other variables remain constant, will increase the perceived annoyance by 0.86 times the median value of sharpness in acum.

- A 1 acum increase in median sharpness, given the other variables remain constant, will increase the perceived annoyance by 0.86 time the $5^{\text {th }}$ percentile value of loudness in sone.

- A 1 asper increase in $5^{\text {th }}$ percentile roughness, given the other variables remain constant, will increase the perceived annoyance by 1.81 units. 
- A 1 unit increase in the loudness-based impulsiveness, given the other variables remain constant, will increase the perceived annoyance by 1.24 units.

$5^{\text {th }}$ percentile of loudness was calculated as per standard DIN 45631/A1 [24]. It calculated the time varying loudness. As the research was focused on the impulsive sounds, time varying models for loudness or any other attributes proved to be most accurate. It was calculated from $1 / 3$ octave band levels generated by $6^{\text {th }}$ order filter. Aures's method was used to determine the value of sharpness with specific loudness determined with DIN 45631/A1 [24,26]. In this method smaller sharpness changes are more detecTable. For the annoyance model median of sharpness was taken into account. Time varying roughness was calculated by the algorithm used in Artemis 11.2 developed by HEAD Acoustics [9]. $5^{\text {th }}$ percentile of that roughness was used in the perceived annoyance model. Loudness based impulsiveness was calculated from loudness over time data generated using Artemis 11.2 as per standard DIN 45631A [24,28].

This annoyance model was then checked for adequacy and goodness of fit by calculating the model residuals against the annoyance ratings obtained by jury testing. The developed annoyance model predicts the perceived annoyance of impulsive sounds within $95 \%$ confidence interval. Also the values of PRESS, Determination of coefficient $\left(\mathrm{R}^{2}\right)$ and rank correlation co-efficient $(\rho)$ were checked for acceptability. It was found that for the given model PRESS value was 201 which is very low. Determination of coefficient was pretty much near $1\left(\mathrm{R}^{2}=0.949\right)$ and adjusted coefficient of determination was $\left(R_{a d j}^{2}=0.930\right)$. Also rank correlation coefficient $(\rho=0.986)$ indicates the predictive power of this model is very high. Thus it was concluded that the fitted model predicts the 
magnitude of perceived annoyance effectively. Hence this model is used as a primary base in all the calculations done while working on extension of this project. 


\section{5: Physical Parameters of an Impulse and their Effect on Annoyance}

The primary objective of this research is to tune the impulsive sound from a commercial printer under the accepTable criteria. Thus it is very important to find the factors which could possibly have an impact on perceived annoyance of an impulsive noise. It is assumed that these factors should be physical parameters of an impulse so that they can be controlled. A brief discussion on these parameters is included further in this Chapter. If we are able to identify any relation between objective factors and the perceived annoyance, then it is possible to tweak those factors for minimum annoyance level. The best way to identify significant factors is by running a planned experiment. Thus it was decided to run experiments as per the well established theory of two level factorial designs [30].

\section{1: Physical Parameters of a single impulse}

To start the analysis, the following parameters related to a single impulse are predicted to have some effect on the annoyance; Amplitude, Addition of Background noise, DurationImpulse attack, Duration- Impulse sustain, Duration- Impulse Release, and Frequency Content. The original properties of the sample impulse file used for this computation are listed in the table below. Figures (6-8) give the attack and release of the impulse. Figure (5) shows the original spectral content of strip_05.

Table 2: Physical Properties of Strip_05

\begin{tabular}{|c|c|}
\hline Name & Value \\
\hline Amplitude & $62.47 \mathrm{~dB}$ \\
\hline Attack Time & $1 \mathrm{~ms}$ \\
\hline Release Time & $25 \mathrm{~ms}$ \\
\hline
\end{tabular}




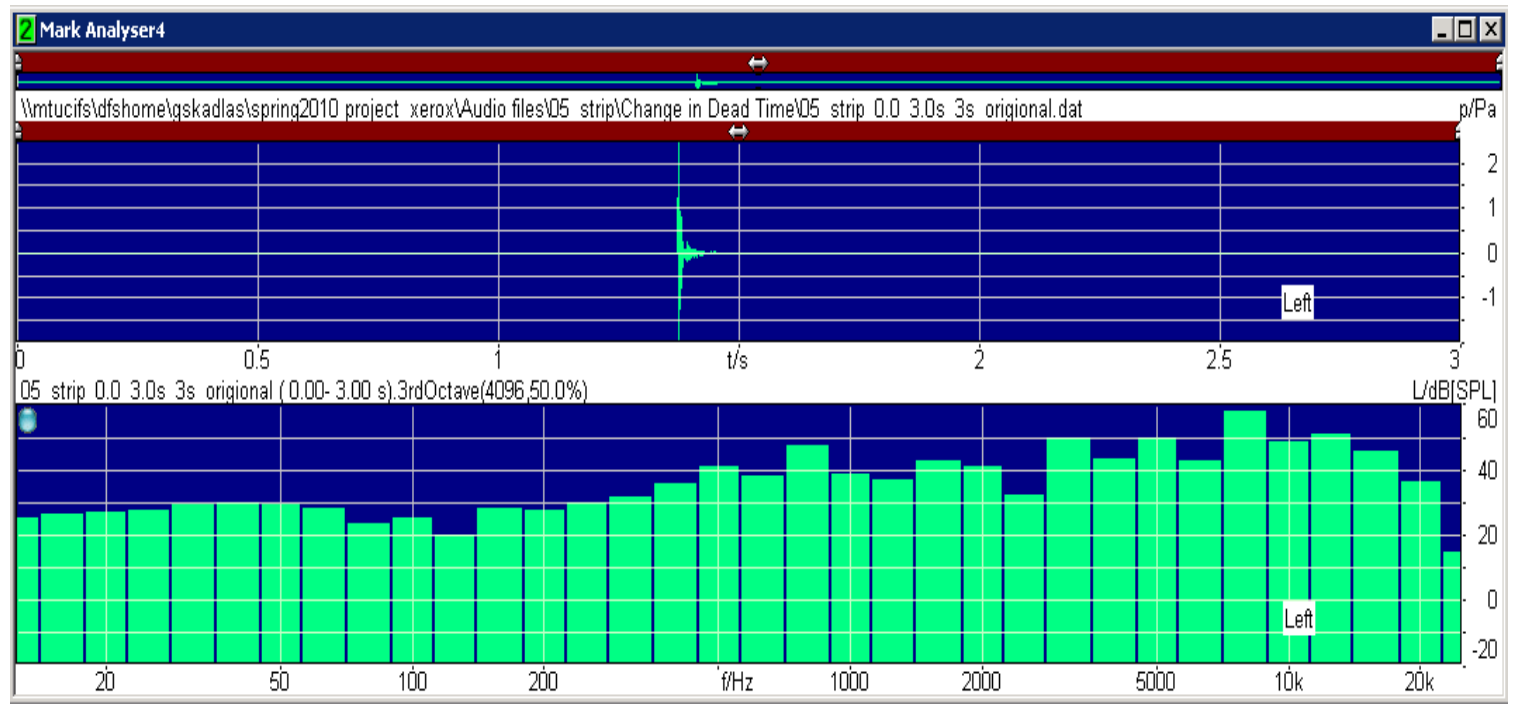

Figure 5: Frequency Content of strip_05 


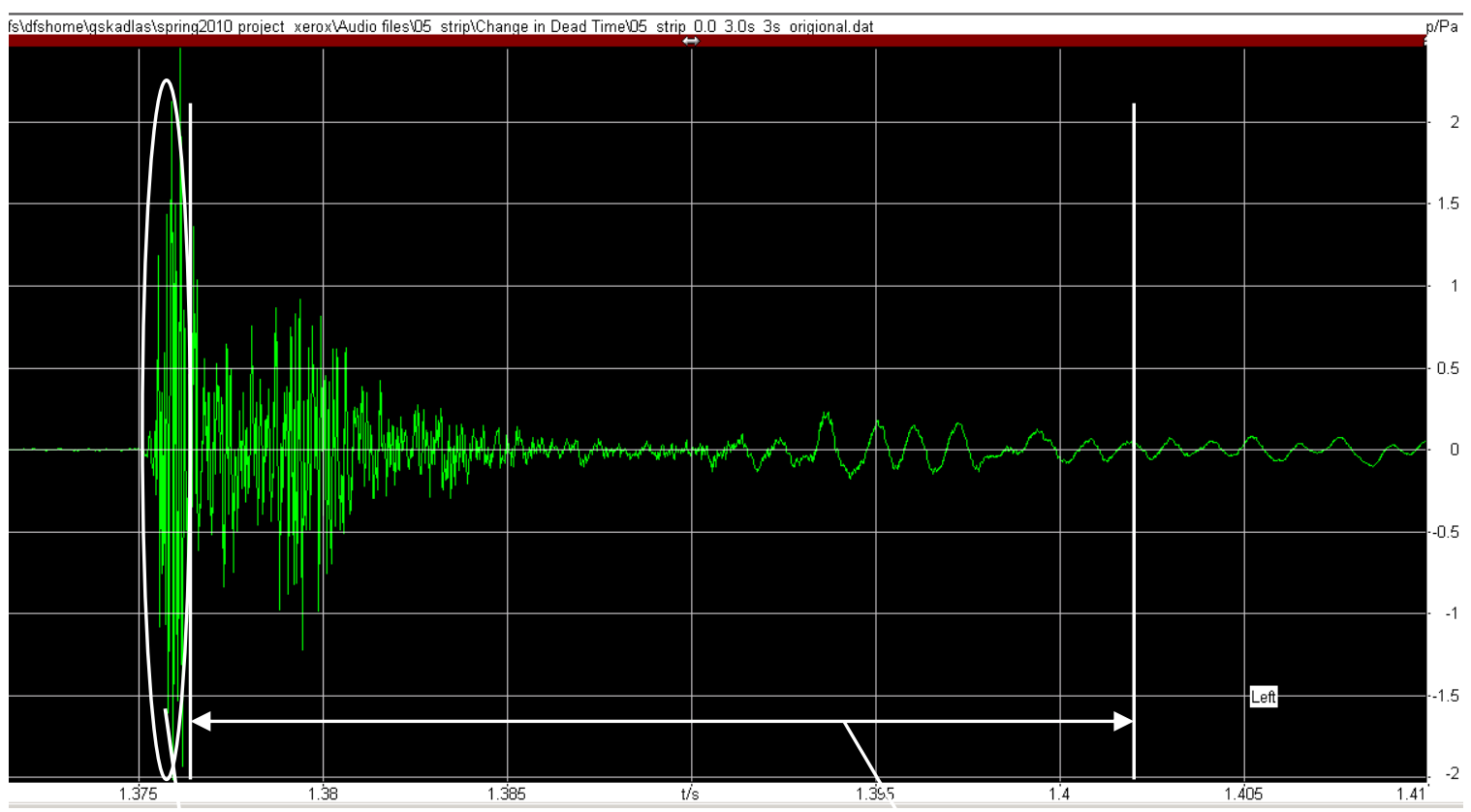

Figure 6: Strip_05

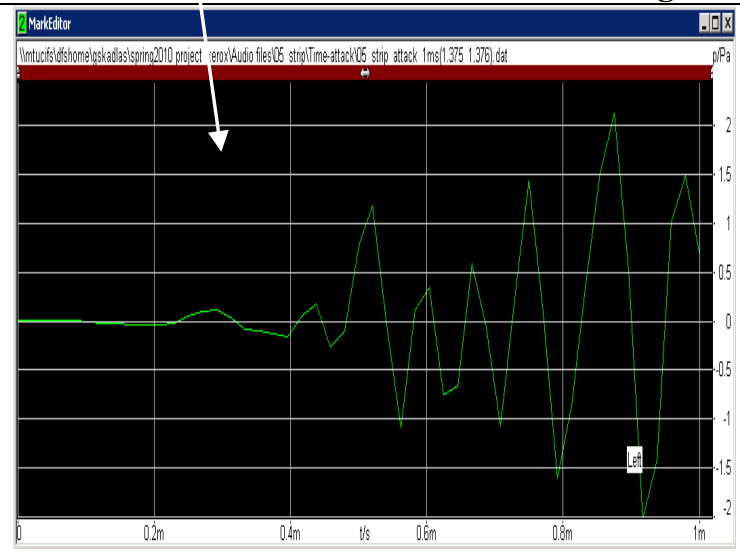

Figure 7: Impulse Attack

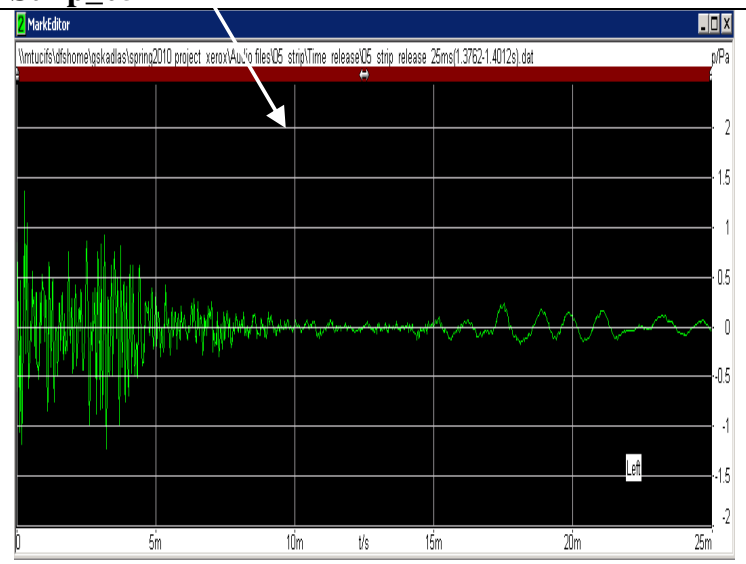

Figure 8: Impulse Release

A) Amplitude- Amplitude of an impulse is nothing but the magnitude of sound pressure level in a dB scale. All the sample sound files received from Xerox were recorded using a binaural head with two channels representing left and right ear of the human.

Channel with the higher value of amplitude is selected for the analysis purposes. It is assumed that, the perceived annoyance will increase with the increase in amplitude. To validate this initial guess, a sample impulse file (strip_05) is selected with a very 
negligible duration of dead time ( $0.2 \mathrm{~s}$ approximately). It is modified for different amplitude variations such as $-20 \mathrm{~dB},-10 \mathrm{~dB},-6 \mathrm{~dB},-3 \mathrm{~dB},+3 \mathrm{~dB},+6 \mathrm{~dB},+10 \mathrm{~dB}$ and $+20 \mathrm{~dB}$. Using Artemis 11.2 following psychoacoustic parameters are calculated for all these files: Loudness N5, Sharpness S50, and Roughness R5. Loudness based impulsiveness is also calculated from loudness Vs time curve. Perceived annoyance for all the cases is computed using the objective metric as described in Chapter 4. The calculated values are given in Table 3.

Table 3: Effect of Variation in Amplitude of an Impulse on Perceived Annoyance

\begin{tabular}{|c|c|c|c|c|c|c|}
\hline $\begin{array}{c}\text { Variation } \\
\text { in } \\
\text { Amplitude } \\
\text { Impulsiven } \\
\text { ess (In) }\end{array}$ & $\begin{array}{c}\text { Loudness } \\
\text { Based } \\
\text { (N5) }\end{array}$ & $\begin{array}{c}\text { Loudness } \\
\text { Sharpness } \\
\text { (S50) }\end{array}$ & $\begin{array}{c}\text { Roughness } \\
\text { (R5) }\end{array}$ & $\begin{array}{c}\text { Perceived } \\
\text { Annoyance }\end{array}$ & $\begin{array}{c}\text { Perceived } \\
\text { Annoyance } \\
\text { Rating }\end{array}$ \\
\hline (dB) & (iu) & (sone) & (acum) & (asper) & & \\
\hline-20 & 1.61 & 5.68 & 0.85 & 0.84 & 35.39 & $\mathbf{3 5 . 3 9}$ \\
\hline-10 & 3.35 & 10.89 & 1.14 & 4.96 & 51.54 & $\mathbf{5 1 . 5 4}$ \\
\hline-6 & 4.44 & 14.06 & 1.15 & 7.34 & 60.42 & $\mathbf{6 0 . 4 2}$ \\
\hline-3 & 5.45 & 16.97 & 1.19 & 9.34 & 68.72 & $\mathbf{6 8 . 7 2}$ \\
\hline 0 & 6.66 & 20.47 & 1.2 & 11.65 & 78.2 & $\mathbf{7 8 . 2}$ \\
\hline 3 & 8.14 & 24.67 & 1.22 & 14.34 & 89.6 & $\mathbf{8 9 . 6}$ \\
\hline 6 & 9.89 & 29.64 & 1.27 & 16.95 & 103.09 & $\mathbf{1 0 0}$ \\
\hline 10 & 12.82 & 37.86 & 1.34 & 20.02 & 123.43 & $\mathbf{1 0 0}$ \\
\hline 20 & 24.15 & 69.23 & 1.61 & 28.31 & 204.87 & $\mathbf{1 0 0}$ \\
\hline
\end{tabular}




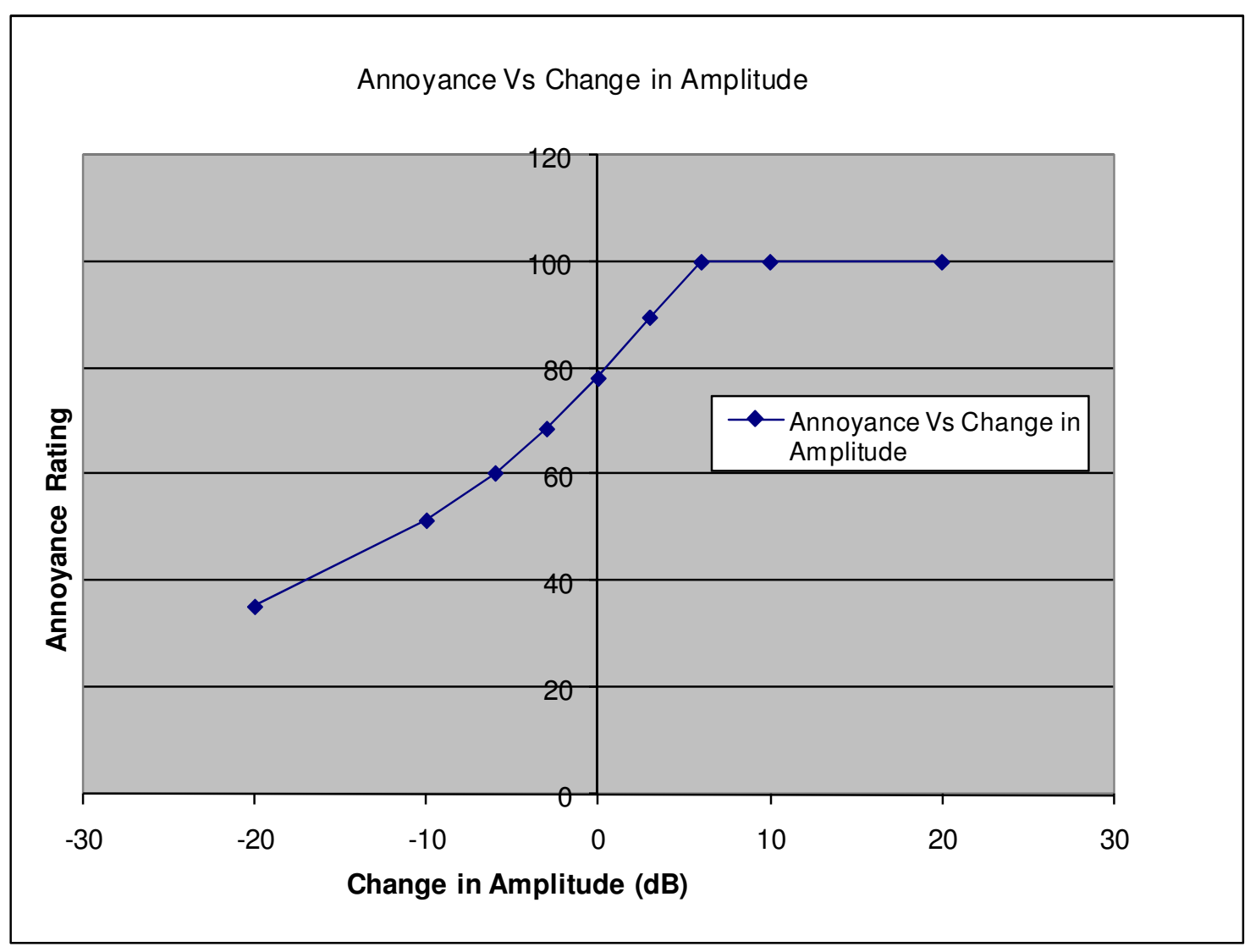

Figure 9: Effect of Variation in Amplitude of an Impulse on Perceived Annoyance

The effect of variation in amplitude of an impulse on perceived annoyance is shown in Figure (9). As amplitude increases, perceived annoyance also increases to its max level i.e. 100. If the amplitude is further increased, the calculated value of perceived annoyance will still increase, but the sound will be rated at same maximum annoyance value of 100 .

The same trend is observed in case of loudness $\left(5^{\text {th }}\right.$ percentile), roughness (median value), and sharpness ( $5^{\text {th }}$ percentile) as shown in Figures (10-13) 


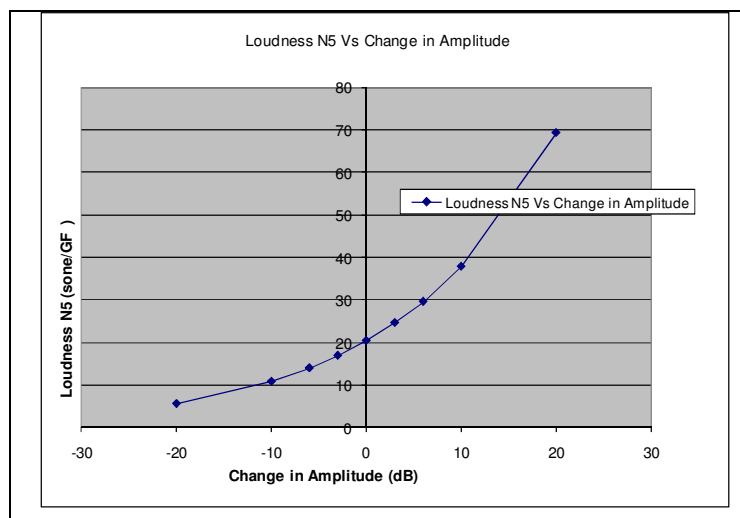

Figure 10: Effect of Variation in Amplitude of an Impulse on Loudness N5

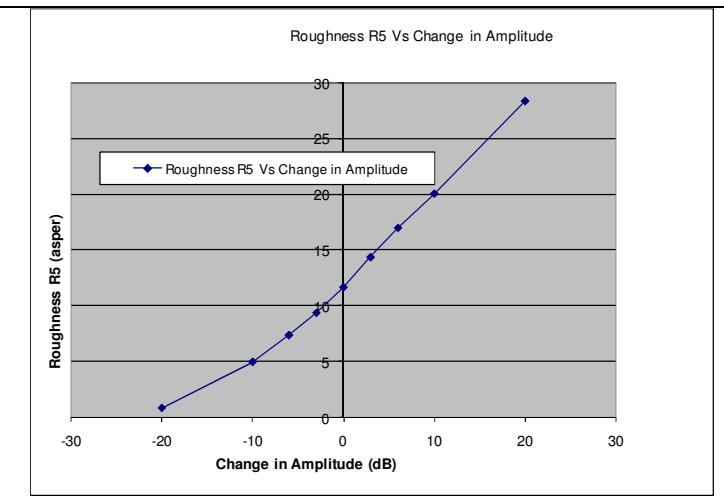

Figure 12: Effect of Variation in Amplitude of an Impulse on Roughness R5

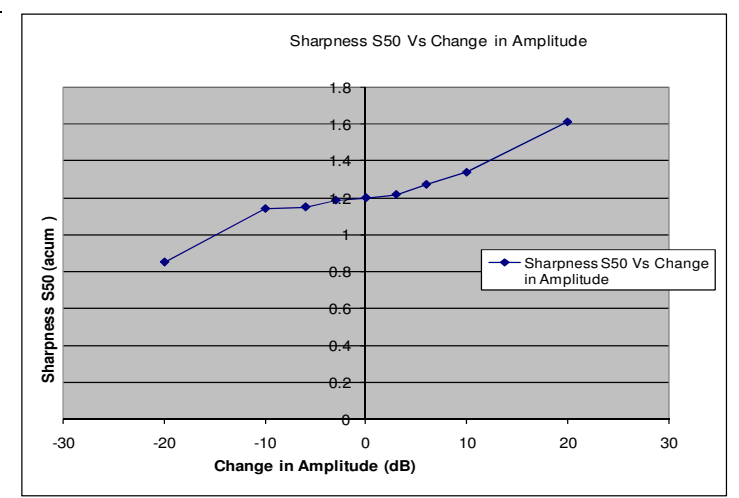

Figure 11: Effect of Variation in Amplitude of an

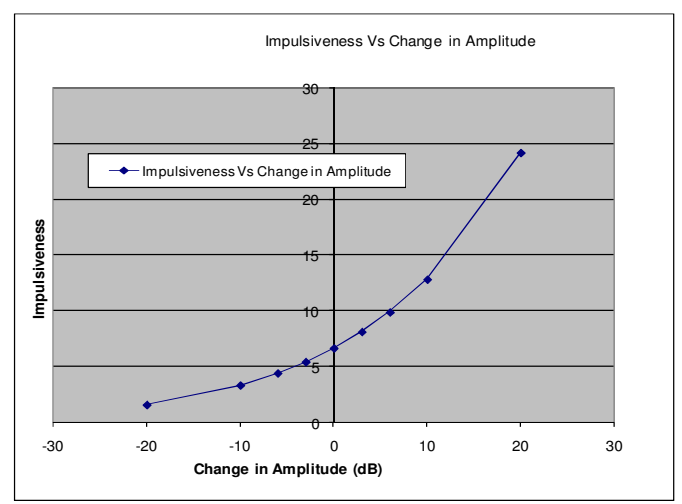

Figure 13: Effect of Variation in Amplitude of an Impulse on Impulsiveness

B) Background Noise: Next the annoyance of an impulse in the present of background noise is studied. It is important to study how human hear will perceive the same impulse in a silent environment compared to a noisy environment. This is achieved by adding a white noise file (back_2) to the single impulse. The sound pressure level of the recorded background noise is $53 \mathrm{~dB}$. Time history and the spectral content of 'back_02' are shown in Figure (14). It is modified for different amplitude variations such as $-20 \mathrm{~dB},-10 \mathrm{~dB},-6 \mathrm{~dB},-3 \mathrm{~dB},+3 \mathrm{~dB},+6 \mathrm{~dB},+10 \mathrm{~dB}$ and $+20 \mathrm{~dB}$ and then added to the original impulse file. Table 4 shows different psychoacoustic attributes computed 
for all the mentioned cases. Perceived annoyance rating is then computed using the equation discussed in Chapter 4. The trend of annoyance curve over background noise shows that as the background noise increases, annoyance also increases. It is pretty evident that higher level of background noise has a more impact on annoyance than the lower level. That means in a noisy environment, impulse noise can sound more annoying; but in a quiet environment not much difference in annoyance level than the original will be experienced.

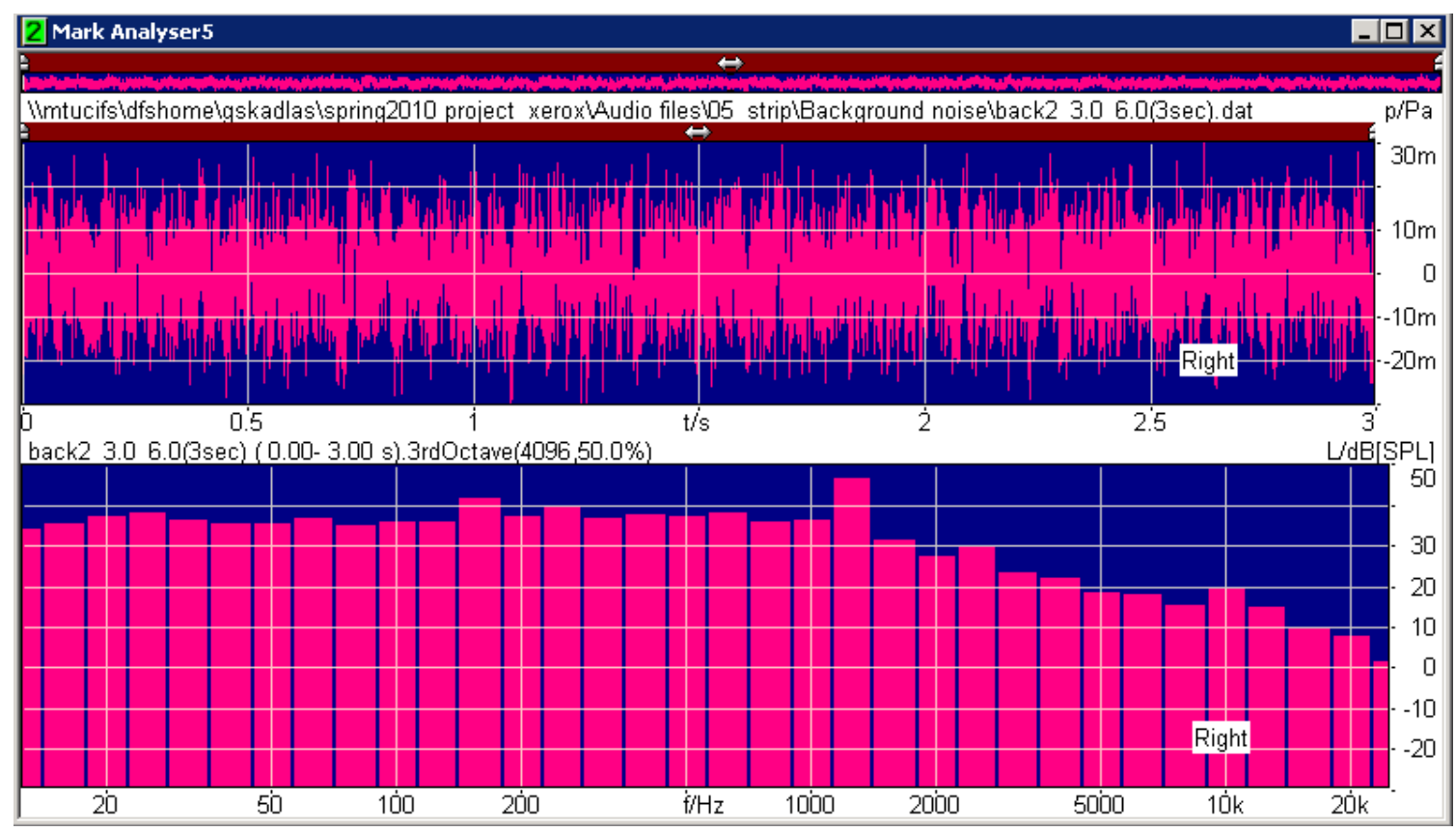

Figure 14: Background Noise file Properties (back_02) 
Table 4: Effect of Variation in Background Noise Amplitude of an Impulse on Perceived Annoyance

\begin{tabular}{|c|c|c|c|c|c|c|}
\hline $\begin{array}{c}\text { Variation } \\
\text { in } \\
\text { Amplitude } \\
\text { Impulsiven } \\
\text { ess (In) }\end{array}$ & $\begin{array}{c}\text { Loudness } \\
\text { Based } \\
\text { (N5) }\end{array}$ & $\begin{array}{c}\text { Loudness } \\
\text { (S50) }\end{array}$ & $\begin{array}{c}\text { Roughness } \\
(\mathbf{R 5})\end{array}$ & $\begin{array}{c}\text { Perceived } \\
\text { Annoyance }\end{array}$ & $\begin{array}{c}\text { Perceived } \\
\text { Annoyance } \\
\text { Rating }\end{array}$ \\
\hline (dB) & $\mathbf{( i u )}$ & (sone) & (acum) & (asper) & & \\
\hline-20 & 6.83 & 20.51 & 1.18 & 11.69 & 78.18 & $\mathbf{7 8 . 1 8}$ \\
\hline-10 & 7.32 & 20.7 & 1.19 & 11.66 & 79.13 & $\mathbf{7 9 . 1 3}$ \\
\hline-6 & 7.71 & 20.88 & 1.27 & 11.6 & 81.02 & $\mathbf{8 1 . 0 2}$ \\
\hline-3 & 8.11 & 21.07 & 1.36 & 11.55 & 83.33 & $\mathbf{8 3 . 3 3}$ \\
\hline 0 & 8.64 & 21.31 & 1.46 & 11.48 & 85.92 & $\mathbf{8 5 . 9 2}$ \\
\hline 3 & 9.34 & 21.64 & 1.55 & 11.35 & 88.76 & $\mathbf{8 8 . 7 6}$ \\
\hline 6 & 10.25 & 22.06 & 1.64 & 11.26 & 91.87 & $\mathbf{9 1 . 8 7}$ \\
\hline 10 & 11.86 & 22.83 & 1.76 & 10.94 & 96.8 & $\mathbf{9 6 . 8}$ \\
\hline 20 & 18.74 & 26.32 & 2.09 & 9.04 & 114.54 & $\mathbf{1 0 0}$ \\
\hline
\end{tabular}

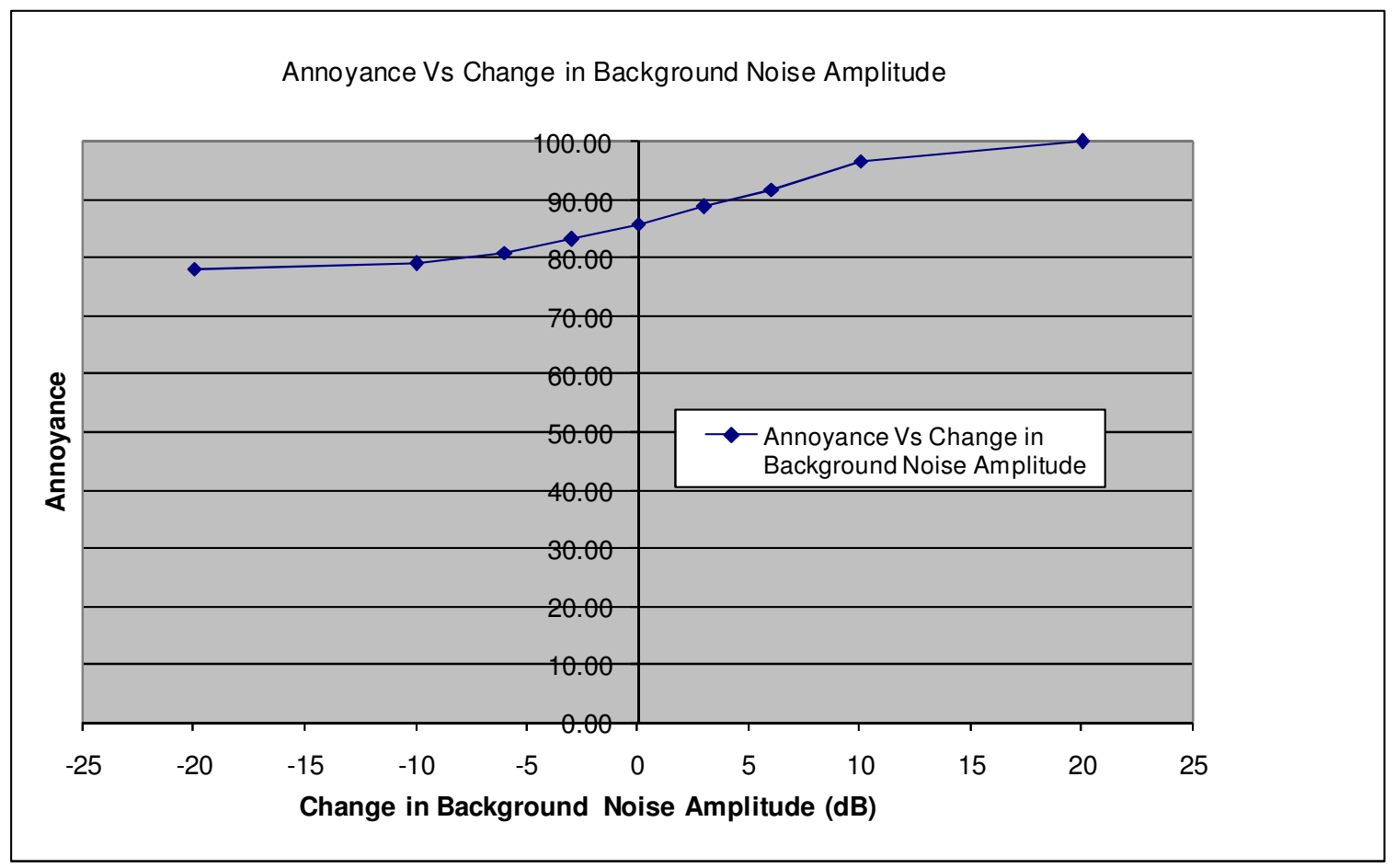

Figure 15: Effect of Variation in Background Noise Amplitude of an Impulse on Perceived Annoyance

Figures 16 through 19 show the trends of loudness, sharpness, roughness and impulsiveness. It is found that loudness, sharpness and impulsiveness have the same trend 
similar to annoyance. On the contrary roughness tends to decrease with the increase in the background noise.

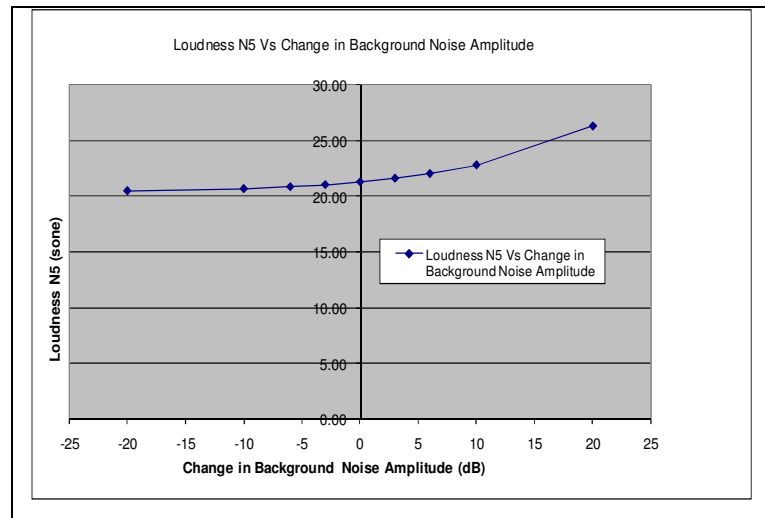

Figure 16: Effect of Variation in Background Noise Amplitude of an Impulse on Loudness N5

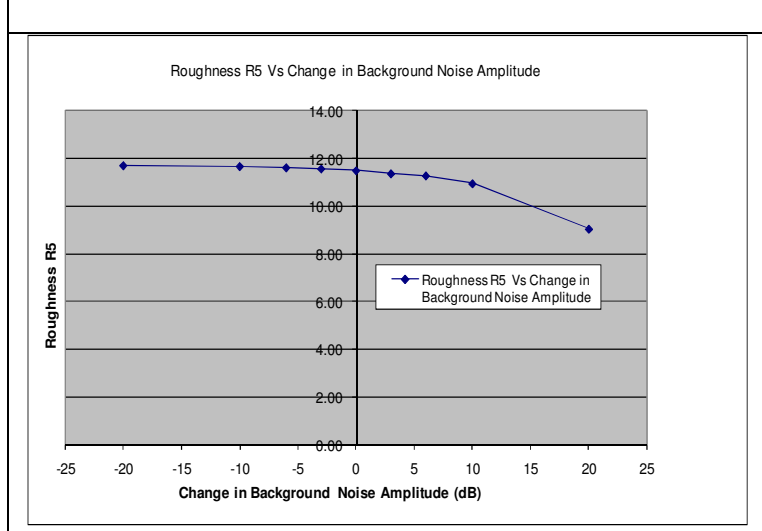

Figure 18: Effect of Variation in Background Noise Amplitude of an Impulse on Roughness R5

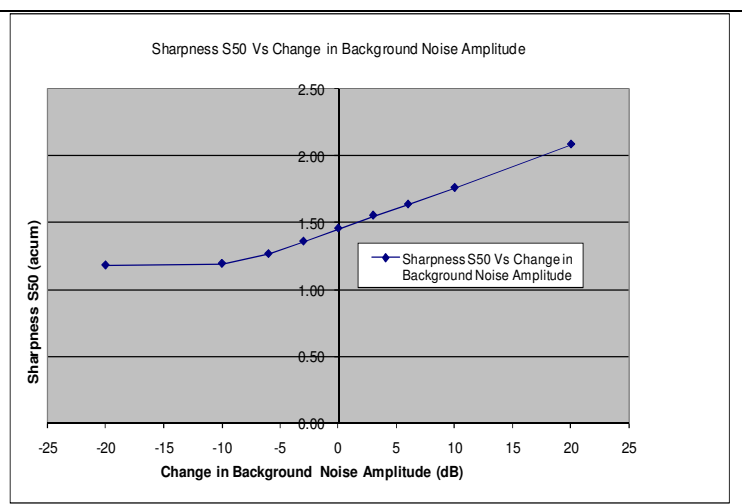

Figure 17: Effect of Variation in Background Noise Amplitude of an Impulse on Sharpness S50

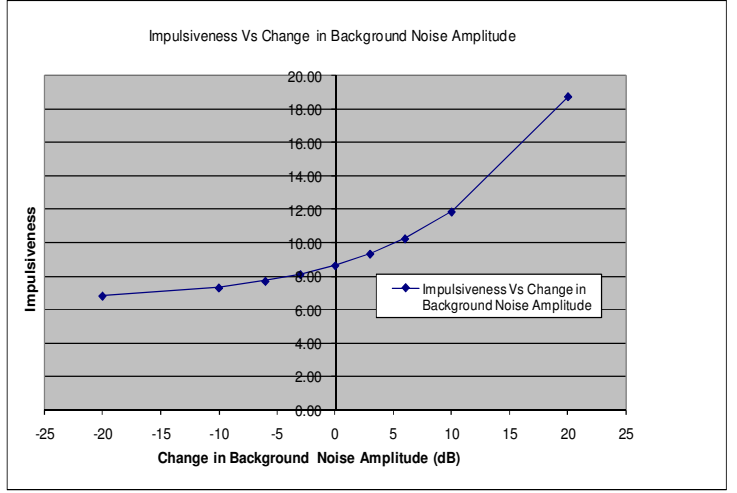

Figure 19: Effect of Variation in Background Noise Amplitude of an Impulse on Impulsiveness

C) Impulse Attack Time: The impulse duration can typically be divided as Attack, Decay, Sustain and Release [42]. Timbre or the tone quality of the impulse signal is determined by these four factors. The time required to initiate the impulse is termed as attack time. It is nothing but the time required for the impulse to go from the noise floor to the peak level. To study the effect of various attack times on the annoyance, the given impulse is modified to for different attack times and is then computed for its perceived annoyance value. Calculated values of loudness, roughness, sharpness, 
impulsiveness and perceived annoyance are tabulated in Table 5. The annoyance curve shows that with the increase in attack time, annoyance rating increases up to its maximum level of 100 and then it drop down a little if we further go on increasing the attack time.

Table 5: Effect of Variation in Attack Time of an Impulse on Perceived Annoyance

\begin{tabular}{|c|c|c|c|c|c|c|}
\hline $\begin{array}{c}\text { Attack } \\
\text { Time }\end{array}$ & $\begin{array}{c}\text { Loudness } \\
\text { Based }\end{array}$ & $\begin{array}{c}\text { Loudness } \\
(\mathbf{N 5})\end{array}$ & $\begin{array}{c}\text { Sharpness } \\
\text { (S50) }\end{array}$ & $\begin{array}{c}\text { Roughness } \\
(\mathbf{R 5})\end{array}$ & $\begin{array}{c}\text { Perceived } \\
\text { Annoyance }\end{array}$ & $\begin{array}{c}\text { Perceived } \\
\text { Annoyance }\end{array}$ \\
\hline $\mathbf{( m s )}$ & $\mathbf{( i u )}$ & $\mathbf{( s 0 n e )}$ & $\mathbf{( a c u m )}$ & (asper) & & \\
\hline 0.5 & 6.73 & 20.32 & 1.2 & 12.16 & 79.02 & $\mathbf{7 9 . 0 2}$ \\
\hline 1 & 6.66 & 20.47 & 1.2 & 11.65 & 78.2 & $\mathbf{7 8 . 2}$ \\
\hline 5 & 8.64 & 31.36 & 1.2 & 22.52 & 111.58 & $\mathbf{1 0 0}$ \\
\hline 10 & 9.74 & 37.1 & 1.2 & 19.49 & 113.35 & $\mathbf{1 0 0}$ \\
\hline 20 & 11.08 & 37.17 & 1.2 & 15.52 & 107.86 & $\mathbf{1 0 0}$ \\
\hline 30 & 11.91 & 37.36 & 1.2 & 13.9 & 106.19 & $\mathbf{1 0 0}$ \\
\hline 50 & 12.63 & 34.84 & 1.06 & 12.88 & 98.47 & $\mathbf{9 8 . 4 7}$ \\
\hline 75 & 13.31 & 31.41 & 0.98 & 12.25 & 92.79 & $\mathbf{9 2 . 7 9}$ \\
\hline 100 & 12.99 & 31.44 & 0.94 & 12.07 & 91.2 & $\mathbf{9 1 . 2}$ \\
\hline
\end{tabular}

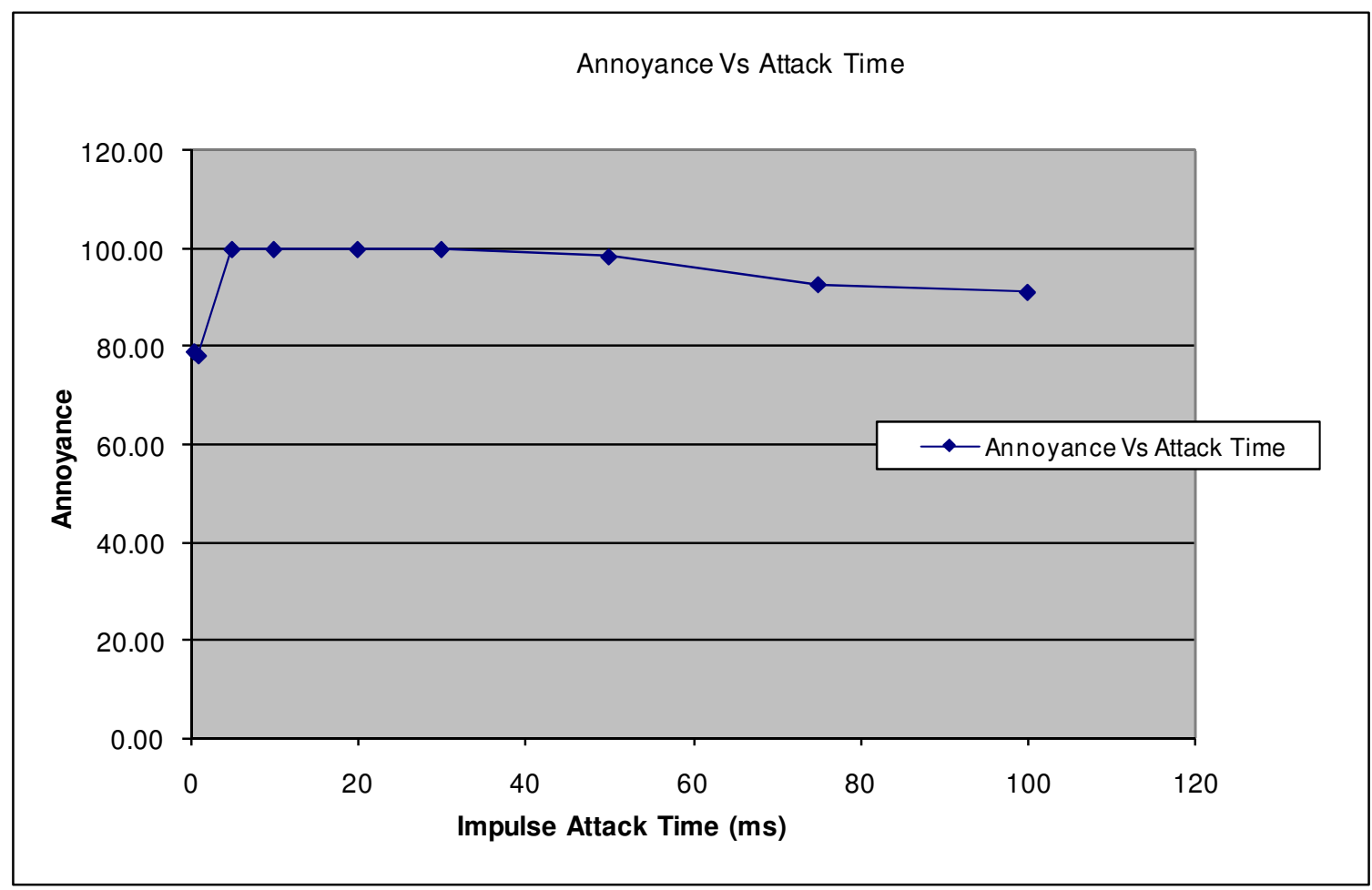

Figure 20: Effect of Variation in Attack Time of an Impulse on Perceived Annoyance 


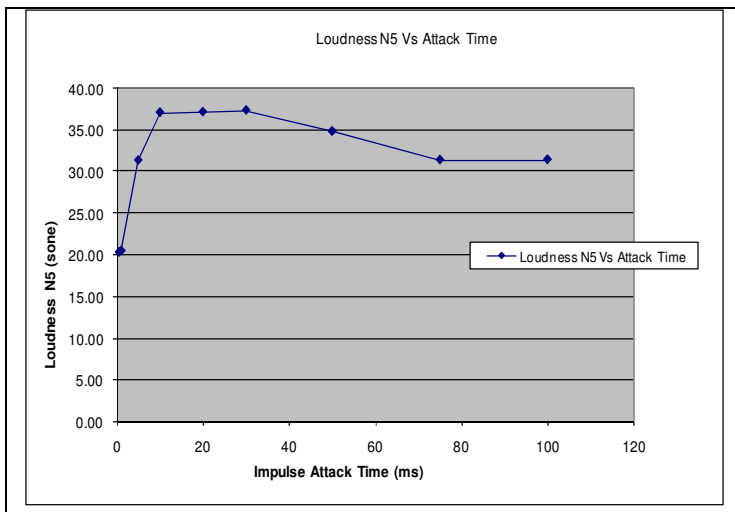

Figure 21: Effect of Variation in Attack Time of an Impulse on Loudness N5

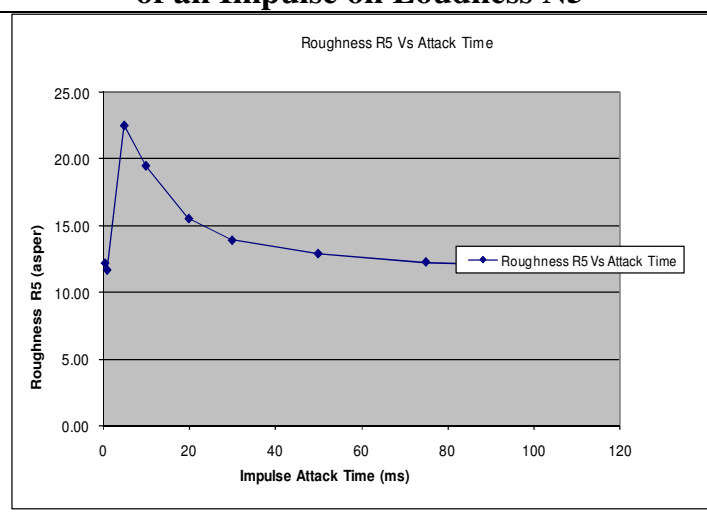

Figure 23: Effect of Variation in Attack Time of an Impulse on Roughness R5

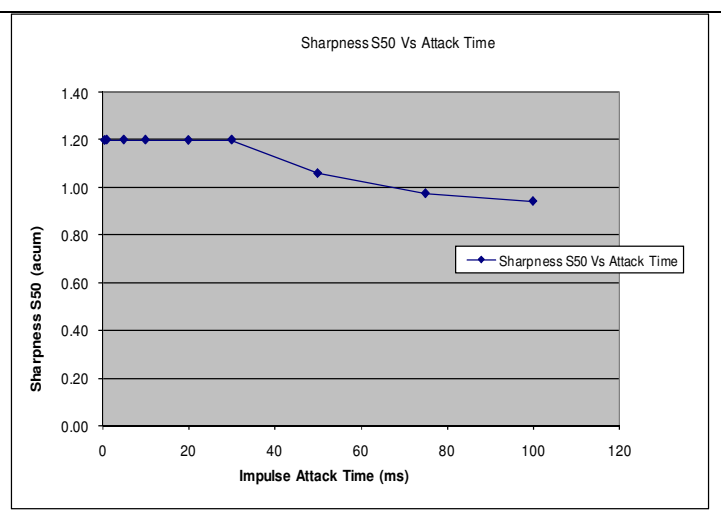

Figure 22: Effect of Variation in Attack Time of an Impulse on Sharpness S50

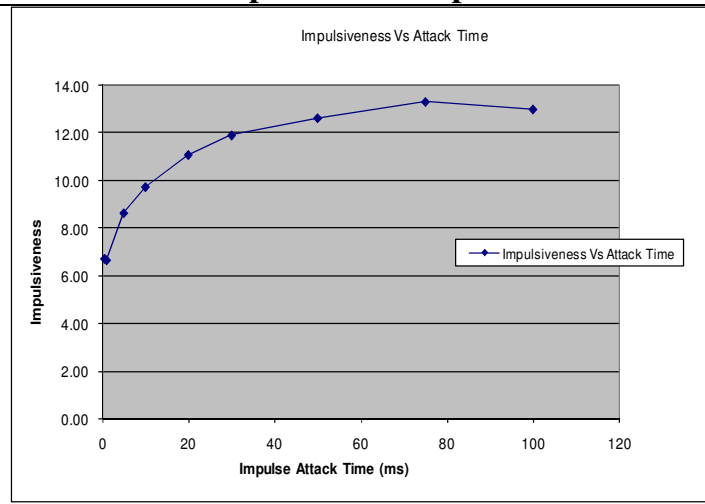

Figure 24: Effect of Variation in Attack Time of an Impulse on Impulsiveness

D) Impulse Sustain Time: Sustain time of an impulse is defined by how long the sound resonates at its peak level [42]. Generally the time taken by impulse to come from its peak value to $95 \%$ of the peak value is referred as the sustain time. For all the sample printer files, sustain time is found to be very negligible. Also, increasing and decreasing sustain time in case of printer impulse is not a practically feasible option. Considering sustain time as one of the active parameters would have made sense in case of violin or piano etc where impulse sound resonates for some time before dying off. Thus it was decided to neglect this parameter. 
E) Impulse Release Time: Release time of an impulse is defined by how rapidly the noise fades away to its noise floor [42]. This decay is exponential and time for the impulse to reach from $90 \%$ to $10 \%$ of the peak value is taken as release time for the computation purposes. It is our initial guess that release time can be one of the important factors in deciding annoyance level of an impulsive stimulus. The original impulse is then modified for different release times $2.5 \mathrm{~ms}, 5 \mathrm{~ms}, 10 \mathrm{~ms}, 25 \mathrm{~ms}, 50 \mathrm{~ms}$, $100 \mathrm{~ms}, 250 \mathrm{~ms}, 500 \mathrm{~ms}, 1000 \mathrm{~ms}, 4000 \mathrm{~ms}, 8000 \mathrm{~ms}$. Release time of the original file is $25 \mathrm{~ms}$. Perceived annoyance along with other psychoacoustic parameters is calculated for all these files. The results are tabulated below in Table 6. Figures (25) to (29) show the trend of perceived annoyance, loudness N5, sharpness S50, roughness R5 and impulsiveness respectively. From Figure (25), it is observed that perceived annoyance increases with increase in release time till $100 \mathrm{~ms}$. After that if the release time is still increased, annoyance level would drop down. Similar trend is observed in other psychoacoustics attributes as well. The possible reason could be the frequency change of the release part of the impulse. As the release part of the impulse is stretched using Artemis 11.2, frequency of the signal moves down leading to lower value of perceived annoyance. 
Table 6: Effect of Variation in Release Time of an Impulse on Perceived Annoyance

\begin{tabular}{|c|c|c|c|c|c|c|}
\hline $\begin{array}{c}\text { Release } \\
\text { Time }\end{array}$ & $\begin{array}{c}\text { Loudness } \\
\text { Based } \\
\text { Impulsiven } \\
\text { ess (In) }\end{array}$ & $\begin{array}{c}\text { Loudness } \\
\text { (N5) }\end{array}$ & $\begin{array}{c}\text { Sharpness } \\
\mathbf{( S 5 0 )}\end{array}$ & $\begin{array}{c}\text { Roughness } \\
(\mathbf{R 5})\end{array}$ & $\begin{array}{c}\text { Perceived } \\
\text { Annoyance }\end{array}$ & $\begin{array}{c}\text { Perceived } \\
\text { Annoyance } \\
\text { Rating }\end{array}$ \\
\hline (ms) & $\mathbf{( i u )}$ & (sone) & (acum) & (asper) & & \\
\hline 2.5 & 4.25 & 13.4 & 1.15 & 8.57 & 61.72 & $\mathbf{6 1 . 7 2}$ \\
\hline 5 & 4.47 & 14.7 & 1.15 & 8.85 & 63.77 & $\mathbf{6 3 . 7 7}$ \\
\hline 10 & 4.88 & 14.71 & 1.15 & 10.08 & 66.52 & $\mathbf{6 6 . 5 2}$ \\
\hline 25 & 6.66 & 20.47 & 1.2 & 11.65 & 78.2 & $\mathbf{7 8 . 2}$ \\
\hline 50 & 9.67 & 27.48 & 1.3 & 13.73 & 95.17 & $\mathbf{9 5 . 1 7}$ \\
\hline 100 & 12.65 & 31.51 & 1.37 & 12.69 & 103.45 & $\mathbf{1 0 0}$ \\
\hline 250 & 13.39 & 29.25 & 0.95 & 11.74 & 89.4 & $\mathbf{8 9 . 4}$ \\
\hline 500 & 9.25 & 28.34 & 0.55 & 11.4 & 73.13 & $\mathbf{7 3 . 1 3}$ \\
\hline 1000 & 6.81 & 23.88 & 0.37 & 10.59 & 62.87 & $\mathbf{6 2 . 8 7}$ \\
\hline 4000 & 1.74 & 9.92 & 0.24 & 4.13 & 39.43 & $\mathbf{3 9 . 4 3}$ \\
\hline 8000 & 0.61 & 4.02 & 0.21 & 1.14 & 31.25 & $\mathbf{3 1 . 2 5}$ \\
\hline
\end{tabular}

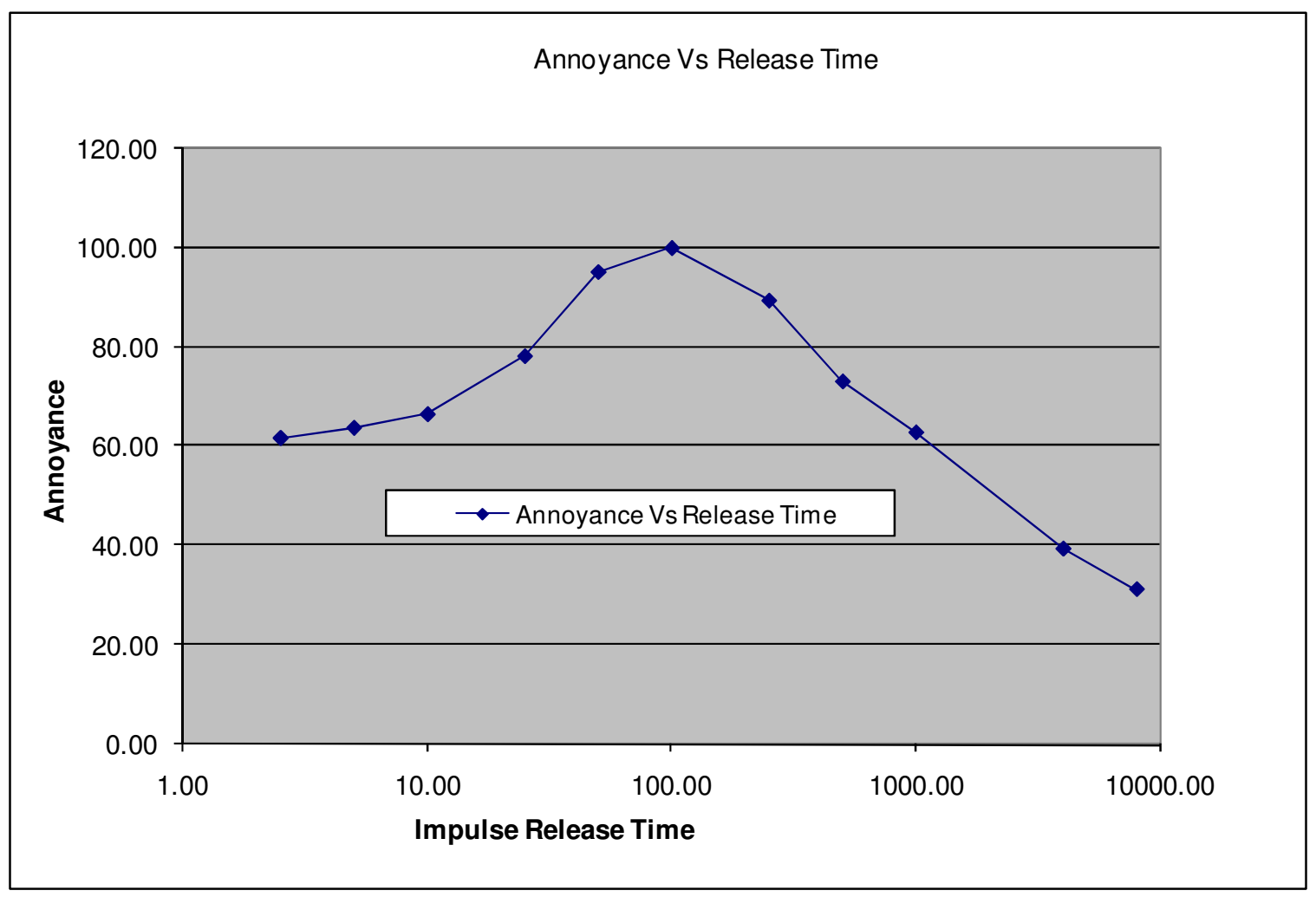

Figure 25: Effect of Variation in Release Time of an Impulse on Perceived Annoyance 


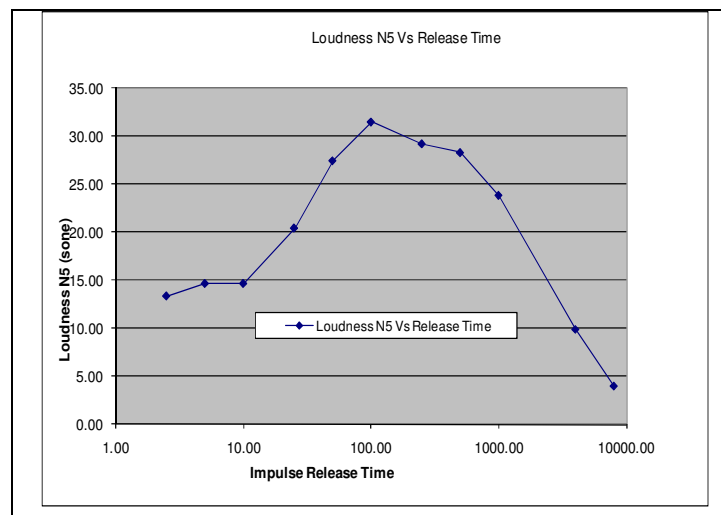

Figure 26: Effect of Variation in Release Time of an Impulse on Loudness N5

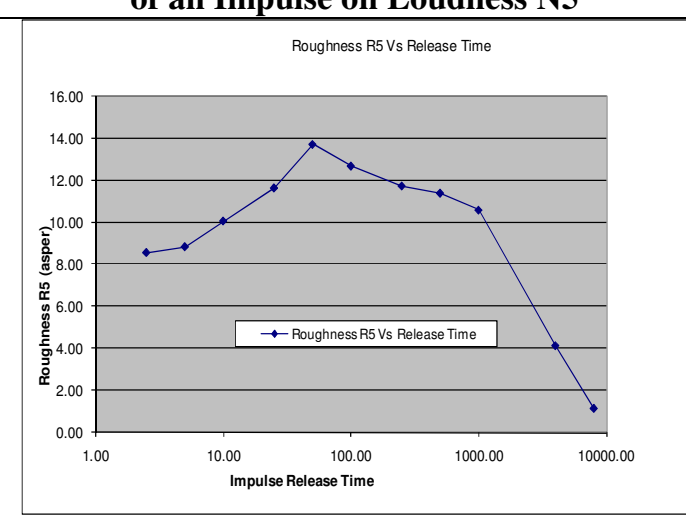

Figure 28: Effect of Variation in Release Time of an Impulse on Roughness R5

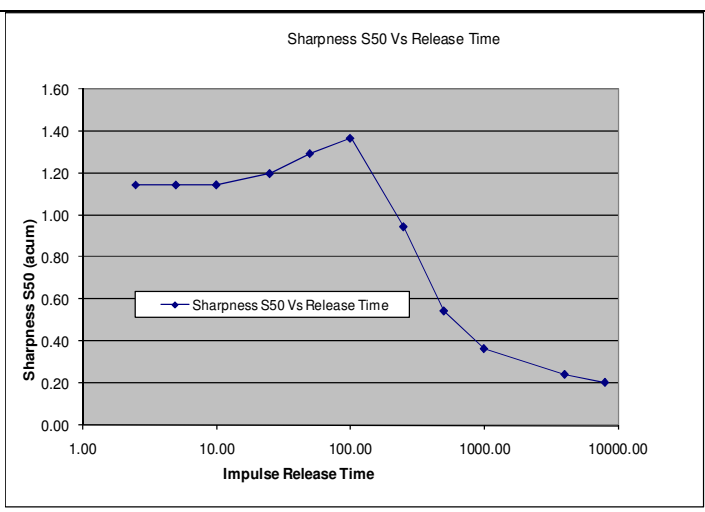

Figure 27: Effect of Variation in Release Time of an Impulse on Sharpness S50

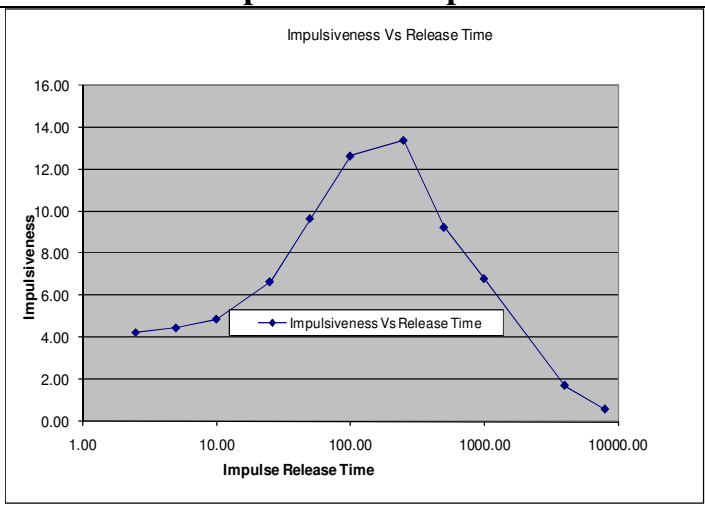

Figure 29: Effect of Variation in Release Time of an Impulse on Impulsiveness

F) Frequency Content: Annoyance of any sound is very much dependant on its spectral content. A listener would perceive high frequency sound a lot annoying than low frequency sound. On the contrary low frequency sound may sound rough to human ear. Thus it is very important to study the prominent frequencies in an impulsive sound if its annoyance needs to be controlled. Frequency content of an impulse can be controlled by application of various filters. Following Table 7 shows the effect of low pass Butterworth filters of different frequencies on the annoyance and the other psychoacoustic metrics. Low pass $4^{\text {th }}$ order Butterworth filter is considered as the best 
and most feasible filter setting in this study. Detailed analysis on various filter settings is explained in Chapter 6.

Table 7: Effect of Variation in Frequency Content of an Impulse on Perceived Annoyance

\begin{tabular}{|c|c|c|c|c|c|c|}
\hline $\begin{array}{c}\text { LP Filter } \\
\text { Frequency }\end{array}$ & $\begin{array}{c}\text { Loudness } \\
\text { Based } \\
\text { Impulsive } \\
\text { ness (In) }\end{array}$ & $\begin{array}{c}\text { Loudness } \\
\text { (N5) }\end{array}$ & $\begin{array}{c}\text { Sharpness } \\
\text { (S50) }\end{array}$ & $\begin{array}{c}\text { Roughness } \\
\text { (R5) }\end{array}$ & $\begin{array}{c}\text { Perceived } \\
\text { Annoyance }\end{array}$ & $\begin{array}{c}\text { Perceived } \\
\text { Annoyance } \\
\text { Rating }\end{array}$ \\
\hline (Hz) & (iu) & (sone) & (acum) & (asper) & & \\
\hline 250 & 0.8307 & 1.587933 & 0.2790564 & 0.18591124 & 29.477653 & $\mathbf{2 9 . 4 7 7 6 5 3}$ \\
\hline 500 & 2.0284 & 3.973602 & 0.3986896 & 0.63615215 & 32.7590926 & $\mathbf{3 2 . 7 5 9 0 9 2 6}$ \\
\hline 1000 & 3.3824 & 7.36206 & 0.514032 & 1.8755765 & 38.5734969 & $\mathbf{3 8 . 5 7 3 4 9 6 9}$ \\
\hline 2000 & 4.4633 & 9.71058 & 0.624346 & 3.7395792 & 45.2471051 & $\mathbf{4 5 . 2 4 7 1 0 5 1}$ \\
\hline 3000 & 5.1119 & 12.76669 & 0.7099892 & 5.4765873 & 51.776602 & $\mathbf{5 1 . 7 7 6 6 0 2}$ \\
\hline 4000 & 5.5842 & 15.41107 & 0.8855098 & 6.50214338 & 58.1594065 & $\mathbf{5 8 . 1 5 9 4 0 6 5}$ \\
\hline 6000 & 6.101 & 17.82817 & 1.025252 & 8.3210907 & 66.0758068 & $\mathbf{6 6 . 0 7 5 8 0 6 8}$ \\
\hline 8000 & 6.4352 & 19.42982 & 1.1008077 & 9.85874844 & 71.9480928 & $\mathbf{7 1 . 9 4 8 0 9 2 8}$ \\
\hline
\end{tabular}

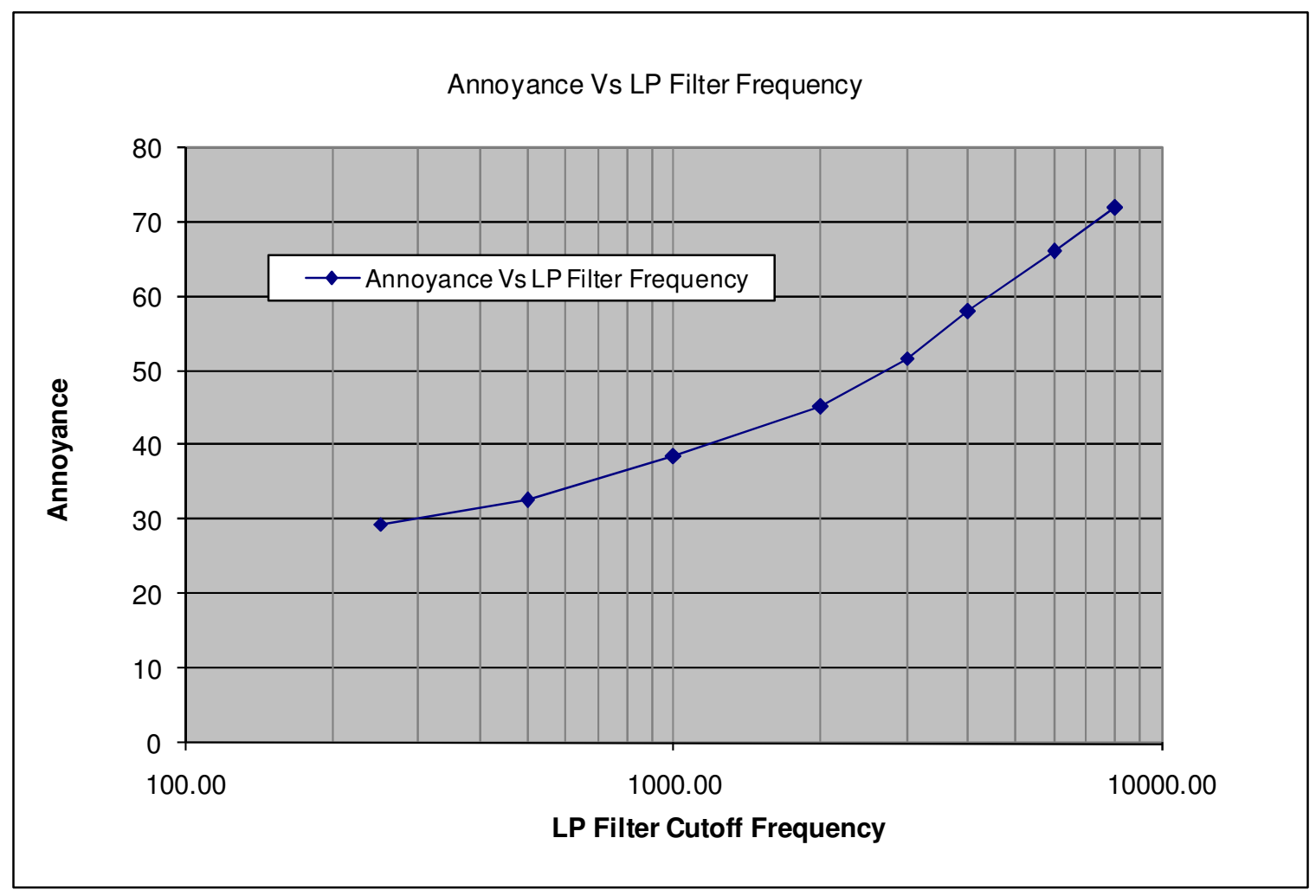

Figure 30: Effect of Low Pass Filter on Perceived Annoyance 


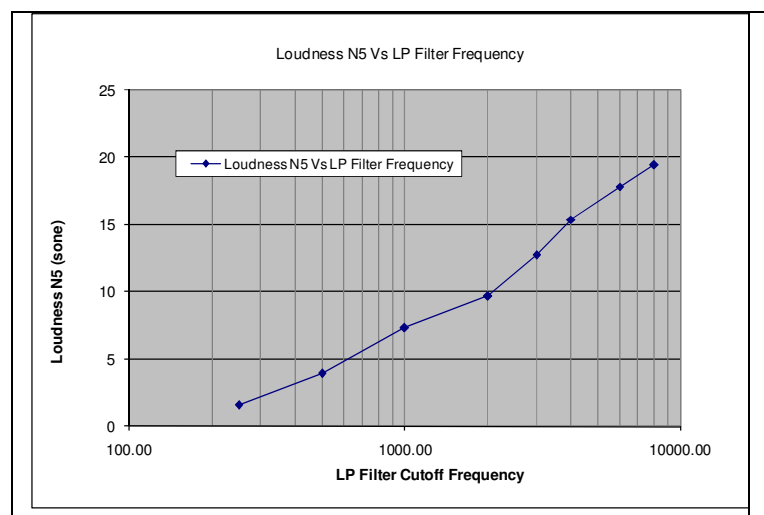

Figure 31: Effect of Low Pass Filter on Loudness N5

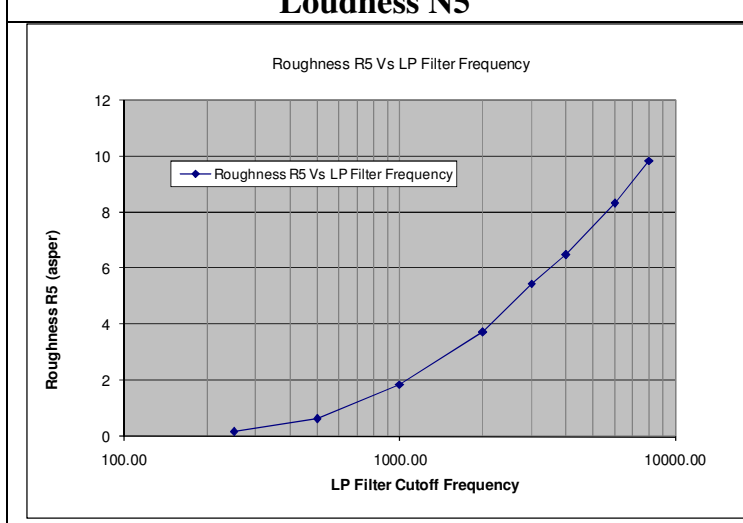

Figure 33: Effect of Low Pass Filter on Roughness R5

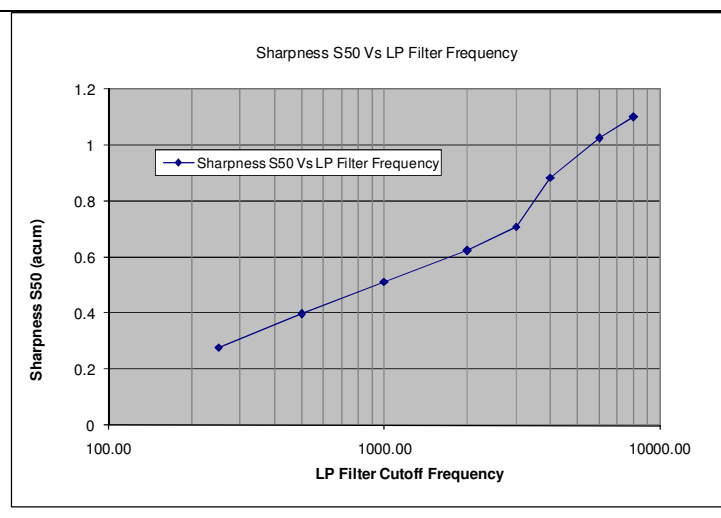

Figure 32: Effect of Low Pass Filter on Sharpness S50

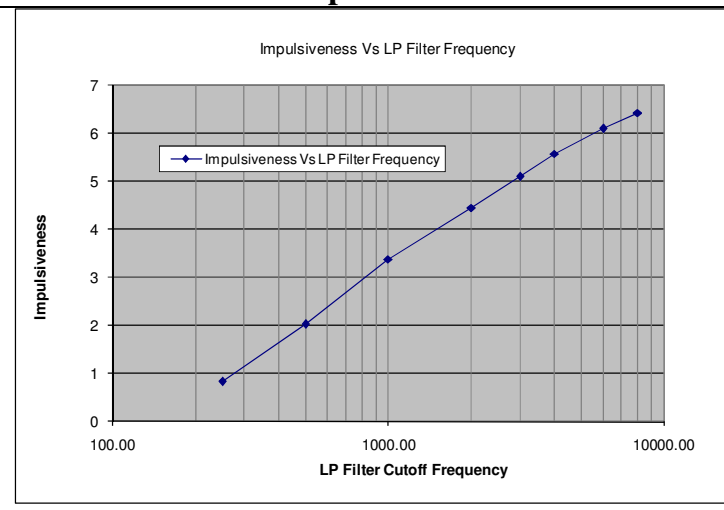

Figure 34: Effect of Low Pass Filter on Impulsiveness

From Figure (30) it is clear that perceived annoyance of an impulse decreases with low pass filter. Same trend is seen in case of other psychoacoustic metrics. 


\section{6: Filter Analysis}

Following filter analysis is done to study the effect of various filters such as bandstop, bandpass, low pass and highpass filters on the perceived annoyance of an impulsive noise. The effect of these filter settings on other psychoacoustic criteria as such as loudness, sharpness, roughness and loudness based impulsiveness is also studied. The conclusion from this analysis leads to the best filter selection for the next DOE.

The sample impulse file (05_strip - $0.2 \mathrm{~s}$ dead time) is used for the calculations purposes. Annoyance is calculated by changing following four variables from different filter settings [41] one at a time. These four variables are;

a) Kind of filter (Band Pass, Band Stop, Low Pass and High Pass)

b) Type of filter (Butterworth, Bessel, Tschebycheff $0.5 \mathrm{~dB}$ and Tchebycheff $3 \mathrm{~dB}$

c) Filter order (1,2 and 4)

d) Filter Frequency

For the following filter analysis bandstop and bandpass filters are studied simultaneously and lowpass and highpass filter are studied simultaneously. The analysis is done in 2 steps.

\section{1: Bandpass and Bandstop Filters}

\section{Step 1: Effect of various filter orders at various frequencies}

In this step, for a particular filter type and filter order and frequency are changed.

The filter order changed from 1 to 4 and filter bands of constant bandwidth $3000 \mathrm{~Hz}$ are 
changed as follows: $250-3250 \mathrm{~Hz}, 500-3500 \mathrm{~Hz}, 1000-4000 \mathrm{~Hz}, 2000-5000 \mathrm{~Hz}, 3000-$ $6000 \mathrm{~Hz}, 4000-7000 \mathrm{~Hz}, 5000-8000 \mathrm{~Hz}$ and $6000-9000 \mathrm{~Hz}$. Mean of these frequency bands is calculated for the ease of plotting and annoyance for a particular frequency band is assigned to its corresponding mean. Figures (35-38) show perceived annoyance for butterworth, Bessel, Tschebycheff $0.5 \mathrm{~dB}$ and Tschebycheff $3 \mathrm{~dB}$ filters.

After studying these Figures following observations can be noted:

a) The bandpass filters have the general tendency for lower annoyance value and bandstop filters give higher values for annoyance except for order 1.

b) Also, for bandpass filters annoyance value is found maximum within frequency range of $2000-6000 \mathrm{~Hz}$, where ear is most sensitive to the vibrations.

c) For bandpass filters, as we go on increasing the order, the amplitude of perceived annoyance drops. Thus it is advisable to choose filter order 4 or the fastest roll off for the filter setting. 


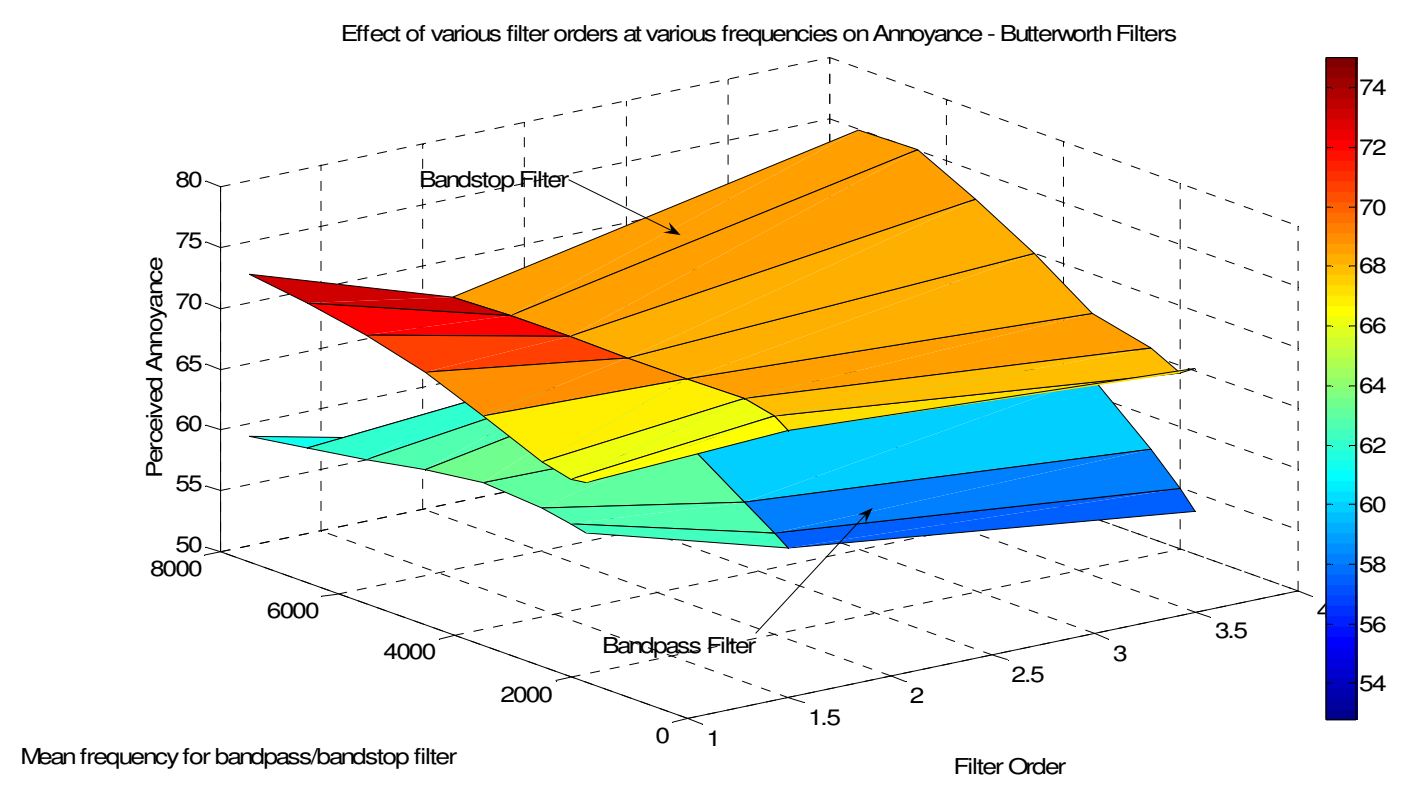

Figure 35: Effect of Various Filter Orders as Various Frequency Bands on Annoyance- BP and BS Butterworth Filters

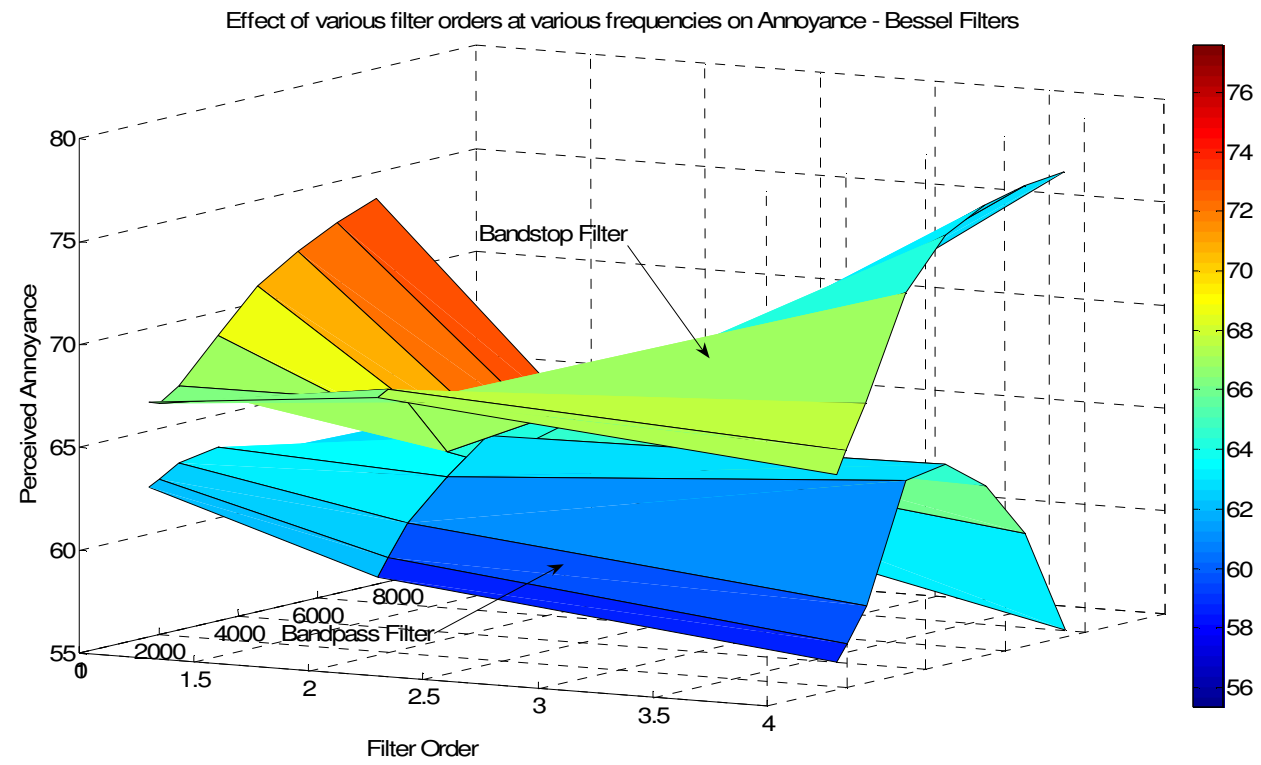

Figure 36: Effect of Various Filter Orders as Various Frequency Bands on Annoyance- BP and BS Bessel Filters 


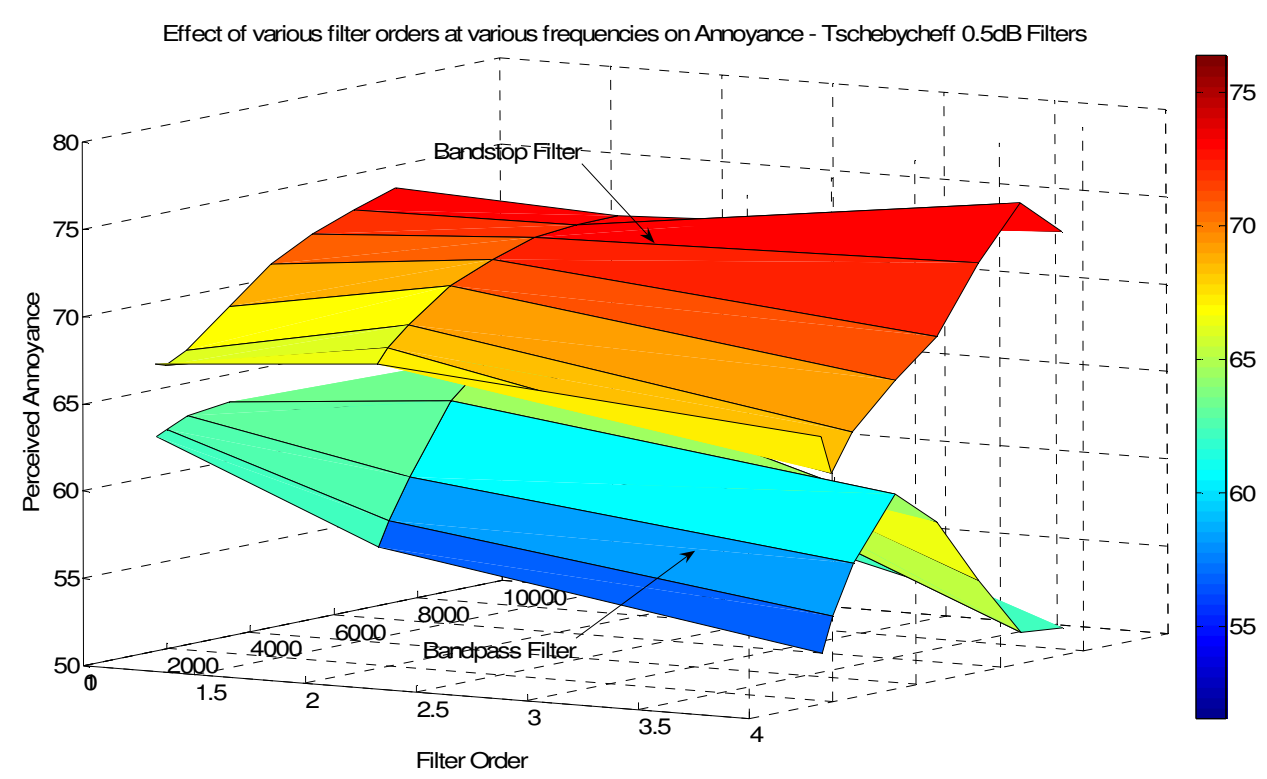

Figure 37: Effect of Various Filter Orders as Various Frequency Bands on Annoyance- BP and BS Tschebycheff0.5dB Filters

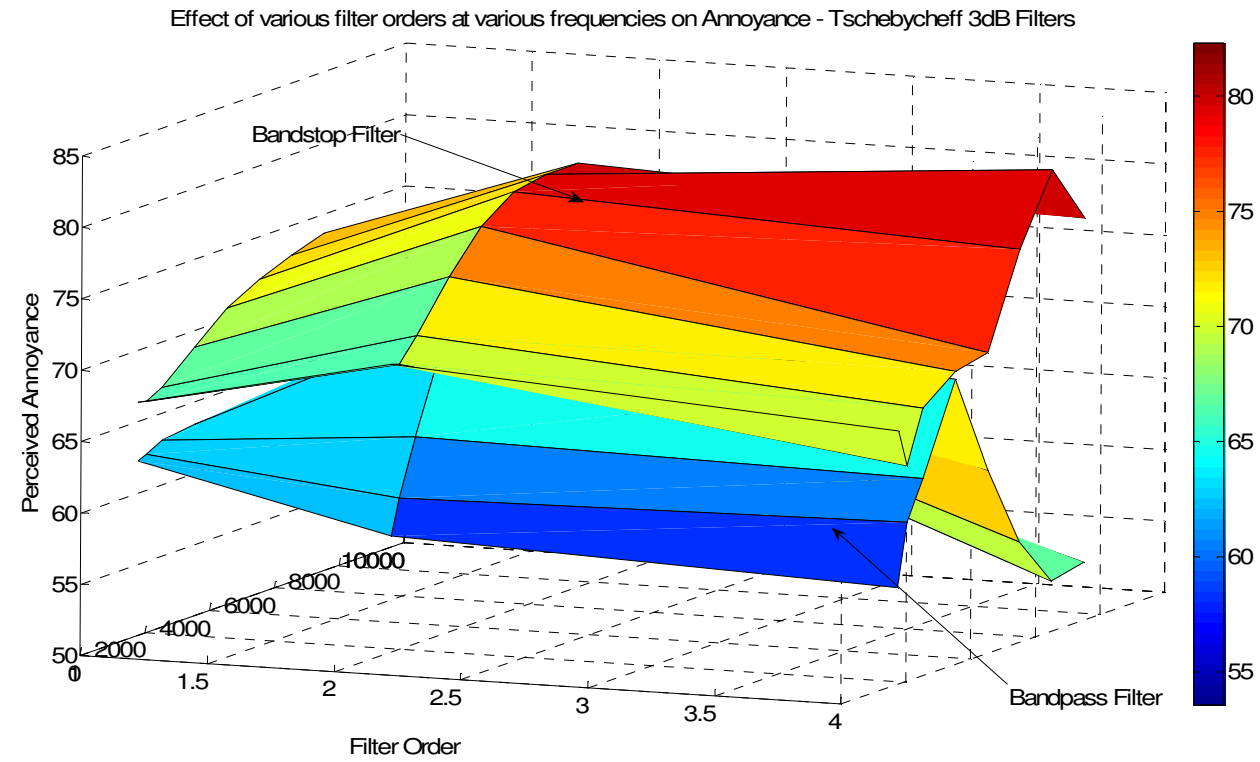

Figure 38: Effect of Various Filter Orders as Various Frequency Bands on Annoyance- BP and BS Tschebycheff3dB Filters 


\section{Step 2: Effect of various filter types at various frequencies}

For this step, order of the filter is kept constant at 4 . The amplitude of perceived annoyance is plotted for four different filter types against the frequency bands described above.

From Figure (39), it is observed that Tschebycheff $0.5 \mathrm{~dB}$ could turn out to be the best filter setting amongst all four filter types in case of band pass filters. Butterworth is the next best filter.

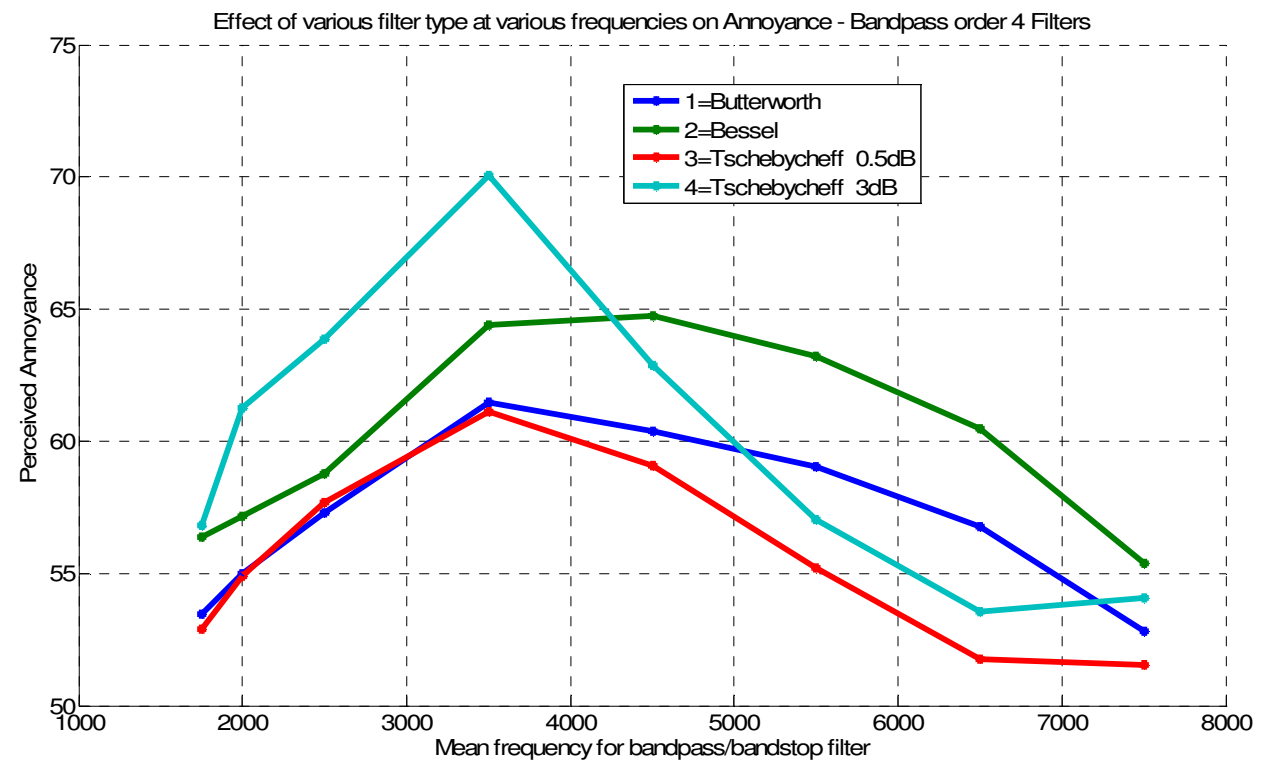

Figure 39: Effect of Various Filter Types at Various Frequency Bands on Annoyance- Bandpass order 4 Filters

The Figure (40) is a 2 dimensional representation for perceived annoyance for band pass Tschebycheff $0.5 \mathrm{~dB}$ filter. It tells the variation in annoyance as we move frequency and the filter order. It is observed from the Figure that, effect of order is not significant in frequency range of 2000-6000 Hz. For lower frequency pass bands and higher frequency pass bands, perceived annoyance decreases as we go on increasing the order.

All the band pass filter types show the same trend. For the simplicity purpose only one filter type (Tschebycheff $0.5 \mathrm{~dB}$ ) is shown below. 


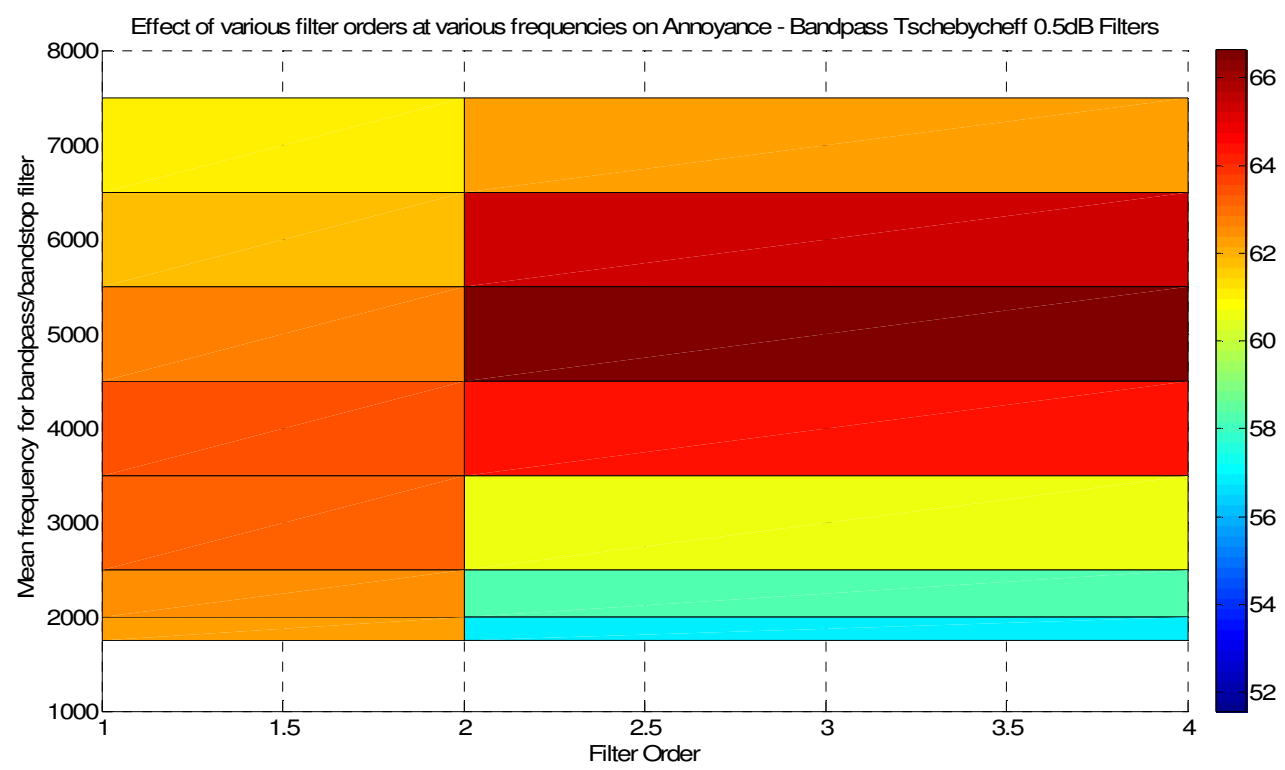

Figure 40: Effect of Various Filter Orders at Various Frequency Bands on Annoyance- Bandpass Tschebycheff 0.5dB Filter

\section{2: Lowpass and Highpass Filters}

\section{Step 1: Effect of various filter orders at various frequencies}

In this step, for a particular filter type and filter kind order and frequency are changed. The filter order changed from 1 to 4 and following filter cut off frequencies are used: $250 \mathrm{~Hz}, 500 \mathrm{~Hz}, 1000 \mathrm{~Hz}, 2000 \mathrm{~Hz}, 4000 \mathrm{~Hz}, 6000 \mathrm{~Hz}, 8000 \mathrm{~Hz}$. Figures (41-48) show perceived annoyance for butterworth, Bessel, Tschebycheff $0.5 \mathrm{~dB}$ and Tschebycheff $3 \mathrm{~dB}$ filters.

After studying these Figures following observations can be noted:

a) The Lowpass filters have the general tendency for lower annoyance value and highpass filters give higher values for annoyance except for order 1.

b) For lowpass filters, perceived annoyance increases with increase in cut off frequency. 
c) For lowpass filters, as we go on increasing the order, the amplitude of perceived annoyance drops. Thus it is advisable to choose filter order 4 or the fastest roll off for the filter setting.

The Figures (42, 44, 46, and 48) are 2 dimensional representations for perceived annoyance for band pass filters. They tell the variation in annoyance as we move up the frequency and the filter order. It is observed from the Figure that, effect of order reduces as we move up the frequency. For lower cutoff frequencies, perceived annoyance decreases as we go on increasing the order.

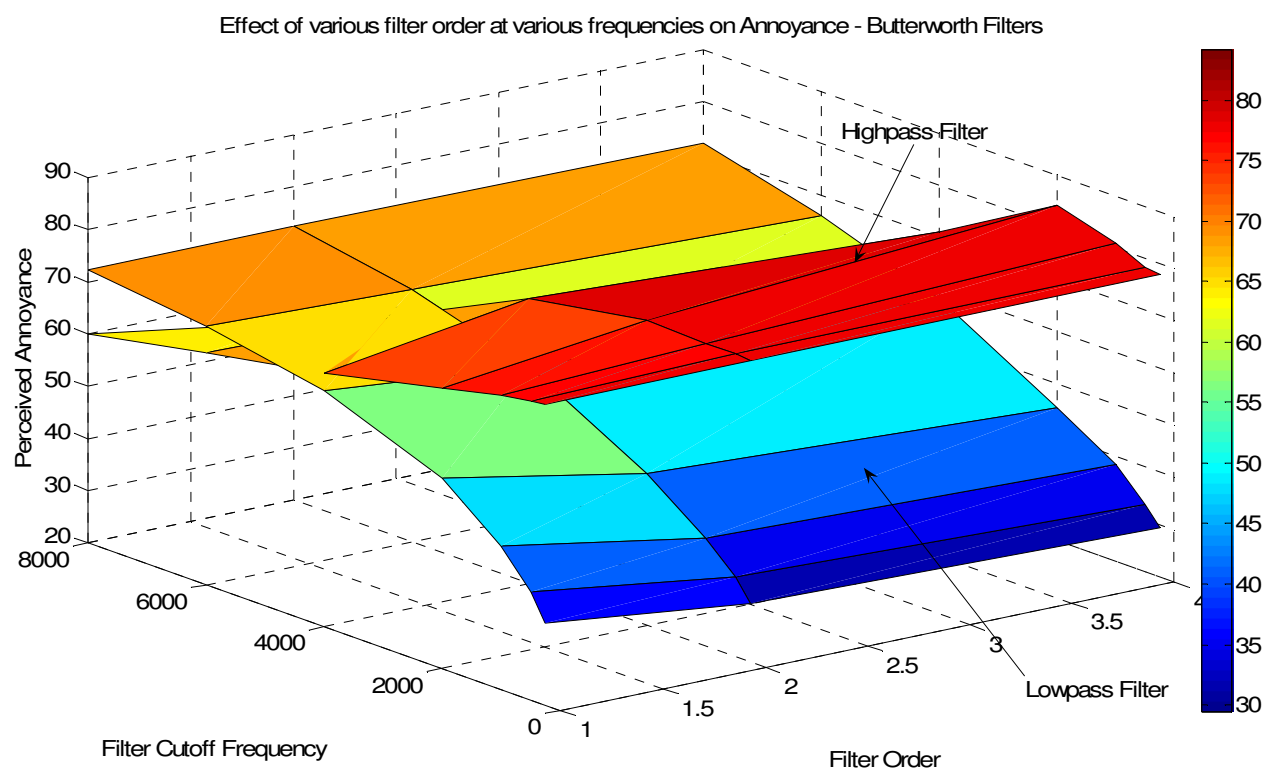

Figure 41: Effect of Various Filter Orders as Various Frequency Bands on Annoyance- LP and HP Butterworth Filters 
Effect of various filter order at various frequencies on Annoyance - LP Butterworth Filters

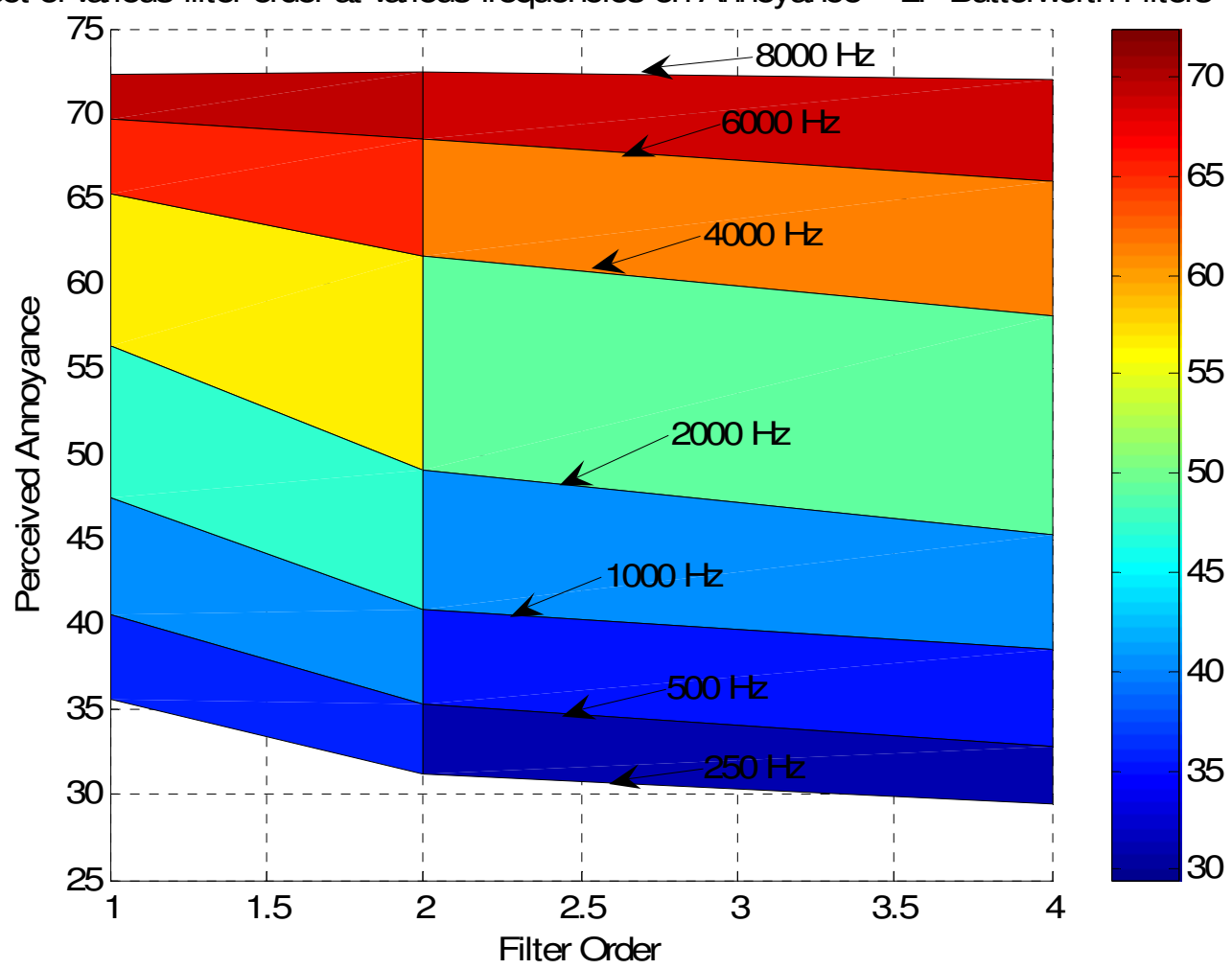

Figure 42: Effect of Various Filter Orders at Various Frequency Bands on Annoyance- Lowpass Butterworth Filter

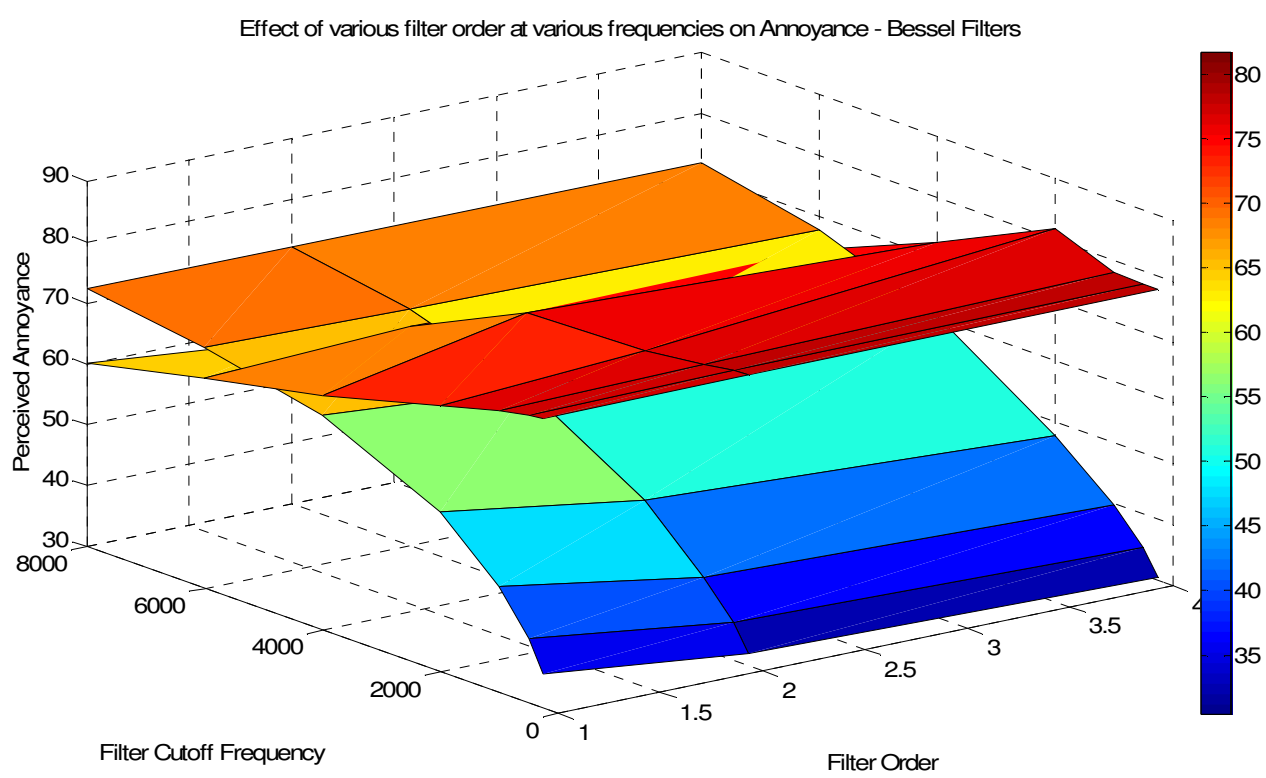

Figure 43: Effect of Various Filter Orders as Various Frequency Bands on Annoyance- LP and HP Bessel Filters 
Effect of various filter order at various frequencies on Annoyance - Bessel Filters

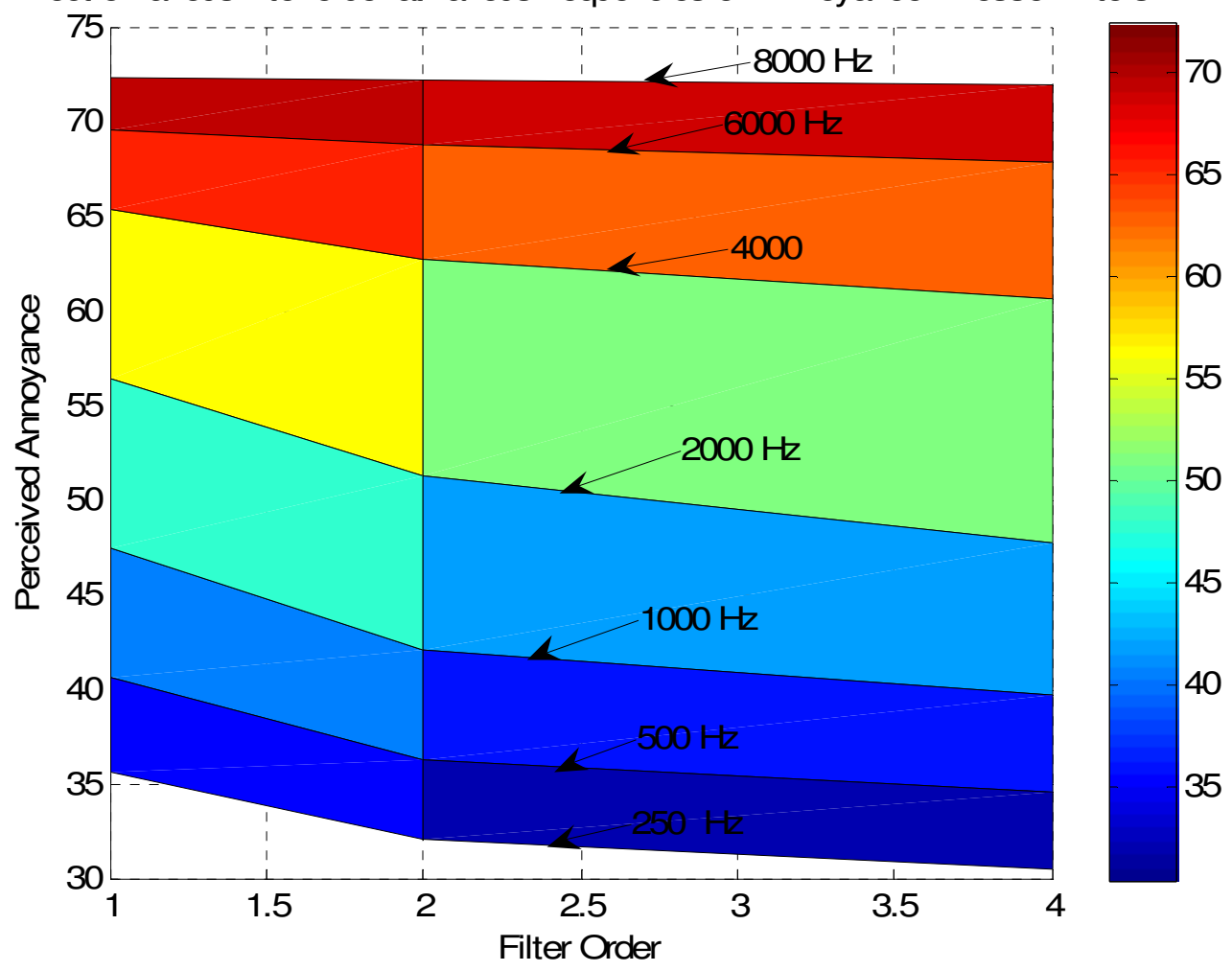

Figure 44: Effect of Various Filter Orders at Various Frequency Bands on Annoyance- Lowpass Bessel Filter

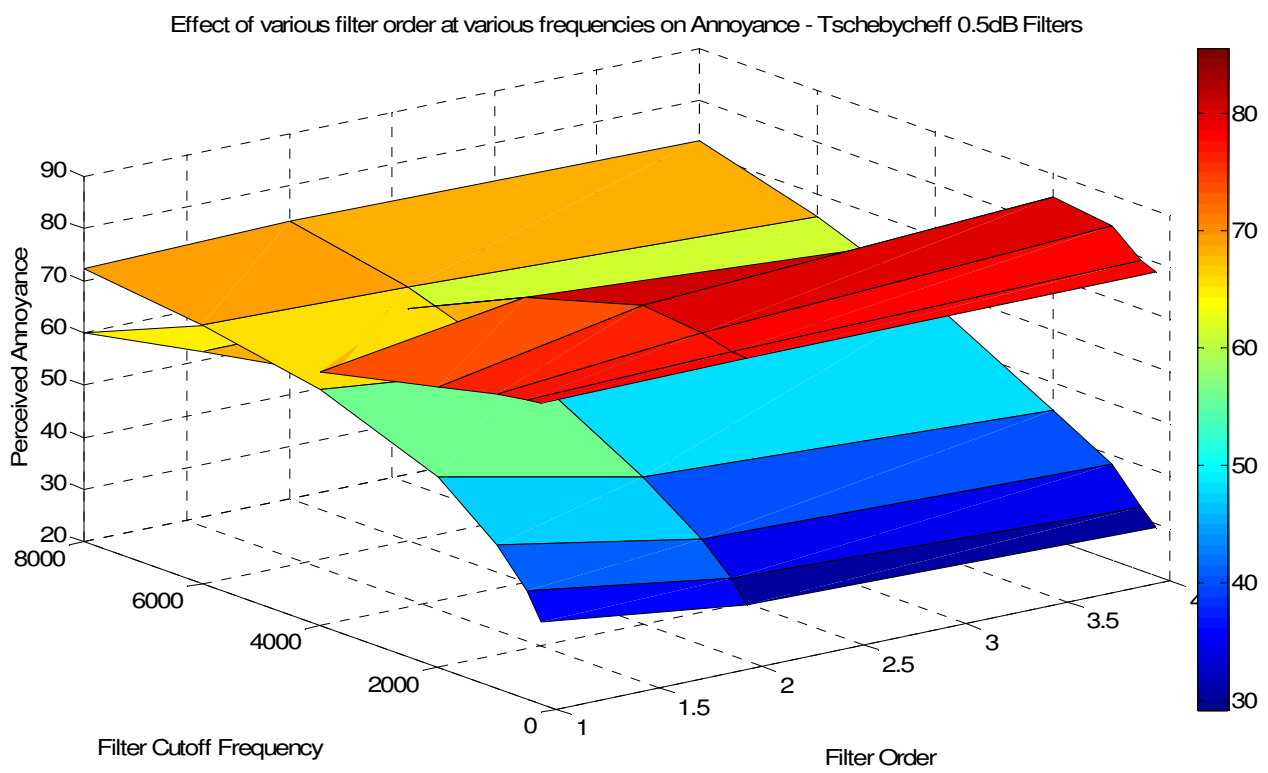

Figure 45: Effect of Various Filter Orders as Various Frequency Bands on Annoyance- LP and HP Tschebycheff 0.5dB Filters 
Effect of various filter order at various frequencies on Annoyance - Tschebycheff $0.5 \mathrm{~dB}$ Filters
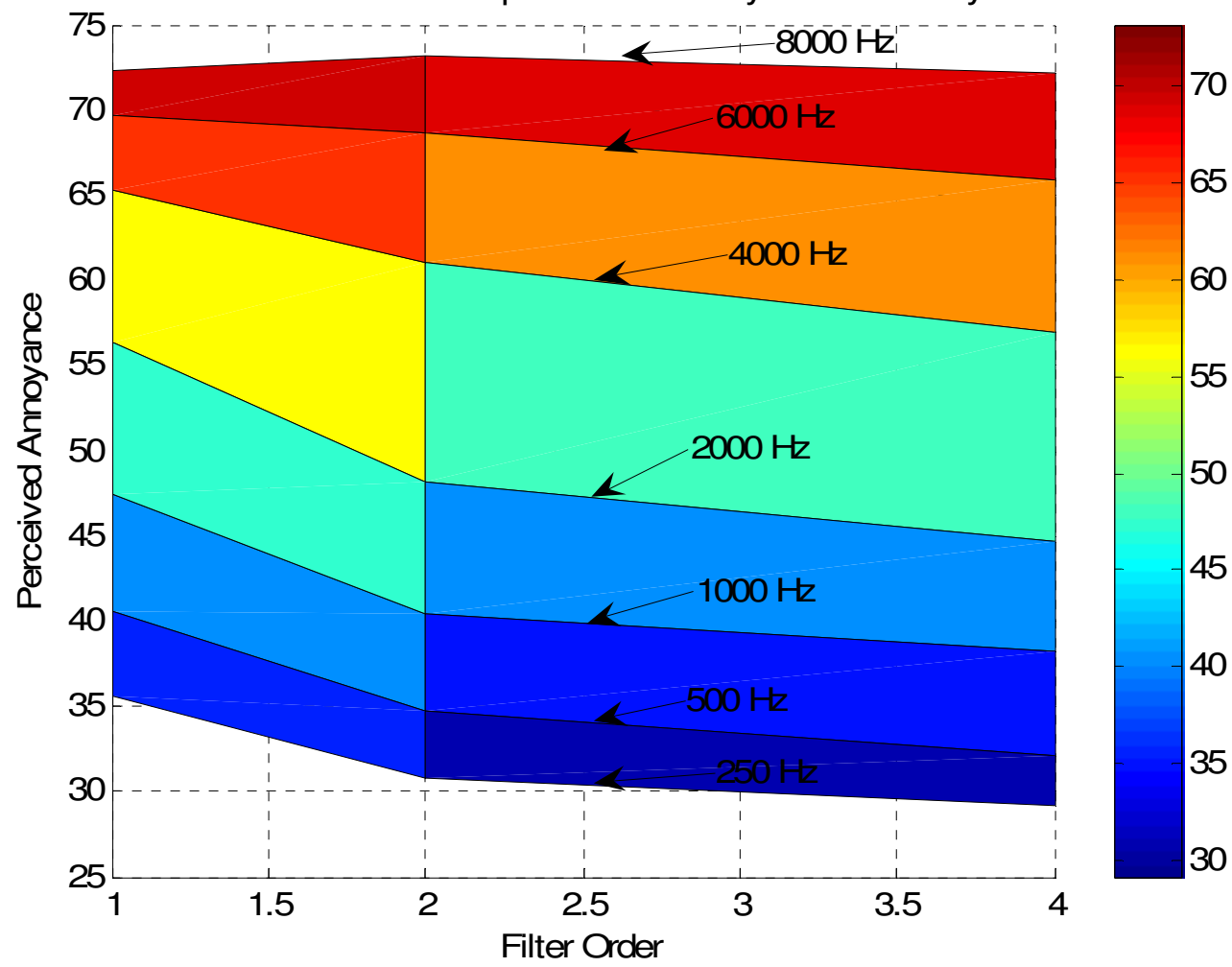

Figure 46: Effect of Various Filter Orders at Various Frequency Bands on Annoyance- Lowpass Tschebycheff 0.5dB Filter

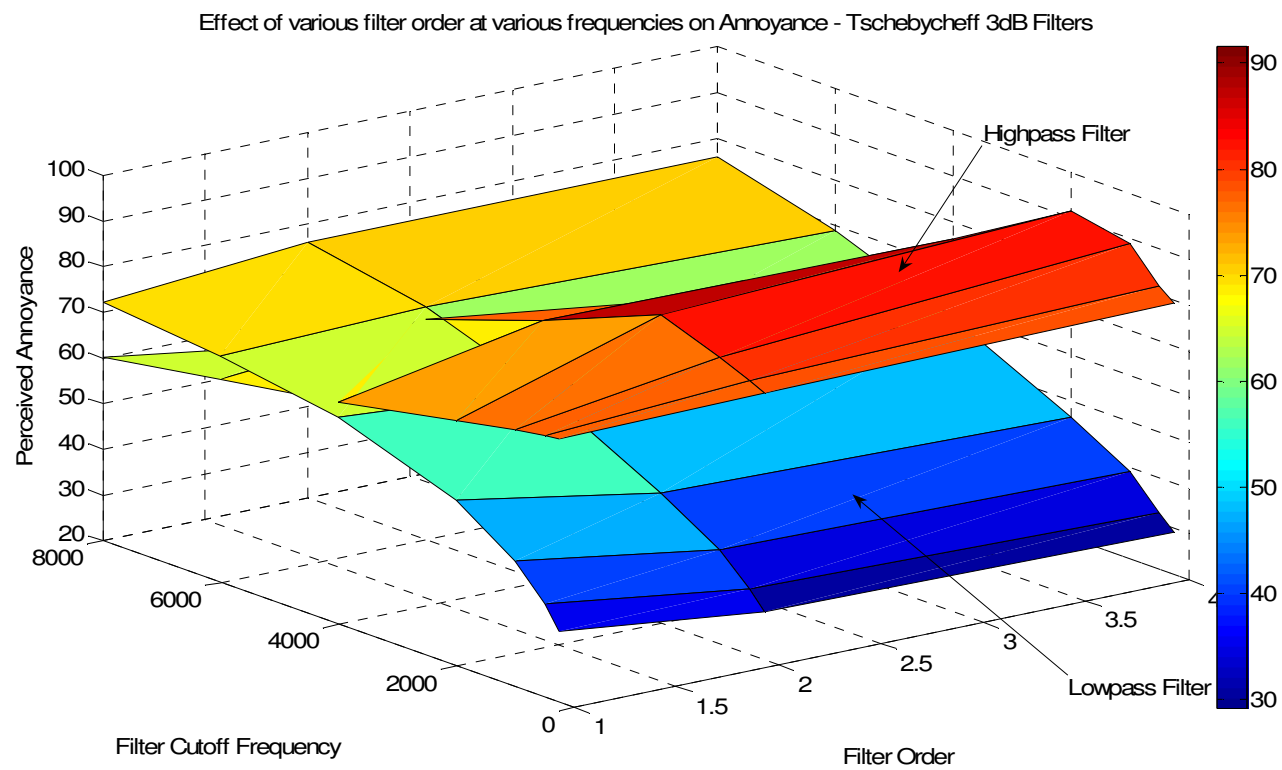

Figure 47: Effect of Various Filter Orders as Various Frequency Bands on Annoyance- LP and HP Tschebycheff 3dB Filters 
Effect of various filter order at various frequencies on Annoyance - Tschebycheff 3dB Filters

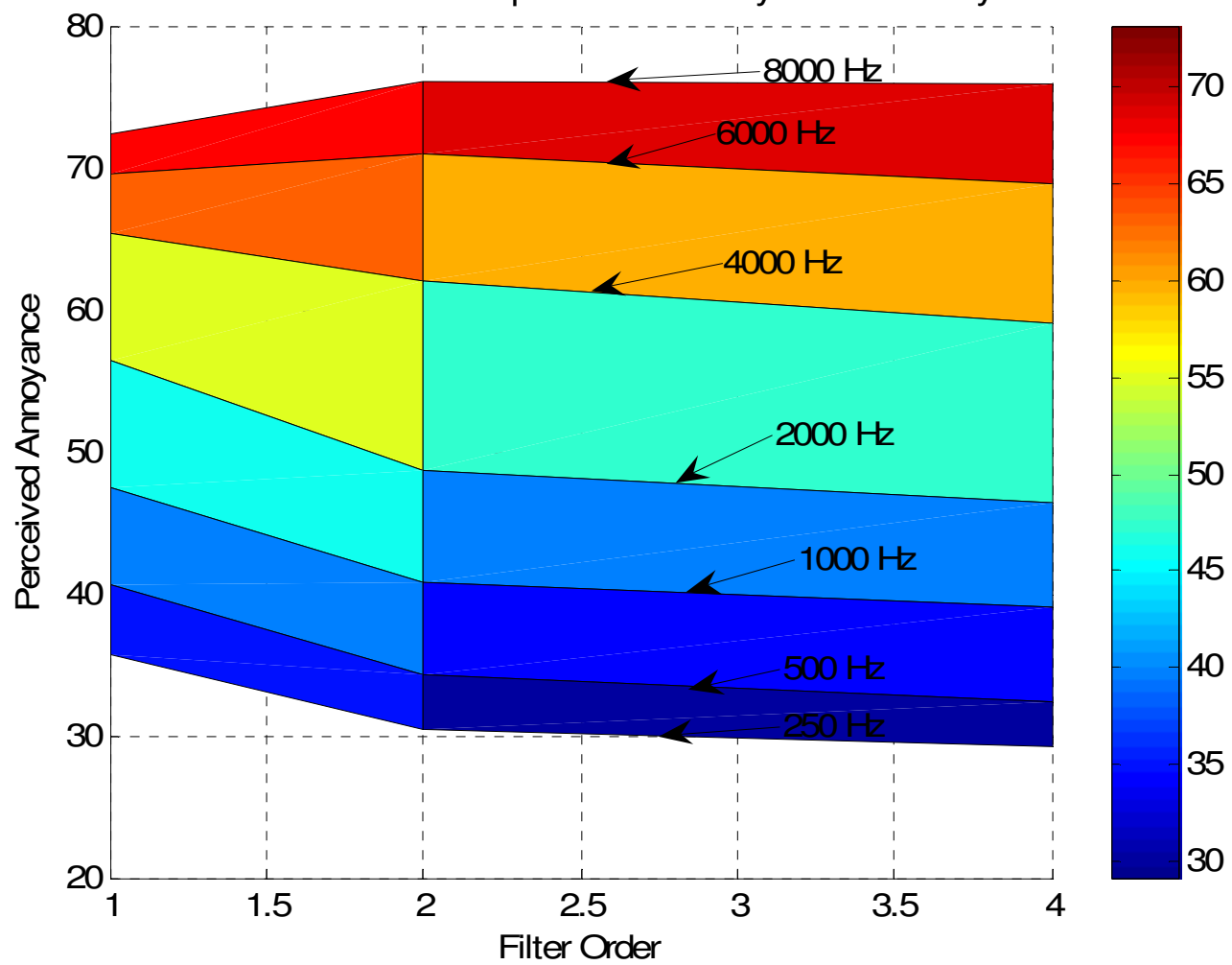

Figure 48: Effect of Various Filter Orders at Various Frequency Bands on Annoyance- Lowpass Tschebycheff 3dB Filter

\section{Step 2: Effect of various filter types at various frequencies}

For this step, order of the filter is kept constant at 4 . The amplitude of perceived annoyance is plotted for four different filter types against the frequency bands described earlier in this Chapter.

From Figure (49), it is observed that Tschebycheff $0.5 \mathrm{~dB}$ has the minimum value for perceived annoyance. It could turn out to be the best filter setting amongst all four filters types in case of low pass filters as well. Butterworth is the next best filter. 


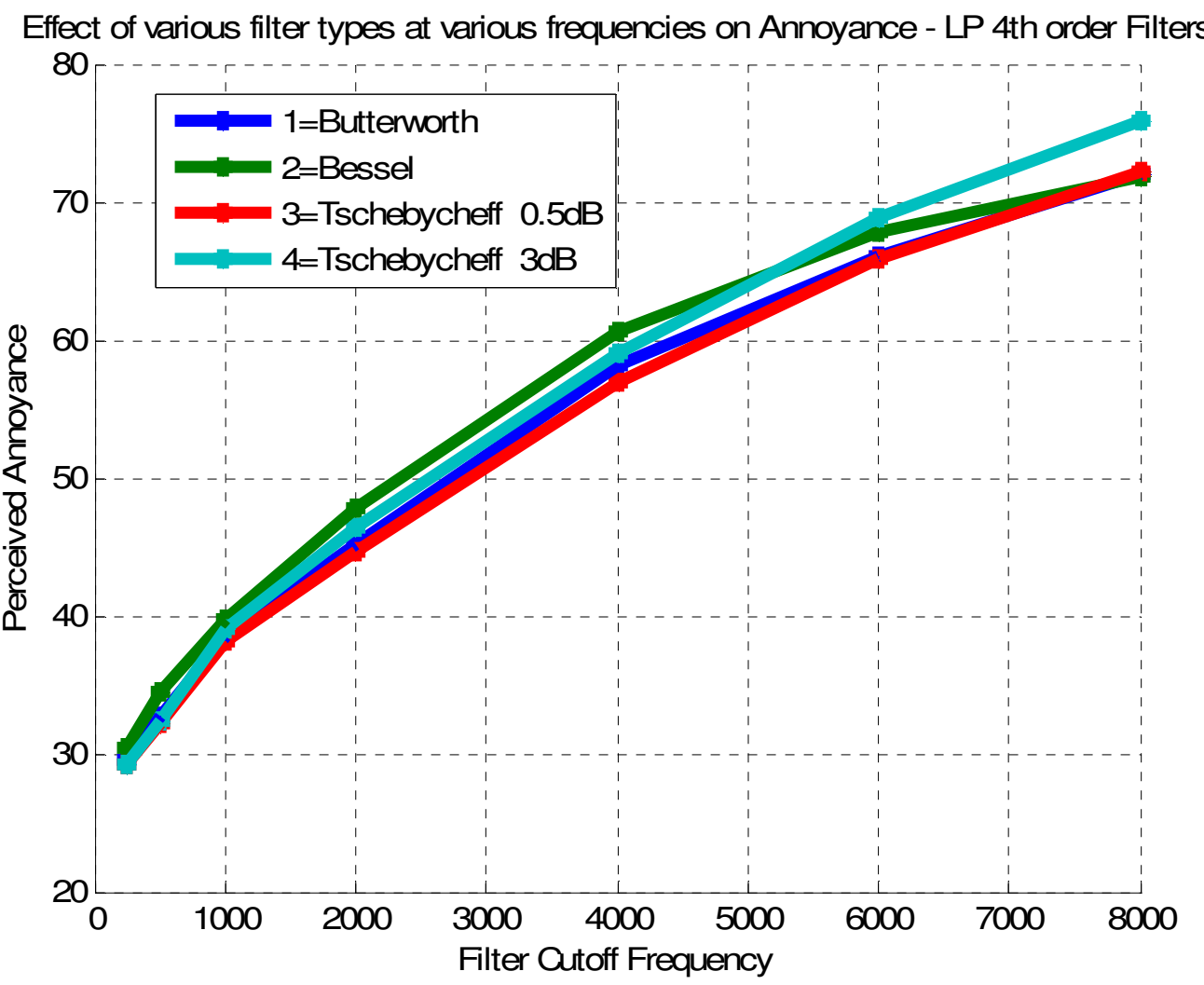

Figure 49: Effect of Various Filter Types at Various Frequency Bands on Annoyance- Lowpass order 4 Filters

\section{3: Filter Setting Used in DOE}

Though from the results it is clear that Tschebycheff $0.5 \mathrm{~dB}$ turns out to be the best filter setting for minimizing the annoyance, it could be difficult to simulate the settings in the physical world. The butterworth filter has much simpler transfer function which is simpler to duplicate physically. Also butterworth filter has pretty similar effect on the perceived annoyance when compared to the Tschebycheff $0.5 \mathrm{~dB}$ filter. Thus, for DOE purposes, butterowth forth order filter is used. Also, from the above results it looks like LP filters have tendency for low annoyance. Hence the filter kind is fixed at LP. While setting the levels for DOE, we decided to have 3 levels for the filter: a) LP $1000 \mathrm{~Hz}$ 
(passing only low frequencies) b) LP $6000 \mathrm{~Hz}$ (encompassing most sensitive auditory zone of $2000 \mathrm{~Hz}-6000 \mathrm{~Hz}$ ) and c) No filter applied. 


\section{7: Design of Experiments}

\section{1: Development of Prediction Model by $2^{5}$ Full Factorial Design}

As the goal of this research is to find how the five factors mentioned in Chapter 6, affect the perceived annoyance of an impulse, a systematically planned design of experiments is necessary. It is very important to reveal how these factors behave in case of determination of annoyance, loudness, sharpness, roughness and loudness based impulsiveness.

It was decided to conduct a two level factorial design with five factors and 2 levels as described in [30]. A complete $2^{5}$ factorial design contains $2^{5}=32$ unique test runs. The two levels for each factors termed as low and high levels are defined in coded units of -1 and +1 . Table 8 gives these 32 unique test conditions in coded forms. The 32 test conditions are depicted by 32 rows. This is how the single sample impulse should be modified and then run through Artemis for psychoacoustic metrics.

The high and low levels for each variable are then by decided subjectively by listening to modified impulses. Two contrasting sounding signals are decided as two variable levels. The variables are the levels used are tabulated in Table 9 and 10. As the spectral content is more complicated to decide on the two different levels, it was decided to have three levels for filter. Thus two different experiment designs were selected to encompass all three filter levels. More explanation on the chosen filter settings was discussed in Section 6.3. 
Table 8: Experimental Runs as per 25 Full Factorial Design

\begin{tabular}{|c|c|c|c|c|c|}
\hline Std Order & Amplitude & $\begin{array}{c}\text { Background } \\
\text { noise }\end{array}$ & $\begin{array}{l}\text { Attack } \\
\text { Time }\end{array}$ & $\begin{array}{c}\text { Release } \\
\text { Time }\end{array}$ & $\begin{array}{c}\text { Frequency } \\
\text { (Filter Setting) }\end{array}$ \\
\hline 1 & -1 & -1 & -1 & -1 & -1 \\
\hline 2 & -1 & -1 & -1 & -1 & 1 \\
\hline 3 & -1 & -1 & -1 & 1 & -1 \\
\hline 4 & -1 & -1 & -1 & 1 & 1 \\
\hline 5 & -1 & -1 & 1 & -1 & -1 \\
\hline 6 & -1 & -1 & 1 & -1 & 1 \\
\hline 7 & -1 & -1 & 1 & 1 & -1 \\
\hline 8 & -1 & -1 & 1 & 1 & 1 \\
\hline 9 & -1 & 1 & -1 & -1 & -1 \\
\hline 10 & -1 & 1 & -1 & -1 & 1 \\
\hline 11 & -1 & 1 & -1 & 1 & -1 \\
\hline 12 & -1 & 1 & -1 & 1 & 1 \\
\hline 13 & -1 & 1 & 1 & -1 & -1 \\
\hline 14 & -1 & 1 & 1 & -1 & 1 \\
\hline 15 & -1 & 1 & 1 & 1 & -1 \\
\hline 16 & -1 & 1 & 1 & 1 & 1 \\
\hline 17 & 1 & -1 & -1 & -1 & -1 \\
\hline 18 & 1 & -1 & -1 & -1 & 1 \\
\hline 19 & 1 & -1 & -1 & 1 & -1 \\
\hline 20 & 1 & -1 & -1 & 1 & 1 \\
\hline 21 & 1 & -1 & 1 & -1 & -1 \\
\hline 22 & 1 & -1 & 1 & -1 & 1 \\
\hline 23 & 1 & -1 & 1 & 1 & -1 \\
\hline 24 & 1 & -1 & 1 & 1 & 1 \\
\hline 25 & 1 & 1 & -1 & -1 & -1 \\
\hline 26 & 1 & 1 & -1 & -1 & 1 \\
\hline 27 & 1 & 1 & -1 & 1 & -1 \\
\hline 28 & 1 & 1 & -1 & 1 & 1 \\
\hline 29 & 1 & 1 & 1 & -1 & -1 \\
\hline 30 & 1 & 1 & 1 & -1 & 1 \\
\hline 31 & 1 & 1 & 1 & 1 & -1 \\
\hline 32 & 1 & 1 & 1 & 1 & 1 \\
\hline
\end{tabular}




\begin{tabular}{|c|c|c|c|}
\hline & \multirow{2}{*}{ Factor } & \multicolumn{2}{|c|}{ Level } \\
\cline { 3 - 4 } & Change in amplitude & minus $10 \mathrm{~dB}$ & plus $10 \mathrm{~dB}$ \\
\hline B & Addition of background noise & back_2 - 20dB & back_2 + 10dB \\
\hline C & Impulse attack time & $0.5 \mathrm{~ms}$ & $30 \mathrm{~ms}$ \\
\hline D & Impulse release time & $5 \mathrm{~ms}$ & $100 \mathrm{~ms}$ \\
\hline E & Spectral Content (LP-order 4) & LP $1000 \mathrm{~Hz}$ & LP 6000 Hz \\
\hline
\end{tabular}

Table 9: Variable Levels for DOE- Setting 1

\begin{tabular}{|c|c|c|c|}
\hline & \multirow{2}{*}{ Factor } & \multicolumn{2}{|c|}{ Level } \\
\cline { 3 - 4 } & Change in amplitude & minus $10 \mathrm{~dB}$ & plus $10 \mathrm{~dB}$ \\
\hline B & Addition of background noise & back_2 - 20dB & back_2 + 10dB \\
\hline C & Impulse attack time & $0.5 \mathrm{~ms}$ & $30 \mathrm{~ms}$ \\
\hline D & Impulse release time & $5 \mathrm{~ms}$ & $100 \mathrm{~ms}$ \\
\hline E & Spectral Content (LP-order 4) & LP $1000 \mathrm{~Hz}$ & No Filter \\
\hline
\end{tabular}

Table 10: Variable Levels for DOE- Setting 2

As this analysis was restricted to a single impulse file, only small part of the original recorded file containing one impulse and very little dead time (0.2s) was selected. This impulse was then modified as per the experimental settings prescribed as per $2^{5}$ factorial design (see Table 8-10). All the 32 files were then analyzed in Artemis 11.2 for loudness $\left(5^{\text {th }}\right.$ percentile), sharpness (median value), and roughness $\left(5^{\text {th }}\right.$ percentile). Loudness based impulsiveness and annoyance is generated using equations 3.6.2 and 4.1 resp. The response values for all the mentioned psychoacoustic metrics are listed below in Table 11. In this Table, calculated annoyance values above 100 are rated at maximum annoyance level of 100. All such cases are marked in grey. 
Table 11: Psychoacoustic Response values for file: 0.2s dead time filter setting 2

\begin{tabular}{|c|c|c|c|c|c|c|c|c|c|c|c|}
\hline StdOrder & A & B & $\mathrm{C}$ & D & $\mathbf{E}$ & $\begin{array}{l}\text { Loudness } \\
\text { N5(sone) }\end{array}$ & \begin{tabular}{|l|} 
Sharpness \\
S50(acum)
\end{tabular} & $\begin{array}{l}\text { Roughness } \\
\text { R5(asper) }\end{array}$ & \begin{tabular}{|l|} 
Impuls \\
iveness
\end{tabular} & $\begin{array}{c}\text { Annoy } \\
\text { ance }\end{array}$ & $\begin{array}{c}\text { Annoyance } \\
\text { Rating }\end{array}$ \\
\hline 1 & -1 & -1 & -1 & -1 & -1 & 2.43 & 0.55 & 0.21 & 1.14 & 30.67 & 30.67 \\
\hline 2 & -1 & -1 & $\overline{-1}$ & -1 & 1 & 7.05 & 0.94 & 1.35 & 2.18 & 38.56 & 38.56 \\
\hline 3 & -1 & -1 & -1 & $\overline{1}$ & -1 & 7.67 & 0.54 & 1.95 & 3.45 & 39.10 & 39.10 \\
\hline 4 & -1 & -1 & -1 & 1 & 1 & 16.67 & 1.07 & 6.01 & 6.23 & 61.62 & 61.62 \\
\hline 5 & -1 & -1 & 1 & -1 & -1 & 12.11 & 0.42 & 2.68 & 4.23 & 42.22 & 42.22 \\
\hline 6 & -1 & -1 & 1 & -1 & 1 & 15.83 & 0.75 & 3.03 & 5.07 & 49.73 & 49.73 \\
\hline 7 & -1 & -1 & 1 & 1 & -1 & 14.85 & 0.50 & 3.50 & 5.08 & 46.77 & 46.77 \\
\hline 8 & -1 & -1 & 1 & 1 & 1 & 24.42 & 1.05 & 7.38 & 7.59 & 72.47 & 72.47 \\
\hline 9 & -1 & 1 & -1 & -1 & -1 & 13.66 & 0.77 & 1.07 & 10.80 & 52.13 & 52.13 \\
\hline 10 & -1 & 1 & -1 & -1 & 1 & 20.29 & 2.01 & 3.47 & 16.74 & 89.91 & 89.91 \\
\hline 11 & -1 & 1 & -1 & 1 & -1 & 14.26 & 0.80 & 1.36 & 12.08 & 40.65 & 40.65 \\
\hline 12 & -1 & 1 & -1 & 1 & 1 & 22.84 & 2.06 & 5.32 & 19.35 & 101.81 & 100.00 \\
\hline 13 & -1 & 1 & 1 & -1 & -1 & 16.47 & 0.76 & 1.84 & 12.49 & 70.11 & 70.11 \\
\hline 14 & -1 & $\overline{1}$ & 1 & -1 & 1 & 23.70 & 1.98 & 4.03 & 18.49 & 98.33 & 98.33 \\
\hline 15 & -1 & 1 & 1 & 1 & -1 & 18.14 & 0.80 & 2.01 & 13.40 & 77.26 & 77.26 \\
\hline 16 & -1 & 1 & 1 & 1 & 1 & 29.63 & 2.06 & 5.80 & 20.71 & 116.30 & 100.00 \\
\hline 17 & 1 & -1 & -1 & -1 & -1 & 9.14 & 0.48 & 1.96 & 4.53 & 55.01 & 55.01 \\
\hline 18 & 1 & -1 & -1 & -1 & 1 & 24.38 & 1.11 & 16.44 & 7.78 & 90.32 & 90.32 \\
\hline 19 & 1 & -1 & -1 & 1 & -1 & 27.38 & 0.61 & 6.40 & 13.16 & 57.27 & 57.27 \\
\hline 20 & 1 & -1 & -1 & 1 & 1 & 56.98 & 1.44 & 21.19 & 22.45 & 164.36 & 100.00 \\
\hline 21 & 1 & -1 & 1 & -1 & -1 & 44.51 & 0.46 & 6.44 & 16.33 & 60.46 & 60.46 \\
\hline 22 & 1 & -1 & 1 & -1 & 1 & 56.67 & 1.03 & 18.32 & 18.88 & 134.26 & 100.00 \\
\hline 23 & 1 & -1 & 1 & 1 & -1 & 52.52 & 0.57 & 9.91 & 18.98 & 95.03 & 95.03 \\
\hline 24 & 1 & -1 & 1 & 1 & 1 & 83.20 & 1.46 & 24.18 & 27.39 & 210.28 & 100.00 \\
\hline 25 & 1 & $\frac{1}{1}$ & -1 & -1 & -1 & 13.85 & 0.79 & 1.35 & 11.71 & \begin{tabular}{|l|}
54.15 \\
\end{tabular} & 54.15 \\
\hline 26 & 1 & 1 & -1 & -1 & 1 & 29.02 & 2.05 & 13.24 & 19.19 & \begin{tabular}{|l|}
126.66 \\
\end{tabular} & 100.00 \\
\hline 27 & 1 & 1 & -1 & 1 & -1 & 28.73 & 0.80 & 5.45 & 17.96 & 79.65 & 79.65 \\
\hline 28 & 1 & 1 & -1 & 1 & 1 & 58.78 & 2.14 & 19.59 & 30.56 & 209.22 & 100.00 \\
\hline 29 & 1 & 1 & 1 & -1 & -1 & 46.50 & 0.76 & 5.53 & 21.82 & 95.21 & 95.21 \\
\hline 30 & 1 & 1 & 1 & -1 & 1 & 60.20 & 1.90 & 15.97 & 28.81 & 190.98 & 100.00 \\
\hline 31 & 1 & 1 & 1 & 1 & -1 & 53.94 & 0.80 & 8.36 & 23.80 & 109.39 & 100.00 \\
\hline 32 & 1 & 1 & 1 & 1 & 1 & 86.28 & 2.19 & 21.83 & 35.80 & \begin{tabular}{|l|}
274.22 \\
\end{tabular} & 100.00 \\
\hline
\end{tabular}

Main effects and interaction effects were then calculated in order to obtain a mathematical model of the response [30]. The average or main effect is described as the change in response magnitude when only a single variable changes its level. Interaction effect tells us the dependency of effect of one variable with another variable. Both sign and magnitude of these effects have a meaning. The sign of these effects signifies whether the response increases or decreases with that variable. The magnitude of the 
effect signifies how strong the effect is. Generalized mathematical model for a response for $2 \mathrm{k}$ factorial design can be given by;

$\mathrm{Y}=\mathrm{b}_{0}+\mathrm{b}_{1} \mathrm{x}_{1}+\mathrm{b}_{2} \mathrm{x}_{2}+\ldots \mathrm{b}_{\mathrm{k}} \mathrm{x}_{\mathrm{k}}+\mathrm{b}_{12} \mathrm{x}_{12}+\mathrm{b}_{13} \mathrm{x}_{13}+\ldots$ all two level interactions $+\ldots$. all $\mathrm{k}$ level interactions $+\epsilon$

Equation (7.1.1)

The coefficients $b_{1}, b_{2}$ correspond to main effects where as $b_{12}$ or $b_{123}$ would correspond of the estimates of effects because the coefficients measure the incremental change in the response value as the variable is changed for 1 unit (from 0 to 1 ). Whereas the effects E measure the incremental change in response value as the variable is changed for 2 units $(-1$ to +1$)$. To obtain the all the main and interaction effects calculation matrix is generated. See Appendix A.1.

After the closer examination of these effects, some of the effects have very large amplitude than others. Usually the magnitude of three and higher-level interactions is very low as compared to the main effects or some of the two level interactions. Thus for the computation purposes, it is assumed that these three and higher order interactions are normally distributed around zero. Now, to determine whether other main effects and two factor interaction effects are significant a theory of 'hypothesis testing' is followed. This means that the true mean effects of all third, fourth and fifth order interaction are negligible. With this assumption, the variance of an effect can be calculated from following equation:

$$
s_{\text {eff ect }}^{2}=\sum_{\text {Highar order interactions }} \frac{\left(E_{i}-\mu_{E_{i}}\right)^{2}}{\text { no.of higher order interactions }}
$$


Where,

$$
\begin{aligned}
& s_{i f f e t}^{z}=\text { Variance of an effect } \\
& E_{i}=\text { Magnitude of an effect } \\
& \mu_{E_{i}}=0=\text { True mean of the effects }
\end{aligned}
$$

This standard error is used to construct the $95 \%$ confidence interval with t- value. In our case as we have 16 three and higher order interactions. Thus standard t-value for 16 DOF and $95 \%$ confidence interval is $t_{16,0.975}=2.12$. Confidence interval for effect estimate is then calculated by following formula:

\section{Effect estimate $\pm\left(t_{16,0.975}\right) *\left(S_{\text {effoct }}\right)$}

If this confidence interval of an effect estimate includes zero, then it satisfies the null hypothesis of zero mean. This effect can be termed as not significant. If the confidence interval does not include zero, then it rejects the null hypothesis of zero mean. In this case, the effect is significant and surely does have a considerable impact on the response.

The next step after obtaining the significant effects is to formulate a mathematical model for the response. If all the insignificant factors are neglected from the equation 7.1.1, we get much simpler mathematical model for the response with some scope for variance. Predicted response is then generated with this new fitted model for each of the test condition. This fitted model is then subjected to further analysis and confirmatory 
tests to check the model adequacy. Table 12 gives the coefficients for the fitted model for perceived annoyance and all other psychoacoustic attributes. From the Table it seems that all five main factors and only amplitude-background noise and attack time- frequency interactions are significant in case of perceived annoyance. Also one third order interaction seems to be significant. This third order interaction can be neglected as this could be an outlier for our initial hypothesis of zero mean. The term 'NS' means that particular effect is not significant. 
Table 12: Coefficients for Significant Factors in Predicted Model for annoyance, loudness, roughness, sharpness and impulsiveness for file: $0.2 \mathrm{~s}$ dead time filter setting 2

\begin{tabular}{|c|c|c|c|c|c|c|}
\hline $\begin{array}{c}\text { Mathematical } \\
\text { Model }\end{array}$ & & $\begin{array}{c}\text { Perceived } \\
\text { Annoyance }\end{array}$ & $\begin{array}{l}\text { Loudness } \\
\text { N5(sone) }\end{array}$ & $\begin{array}{l}\text { Sharpness } \\
\text { S50(acum) }\end{array}$ & $\begin{array}{c}\text { Roughness } \\
\text { R5(asper) }\end{array}$ & Impulsiveness \\
\hline \multirow{32}{*}{ 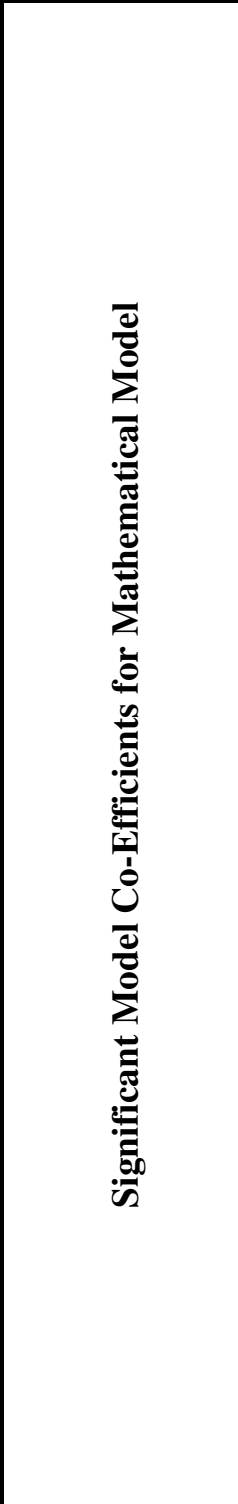 } & Mean & 74.90 & 31.00 & 1.11 & 7.72 & 14.94 \\
\hline & $\mathrm{A}$ & 11.80 & 14.75 & 0.05 & 4.54 & 5.00 \\
\hline & B & 9.94 & 2.51 & 0.30 & -0.46 & 4.66 \\
\hline & $\mathrm{C}$ & 6.83 & 8.93 & $\mathrm{NS}$ & 1.08 & 2.49 \\
\hline & $\mathrm{D}$ & 4.47 & 6.27 & 0.07 & 1.67 & 2.43 \\
\hline & $\bar{E}$ & 12.66 & 7.49 & 0.46 & 3.97 & 3.01 \\
\hline & $\mathrm{AB}$ & -5.51 & -1.11 & -0.04 & -0.38 & -0.90 \\
\hline & $\mathrm{AC}$ & NS & 5.79 & NS & 0.48 & 1.54 \\
\hline & $\mathrm{AD}$ & NS & 3.96 & 0.02 & 0.69 & 1.38 \\
\hline & $\mathrm{AE}$ & NS & 3.69 & 0.04 & 2.61 & 0.90 \\
\hline & $\mathrm{BC}$ & NS & NS & NS & NS & NS \\
\hline & $\mathrm{BD}$ & $\mathrm{NS}$ & $\mathrm{NS}$ & -0.03 & $\mathrm{NS}$ & $\mathrm{NS}$ \\
\hline & $\mathrm{BE}$ & NS & NS & 0.17 & $\mathrm{NS}$ & 1.09 \\
\hline & $\mathrm{CD}$ & NS & $\mathrm{NS}$ & NS & $\mathrm{NS}$ & -0.77 \\
\hline & $\mathrm{CE}$ & -4.32 & NS & NS & $\mathrm{NS}$ & $\mathrm{NS}$ \\
\hline & $\mathrm{DE}$ & NS & 2.59 & 0.04 & 0.55 & 0.88 \\
\hline & $\mathrm{ABC}$ & NS & NS & NS & $\mathrm{NS}$ & NS \\
\hline & $\mathrm{ABD}$ & NS & NS & $\mathrm{NS}$ & $\mathrm{NS}$ & NS \\
\hline & $\mathrm{ABE}$ & -4.25 & NS & -0.03 & NS & NS \\
\hline & ACD & $\mathrm{NS}$ & $\mathrm{NS}$ & $\mathrm{NS}$ & $\mathrm{NS}$ & -0.53 \\
\hline & $\mathrm{ACE}$ & NS & NS & $\mathrm{NS}$ & $\mathrm{NS}$ & NS \\
\hline & $\mathrm{ADE}$ & $\mathrm{NS}$ & $\mathrm{NS}$ & $\mathrm{NS}$ & $\mathrm{NS}$ & $\mathrm{NS}$ \\
\hline & BCD & NS & NS & NS & NS & NS \\
\hline & $\mathrm{BCE}$ & NS & NS & NS & $\mathrm{NS}$ & NS \\
\hline & $\mathrm{BDE}$ & NS & NS & $\mathrm{NS}$ & $\mathrm{NS}$ & NS \\
\hline & $\mathrm{CDE}$ & NS & NS & NS & NS & NS \\
\hline & ABCD & $\mathrm{NS}$ & $\mathrm{NS}$ & NS & $\mathrm{NS}$ & NS \\
\hline & $\mathrm{BCDE}$ & NS & $\mathrm{NS}$ & $\mathrm{NS}$ & $\mathrm{NS}$ & $\mathrm{NS}$ \\
\hline & ACDE & NS & $\mathrm{NS}$ & $\mathrm{NS}$ & $\mathrm{NS}$ & NS \\
\hline & ABDE & NS & NS & NS & NS & NS \\
\hline & ABCE & NS & NS & NS & NS & NS \\
\hline & $\mathrm{ABCDE}$ & NS & NS & NS & NS & NS \\
\hline
\end{tabular}

After studying the calculated annoyance values from Table 11, it is observed that the calculated value of annoyance is more than 100 for many experimental cases. As the scale of annoyance rating is from 0 to 100, annoyance values above 100 are clipped down at 100. This would add an error in the generated mathematical model. Thus it is concluded that just considering the impulse with very small dead time is probably not a 
good idea. To overcome this error the same impulse file with varying dead times are analyzed. Following are additional 4 runs that are run: 1s dead time filter setting 1, 1s dead time filter setting 2 , $3 \mathrm{~s}$ dead time filter setting 1 , and $3 \mathrm{~s}$ dead time filter setting 2 . It was found that as the dead time is increased the values of loudness, sharpness, roughness generated through Artemis 11.2 are decreased. As a result calculated values of loudness based impulsiveness and perceived annoyance also decrease. But if all these five sound files are evaluated subjectively, the annoyance level of the impulse itself feels to be the same even though they give different calculated values. Also dead time in a sound file is not a function of the impulsive event. As this research is limited to just the single impulse, it was decided to not to consider 'dead time' as one of the factors in DOE. Thus it is important to keep the dead time constant while performing DOE. Out of the five different run settings, the forth setting ( $3 \mathrm{~s}$ dead time filter setting 1 ) seems to be the best as perceived annoyance values generated with this values are not clipped except at 2 cases. Table 13 shows the Artemis generated values of loudness ( $5^{\text {th }}$ percentile), sharpness (median value), roughness $\left(5^{\text {th }}\right.$ percentile) for the best setting 4: $3 \mathrm{~s}$ dead time filter setting 1. Values of impulsiveness and perceived annoyance are also calculated in the same Table. Table 14 gives the coefficients for mathematical model generated for all these psychoacoustic metrics with significant effects. The term 'NS' means that particular effect is not significant. From the Table it seems that all five main factors and most of the second order interactions are significant in case of perceived annoyance. Same effects are significant for loudness model. Impulsiveness model also shows same significant effects as it is based on is based on loudness metric. In case of sharpness, main effects and interaction effects related to attack time and release time are not significant. In case of 
roughness, all five main effects are significant and two order interactions related to amplitude are significant. Also in some case one of the third order interactions seems to be significant. This third order interaction can be neglected as this could be an outlier for our initial hypothesis of zero mean. As the research is based on trial and error method, similar analysis is done on other 3 DOE settings as well. Results are listed in Appendix $\mathrm{A} 2$ and $\mathrm{A} 3$.

Table 13: Psychoacoustic Response values for file: 3 s dead time filter setting 1

\begin{tabular}{|c|c|c|c|c|c|c|c|c|c|c|c|}
\hline StdOrder & $\mathbf{A}$ & B & $\mathbf{C}$ & D & $\mathbf{E}$ & $\begin{array}{l}\text { Loudness } \\
\text { N5(sone) }\end{array}$ & $\begin{array}{l}\text { Sharpness } \\
\text { S50(acum) } \\
\end{array}$ & $\begin{array}{c}\text { Roughness } \\
\text { R5(asper) }\end{array}$ & \begin{tabular}{|l} 
Impuls \\
iveness
\end{tabular} & $\begin{array}{c}\text { Annoy } \\
\text { ance }\end{array}$ & $\begin{array}{c}\text { Annoyance } \\
\text { Rating }\end{array}$ \\
\hline 1 & -1 & -1 & -1 & -1 & -1 & 0.76 & 0.63 & 0.09 & 0.14 & 28.47 & 28.47 \\
\hline 2 & -1 & -1 & -1 & -1 & 1 & 1.17 & 0.92 & 0.22 & 0.21 & 29.31 & 29.31 \\
\hline 3 & -1 & -1 & -1 & 1 & -1 & 3.57 & 0.63 & 1.59 & 0.42 & 33.05 & 33.05 \\
\hline 4 & -1 & -1 & -1 & 1 & 1 & 5.07 & 0.92 & 4.13 & 0.71 & 40.11 & 40.11 \\
\hline 5 & -1 & -1 & 1 & -1 & -1 & 2.25 & 0.63 & 2.33 & 0.41 & 33.66 & 33.66 \\
\hline 6 & -1 & -1 & 1 & -1 & 1 & 2.65 & 0.92 & 2.41 & 0.48 & 34.79 & 34.79 \\
\hline 7 & -1 & -1 & 1 & 1 & -1 & 4.88 & 0.63 & 3.11 & 0.63 & 36.77 & 36.77 \\
\hline 8 & -1 & -1 & 1 & 1 & 1 & 6.13 & 0.92 & 5.49 & 0.92 & 43.66 & 43.66 \\
\hline 9 & -1 & 1 & -1 & -1 & -1 & 14.59 & 0.80 & 1.44 & 1.70 & 42.48 & 42.48 \\
\hline 10 & -1 & 1 & -1 & -1 & 1 & 21.33 & 1.78 & 2.31 & 2.30 & 67.32 & 67.32 \\
\hline 11 & -1 & 1 & -1 & 1 & -1 & 14.64 & 0.80 & 1.48 & 2.54 & 43.64 & 43.64 \\
\hline 12 & -1 & 1 & -1 & 1 & 1 & 21.73 & 1.78 & 3.88 & 3.80 & 72.65 & 72.65 \\
\hline 13 & -1 & 1 & 1 & -1 & -1 & 14.85 & 0.80 & 1.80 & 1.80 & 43.42 & 43.42 \\
\hline 14 & -1 & 1 & 1 & -1 & 1 & 21.72 & 1.77 & 2.88 & 2.40 & 69.07 & 69.07 \\
\hline 15 & -1 & 1 & 1 & 1 & -1 & 15.00 & 0.80 & 1.92 & 3.03 & 45.28 & 45.28 \\
\hline 16 & -1 & 1 & 1 & 1 & 1 & 22.26 & 1.78 & 4.29 & 4.42 & 74.96 & 74.96 \\
\hline 17 & 1 & -1 & -1 & -1 & -1 & 2.90 & 0.61 & 1.59 & 0.40 & 32.63 & 32.63 \\
\hline 18 & 1 & -1 & -1 & -1 & 1 & 3.85 & 1.09 & 6.81 & 0.61 & 44.42 & 44.42 \\
\hline 19 & 1 & -1 & -1 & 1 & -1 & 13.64 & 0.61 & 5.98 & 1.42 & 47.48 & 47.48 \\
\hline 20 & 1 & -1 & -1 & 1 & 1 & 19.12 & 1.09 & 15.62 & 2.33 & 76.84 & 76.84 \\
\hline 21 & 1 & -1 & 1 & -1 & -1 & 9.21 & 0.61 & 8.51 & 1.46 & 49.77 & 49.77 \\
\hline 22 & 1 & -1 & 1 & -1 & 1 & 10.09 & 1.09 & 11.47 & 1.67 & 60.03 & 60.03 \\
\hline 23 & 1 & -1 & 1 & 1 & -1 & 18.32 & 0.61 & 9.58 & 2.16 & 57.33 & 57.33 \\
\hline 24 & 1 & -1 & 1 & 1 & 1 & 23.20 & 1.09 & 18.94 & 3.08 & 87.61 & 87.61 \\
\hline 25 & 1 & 1 & -1 & -1 & -1 & 14.78 & 0.80 & 1.51 & 1.77 & 42.83 & 42.83 \\
\hline 26 & 1 & 1 & -1 & -1 & 1 & 21.91 & 1.78 & 7.10 & 2.45 & 77.08 & 77.08 \\
\hline 27 & 1 & 1 & -1 & 1 & -1 & 19.04 & 0.80 & 4.63 & 3.13 & 53.09 & 53.09 \\
\hline 28 & 1 & 1 & -1 & 1 & 1 & 28.21 & 1.78 & 13.27 & 4.91 & 100.91 & 100.00 \\
\hline 29 & 1 & 1 & 1 & -1 & -1 & 18.73 & 0.80 & 5.44 & 2.58 & 53.66 & 53.66 \\
\hline 30 & 1 & 1 & 1 & -1 & 1 & 25.24 & 1.77 & 10.31 & 3.26 & 88.93 & 88.93 \\
\hline 31 & 1 & 1 & 1 & 1 & -1 & 22.90 & 0.80 & 7.44 & 4.15 & 62.09 & 62.09 \\
\hline 32 & 1 & 1 & 1 & 1 & 1 & 31.85 & 1.78 & 15.86 & 6.05 & 112.56 & 100.00 \\
\hline
\end{tabular}


Table 14: Coefficients for Significant Factors in Predicted Model for annoyance, loudness, roughness, sharpness and impulsiveness for file: $3 \mathrm{~s}$ dead time filter setting 1

\begin{tabular}{|c|c|c|c|c|c|c|}
\hline $\begin{array}{c}\text { Mathematical } \\
\text { Model }\end{array}$ & & $\begin{array}{c}\text { Perceived } \\
\text { Annoyance }\end{array}$ & $\begin{array}{l}\text { Loudness } \\
\text { N5(sone) }\end{array}$ & $\begin{array}{l}\text { Sharpness } \\
\text { S50(acum) }\end{array}$ & $\begin{array}{c}\text { Roughness } \\
\text { R5(asper) }\end{array}$ & Impulsiveness \\
\hline \multirow{32}{*}{ 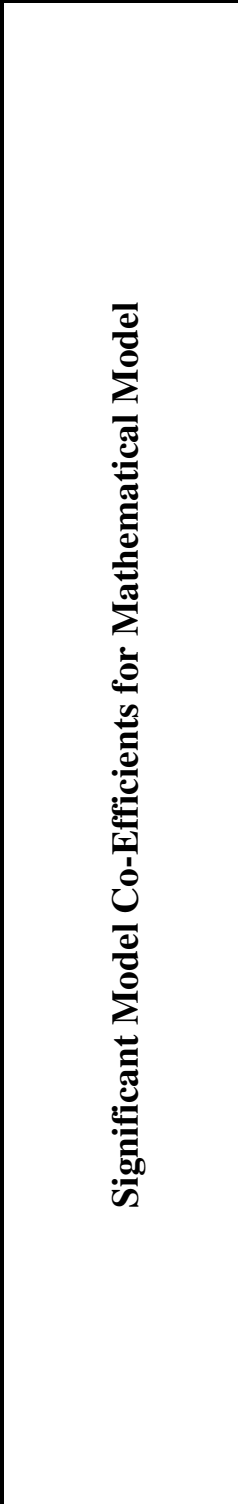 } & Mean & 55.39 & 14.24 & 1.05 & 5.73 & 2.10 \\
\hline & $\mathrm{A}$ & 9.22 & 3.45 & 0.02 & 3.27 & 0.49 \\
\hline & B & 9.39 & 6.31 & 0.24 & -0.38 & 1.04 \\
\hline & $\mathrm{C}$ & 3.43 & 1.34 & $\mathrm{NS}$ & 1.25 & 0.30 \\
\hline & $\mathrm{D}$ & 5.52 & 2.61 & NS & 1.59 & 0.63 \\
\hline & $\bar{E}$ & 11.29 & 2.36 & 0.34 & 2.08 & 0.37 \\
\hline & $\mathrm{AB}$ & -1.80 & -1.17 & -0.02 & -0.42 & -0.09 \\
\hline & $\mathrm{AC}$ & 1.89 & 0.91 & NS & 0.69 & 0.16 \\
\hline & $\mathrm{AD}$ & 2.92 & 1.74 & NS & 0.82 & 0.19 \\
\hline & $\mathrm{AE}$ & 3.47 & 0.39 & 0.02 & 1.34 & 0.08 \\
\hline & $\mathrm{BC}$ & NS & NS & NS & -0.36 & NS \\
\hline & $\mathrm{BD}$ & -1.34 & -1.21 & NS & -0.34 & 0.23 \\
\hline & $\mathrm{BE}$ & 5.19 & 1.38 & 0.15 & NS & 0.18 \\
\hline & $\mathrm{CD}$ & $\mathrm{NS}$ & NS & NS & $\mathrm{NS}$ & $\mathrm{NS}$ \\
\hline & $\mathrm{CE}$ & NS & NS & $\mathrm{NS}$ & $\mathrm{NS}$ & NS \\
\hline & DE & 2.28 & 0.49 & NS & 0.78 & 0.18 \\
\hline & $\mathrm{ABC}$ & NS & NS & NS & NS & NS \\
\hline & $\mathrm{ABD}$ & NS & -0.48 & $\mathrm{NS}$ & $\mathrm{NS}$ & $\mathrm{NS}$ \\
\hline & $\mathrm{ABE}$ & NS & $\mathrm{NS}$ & -0.02 & NS & NS \\
\hline & ACD & NS & $\mathrm{NS}$ & $\mathrm{NS}$ & $\mathrm{NS}$ & NS \\
\hline & $\mathrm{ACE}$ & NS & NS & $\mathrm{NS}$ & $\mathrm{NS}$ & NS \\
\hline & $\mathrm{ADE}$ & NS & NS & NS & $\mathrm{NS}$ & NS \\
\hline & BCD & NS & NS & NS & NS & NS \\
\hline & $\overline{B C E}$ & NS & NS & NS & NS & NS \\
\hline & $\mathrm{BDE}$ & NS & NS & $\mathrm{NS}$ & $\mathrm{NS}$ & NS \\
\hline & $\mathrm{CDE}$ & NS & NS & NS & NS & NS \\
\hline & ABCD & $\mathrm{NS}$ & $\mathrm{NS}$ & NS & $\mathrm{NS}$ & NS \\
\hline & $\mathrm{BCDE}$ & NS & $\mathrm{NS}$ & $\mathrm{NS}$ & $\mathrm{NS}$ & NS \\
\hline & ACDE & NS & $\mathrm{NS}$ & $\mathrm{NS}$ & $\mathrm{NS}$ & NS \\
\hline & ABDE & NS & NS & NS & NS & NS \\
\hline & ABCE & NS & NS & NS & NS & NS \\
\hline & $\mathrm{ABCDE}$ & NS & NS & NS & NS & NS \\
\hline
\end{tabular}

\section{2: Confirmatory tests for checking the model}

The predicted model is checked for its adequacy as per method described in [30].

If the fitted model has all the terms required predicting the response, say $\mathrm{Y}$, model residuals can be calculated. They are nothing but the difference between the measured 
response data and the predicted response. The fitted model is said to be adequate if the model residuals fit the following conditions:

- They should not contain any structured variation.

- They should be centered about mean zero.

- They should be normally distributed.

- They should not vary as a function of predicted response.

- They should not be correlated with factor independent factor, or any variables related to the experiment. Model residuals should be purely random.

Plots of model residuals for annoyance model calculated in case of experimental setting 4: 3s dead time filter setting1 are given in Figures (50-57). They all obey above mentioned requirements proving that the fitted model is adequate. Figure (52) gives the normal probability plot of the model residuals. All the model residuals appear to fall on a straight line in $95 \%$ confidence interval which is a sign of good fitted model. 


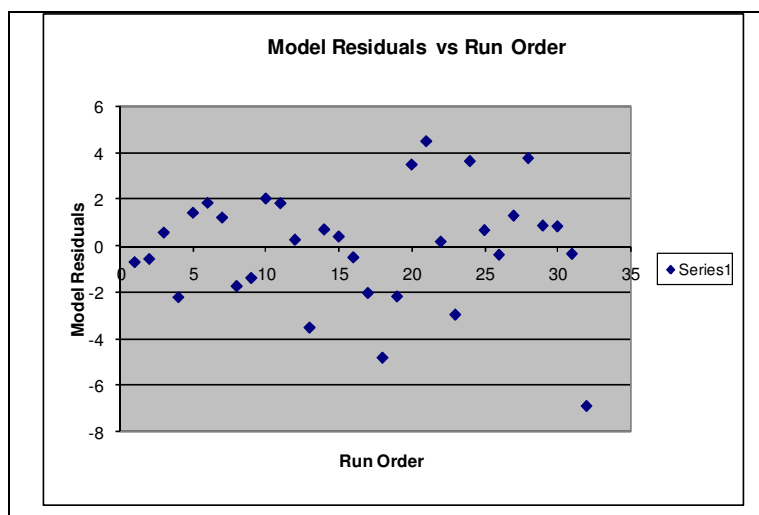

Figure 50: Model Residuals Vs Run Order (3s dead time filter setting 1 )

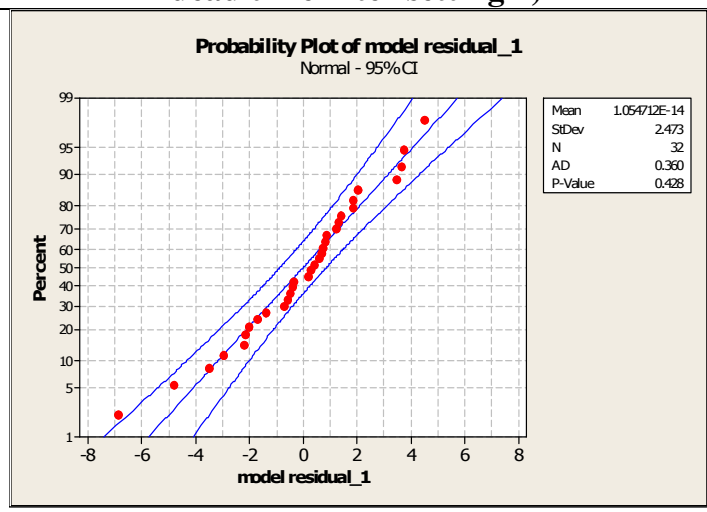

Figure 52: Normal Probability Plot of Model Residuals (3s dead time filter setting 1)

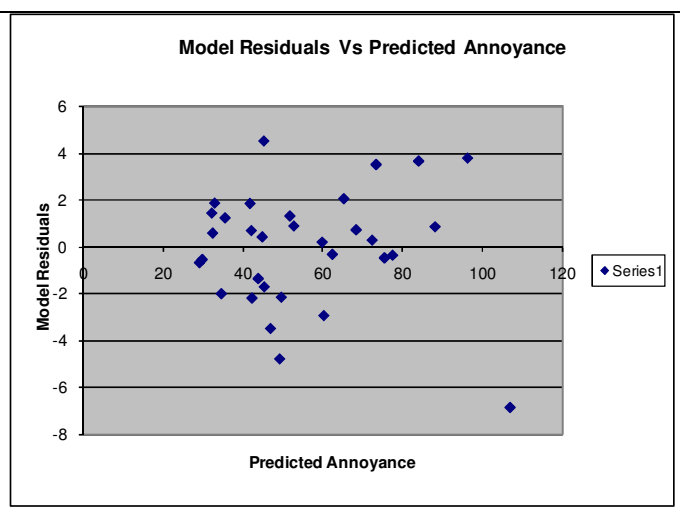

Figure 51: Model Residuals Vs Predicted Annoyance (3s dead time filter setting 1)

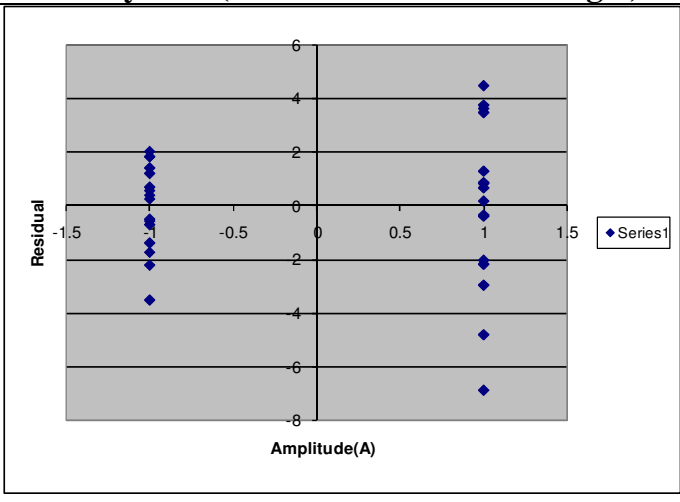

Figure 53: Model Residuals Vs Amplitude (3s dead time filter setting 1 ) 


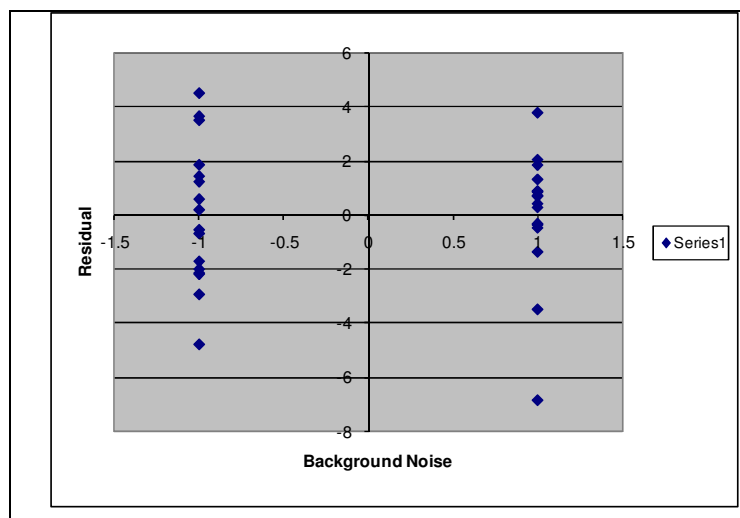

Figure 54: Model Residuals Vs Background Noise (3s dead time filter setting 1)

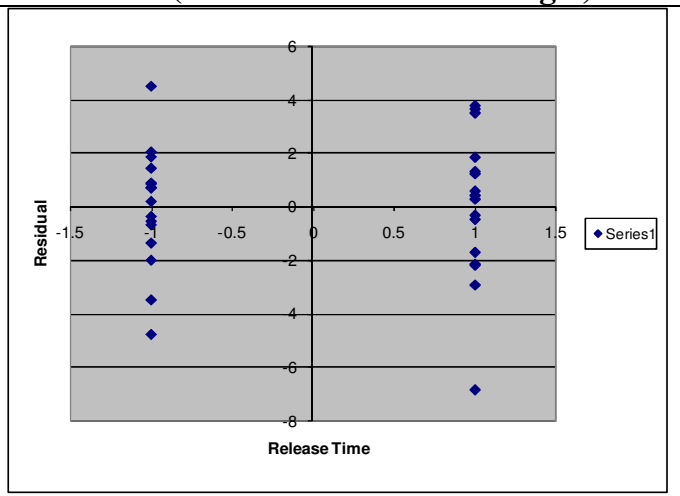

Figure 56: Model Residuals Vs Release Time (3s dead time filter setting 1)

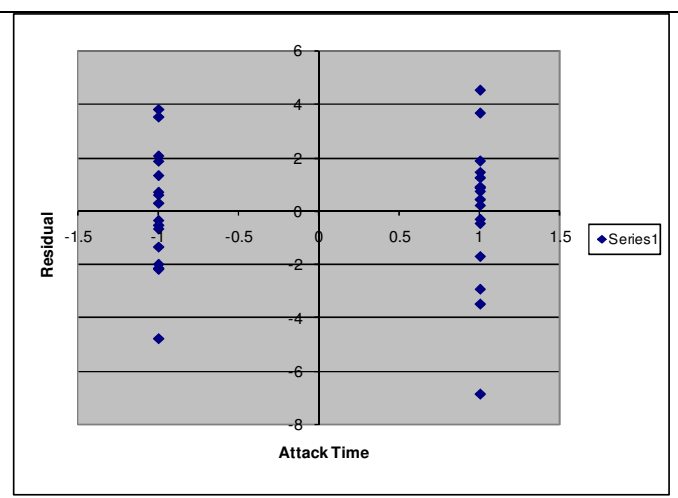

Figure 55: Model Residuals Vs Attack Time (3s dead time filter setting 1)

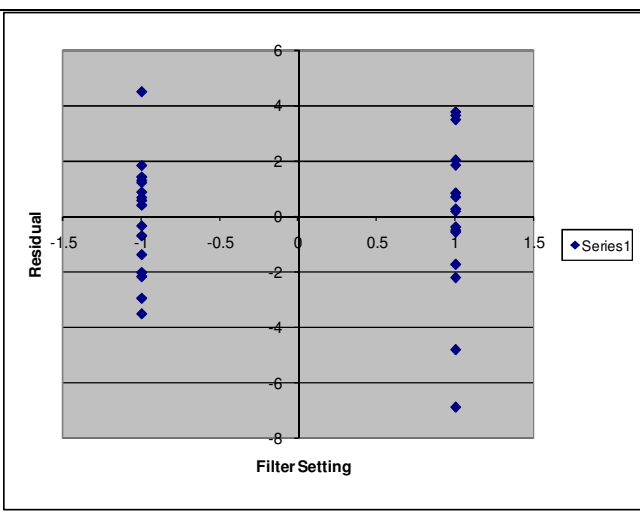

Figure 57: Model Residuals Vs Filter Level (3s dead time filter setting 1 )

\section{3: Coefficient of Determination and PRESS}

Coefficient of determination measures overall model performance [30]. If there is a possibility of introduction of any noise factors in the experiment or if any of the important factors have been missed out in the experiment, then variability in the experiment could be very large. This is quantified by the term coefficient of determination or $\mathrm{R}^{2}$. It is defined as the percentage of the total variability in the data that is accounted for by the model [30]. It is given by following equation: 


$$
R^{2}=\frac{S S(\text { model })}{S S[\text { total }]}
$$

Where, SS(model) is sum of squares calculated for fitted model and SS(total) is total sum of squares. For the best fitted model $\mathrm{R}^{2}$ should be as close to 1 .

A second model which is used to measure model performance is PRESS (Predicted Error Sum of Squares). It evaluates how well the model predicts the data. It is nothing but the sum of squares of difference between measured and the predicted data. It is given by following equation [30, 28]:

PRESS $=\sum_{i=1}^{m}\left(Y_{i}-\vec{Y}_{i 0}\right)^{2}$

Where, $\mathrm{Y}$ is the measured response and $\mathrm{Y}_{-}$cap is the predicted response for the $\mathrm{i}^{\text {th }}$ experimental run in the DOE. The lesser the value of PRESS better the model predictions are.

Table 14 gives the PRESS, coefficient of determination and corrected coefficient for determination values for all the factorial designs run in this research. From these values it is evident that for each of the generated model for fundamental psychoacoustic attribute setting 4 (3s dead time filter setting 1) turns out to be the best. 
Table 15: Model Adequacy Check Results

\begin{tabular}{|c|c|c|c|c|c|c|c|}
\hline & Run & Description & PRESS & SS(model) & SS(total) & $\mathbf{R}^{\wedge} \mathbf{2}$ & $R^{\wedge} 2$ (corr) \\
\hline \multirow{5}{*}{ Annoyance } & 1 & $0.2 \mathrm{~s}$ dead time_setting2 & 1421.99899 & 196527.874 & 197949.873 & 0.99281637 & 0.9229338 \\
\hline & 2 & 1s dead time_setting1 & 1179.95841 & 141323.934 & 142816.9 & 0.9895463 & 0.90551929 \\
\hline & 3 & 1s dead time_setting2 & 896.21347 & 155040.912 & 155937.125 & 0.99425273 & 0.95141574 \\
\hline & 4 & 3s dead time_setting1 & 189.629405 & 111103.489 & 111293.119 & 0.99829613 & 0.98554836 \\
\hline & 5 & 3s dead time_setting2 & 669.019246 & 127240.965 & 127909.984 & 0.99476961 & 0.96208975 \\
\hline \multirow{5}{*}{ Loudness N5 } & 1 & $0.2 \mathrm{~s}$ dead time_setting2 & 178.355756 & 45793.8371 & 45972.1929 & 0.99612036 & 0.9882773 \\
\hline & 2 & 1s dead time_setting1 & 55.3723315 & 19994.5094 & 20049.8818 & 0.99723827 & 0.98952938 \\
\hline & 3 & 1s dead time_setting2 & 54.0823304 & 20387.7024 & 20441.7847 & 0.99735432 & 0.98994764 \\
\hline & 4 & 3s dead time_setting1 & 14.2075508 & 8889.47011 & 8900.30867 & 0.99878223 & 0.99550926 \\
\hline & 5 & 3s dead time_setting2 & 14.1470958 & 9131.41998 & 9142.4883 & 0.99878935 & 0.99557483 \\
\hline \multirow{5}{*}{ Sharpness S50 } & 1 & $0.2 \mathrm{~s}$ dead time_setting2 & 0.06120913 & 50.8678695 & 50.9290787 & 0.99879815 & 0.9945401 \\
\hline & 2 & 1s dead time_setting1 & 0.00062142 & 41.2631417 & 41.2637631 & 0.99998494 & 0.99990197 \\
\hline & 3 & 1s dead time_setting2 & 0.00120991 & 56.5252797 & 56.5264896 & 0.9999786 & 0.99989064 \\
\hline & 4 & 3s dead time_setting1 & $1.2773 \mathrm{E}-05$ & 41.5131833 & 41.5131961 & 0.99999969 & 0.99999797 \\
\hline & 5 & 3s dead time_setting2 & $3.736 \mathrm{E}-05$ & 56.7900085 & 56.7900458 & 0.99999934 & 0.99999661 \\
\hline \multirow{5}{*}{ Roughness R5 } & 1 & $0.2 \mathrm{~s}$ dead time_setting 2 & 19.0446892 & 3460.60951 & 3472.26258 & 0.99664395 & 0.99254519 \\
\hline & 2 & 1s dead time_setting1 & 39.2937593 & 2338.35571 & 2364. & 0.98912784 & 0.9734868 \\
\hline & 3 & 1s dead time_setting2 & 34.227322 & 3370.32403 & 3392.84811 & 0.99336131 & 0.98460783 \\
\hline & 4 & 3s dead time_setting1 & 24.4873813 & 1796.1 & 1805.57057 & 0.9947548 & 0.98743502 \\
\hline & 5 & 3s dead time_setting2 & 29.9407527 & 2632.78363 & 2650.37797 & 0.99336157 & 0.98518227 \\
\hline \multirow{5}{*}{ Impulsiveness } & 1 & $0.2 \mathrm{~s}$ dead time_setting2 & 68.0836566 & 9599.64513 & 9615.19101 & 0.9983832 & 0.99370422 \\
\hline & 2 & 1s dead time_setting1 & 3.96354843 & 800.403875 & 801.815255 & 0.99823977 & 0.9930827 \\
\hline & 3 & 1s dead time_setting2 & 3.84199688 & 820.119442 & 821.5091 & 0.99830841 & 0.99336678 \\
\hline & 4 & 3s dead time_setting1 & 1.43888948 & 209.949446 & 210.399579 & 0.99786058 & 0.99344601 \\
\hline & 5 & 3s dead time_setting2 & 1.52217686 & 214.908878 & 215.385156 & 0.99778871 & 0.993257 \\
\hline
\end{tabular}




\section{8: Conclusions and Recommendations}

\section{1: Conclusions}

For the scope of this project, the analysis was limited to only single impulse. It is assumed that the objective metric for perceived annoyance with psychoacoustic attributes is best applicable to technical impulsive sounds. Thus it was decided to use real life sample impulse files from a Xerox printer for the analysis. The data is recorded at Xerox using binaural HEAD. Every recorded file has two channels one representing each ear. The channel with higher sound pressure level was selected for the analysis.

This analysis was done on the first impulse in a recorded signal called 'strip_05'. The impulse was modified for varying amplitudes, background noise levels, attack and release times and filter settings. Initially the effect of individual variable on the perceived annoyance and other fundamental psychoacoustic attributes was studied. It was found that as amplitude of an impulse increases, annoyance also increases. Also, the results showed that as the background noise increases, annoyance increases. Higher level of background noise has more impact on annoyance than the lower level. The duration of the impulse is initially divided into 3 sections: Attack, Sustain and Release. Printer generated impulses have a negligible sustain time and having control over a sustain time for such impulses complicated. Thus it was decided not to consider 'sustain time' in the analysis. In case of attack time, it was observed that with the increase in attack time, annoyance rating increases up to its maximum level of 100 and then it drops down a little if we further go on increasing the attack time. With the values of varying release time, 
annoyance value initially increases to its maximum annoyance level and then drops if release time was further increased. The change in attack and release durations for an impulse was done by stretching or shrinking the time signal using Artemis 11.2 time editing module.

The effect of spectral content in an impulsive signal was studied by applying different filters to the signal. Artemis 11.2 has a wide bank of filters available. It comes with four different filter types; Butterworth, Bessel, Tschebycheff $0.5 \mathrm{~dB}$, Tschebycheff $3 \mathrm{~dB}$ with four different filter orders from 1 to 4 . Lower order filter signify that the filter attenuation is slow and higher filter signifies that the filter attenuation is fast. The filter analysis shows that, Tschbycheff $0.5 \mathrm{~dB}$ filter with order set as 4 gives the minimum annoyance for low pass, high pass, band pass and bandstop combinations for any frequency. As the response due to butterworth filter is very close to Tchebycheff $0.5 \mathrm{~dB}$ filter and as duplication of butterwoth filter in physical terms is more convenient, it was selected as the best filter setting for planned experiments. Also out of low pass, high pass, band pass and band stop filter settings; low pass filter setting gives the best results.

Mathematical model for annoyance and other psychoacoustic metrics were determined by running $2^{5}$ factorial design on the selected impulse. The total dead time before and after the impulse was fixed as $3 \mathrm{~s}$ as it would give more accurate model. Following are the fitted mathematical models obtained after DOE:

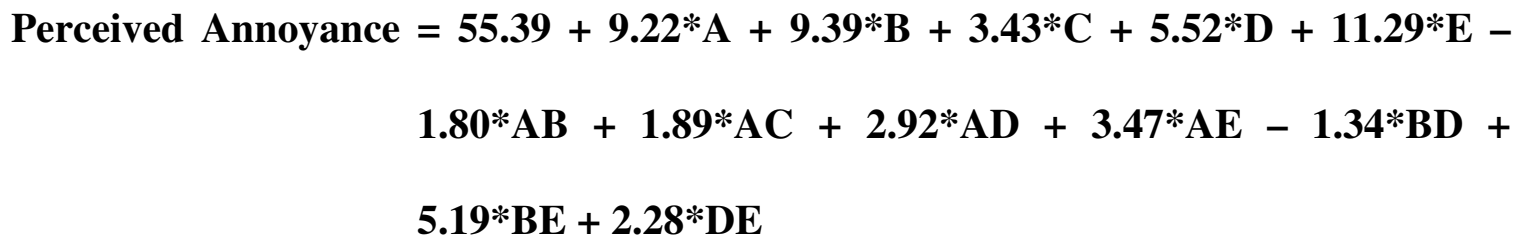



Loudness $(\mathrm{N} 5)=14.24+3.45 * \mathrm{~A}+6.31 * \mathrm{~B}+1.34 * \mathrm{C}+2.61 * \mathrm{D}+2.36 * \mathrm{E}-1.17 * \mathrm{AB}+$ $0.91 * \mathrm{AC}+1.74 * \mathrm{AD}+0.39 * \mathrm{AE}-1.21 * \mathrm{BD}+1.38 * \mathrm{BE}+0.49 * \mathrm{DE}-$ $0.48 * \mathrm{ABD}$
Sharpness $(\mathrm{S50})=1.05+0.02 * \mathrm{~A}+0.24 * \mathrm{~B}+0.34 * \mathrm{E}-0.02 * \mathrm{AB}+0.02 * \mathrm{AE}+0.15 * \mathrm{BE}$ $-0.02 * \mathrm{ABE}$
Roughness $($ R5 $)=5.73+3.27 * \mathrm{~A}-0.38 * \mathrm{~B}+1.25 * \mathrm{C}+1.59 * \mathrm{D}+2.08 * \mathrm{E}-0.42 * \mathrm{AB}+$ $0.69 * \mathrm{AC}+0.82 * \mathrm{AD}+1.34 * \mathrm{AE}-0.36 * \mathrm{BC}-0.34 * \mathrm{BD}+0.78 \mathrm{DE}$
Impulsiveness $=2.10+0.49 * \mathrm{~A}+1.04 * \mathrm{~B}+0.30 * \mathrm{C}+0.63 * \mathrm{D}+0.37 * \mathrm{E}-0.09 * \mathrm{AB}+$ $0.16 * \mathrm{AC}+0.19 * \mathrm{AD}+0.08 * \mathrm{AE}+0.23 * \mathrm{BD}+0.18 * \mathrm{BE}+0.18 * \mathrm{DE}$

where,

A= Amplitude in coded units (+1 to -1$)$

$\mathrm{B}=$ Background Noise in coded units $(+1$ to -1$)$

$\mathrm{C}=$ Attack Time in coded units $(+1$ to -1$)$

$\mathrm{D}=$ Release Time in coded units ( +1 to -1$)$

$\mathrm{E}=$ Filter Setting in coded units $(+1$ to -1$)$ 
From the above equations following can be concluded:

1) All the five factors; amplitude, background noise, attack time, release time and frequency content are significant while modeling perceived annoyance of a single impulse.

2) It is possible to tune the impulse by tweaking these factors under the accepTable criteria. Frequency content and amplitude of the impulse prove to be the most significant factors in case of annoyance.

3) Like annoyance, all five factors seem to be significant in case of loudness prediction. Amplitude of background noise seems to be the most significant factors. Thus it is necessary to maintain the low background noise level near the printer environment.

4) Attack time and the release time of an impulse do not have a significant impact on the sharpness of the impulsive sound. Frequency content is the most significant factor which governs the sharpness perception.

5) Similar to perceived annoyance, impulsiveness model have all five factors significant. It is possible to tune the impulse for low impulsiveness. When that impulsive sound is tuned for minimum impulsiveness, it will have the low annoyance value.

\section{2: Recommendations}

The newly developed mathematical models for annoyance, loudness, sharpness roughness and impulsiveness are in coded units. Thus, it is recommended to convert the values of tuning factors, amplitude, background noise, attack time, release time and frequency setting into coded units while optimizing the metric for required annoyance value. Following equation should be used to perform this transformation: 
$x=\frac{r-\frac{r_{-1}+r_{+1}}{2}}{\frac{r_{-1}-r_{+1}}{2}}$

Equation (8.2.1)

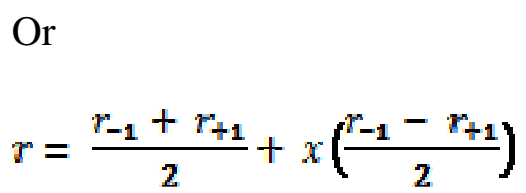

Equation (8.2.2)

Where $\mathrm{x}$ is the coded level associated with the actual level for a variable, $\mathrm{r}_{\mathrm{r}} \mathrm{r}_{-1}$ and $\mathrm{r}_{+1}$ are the actual low and high levels for that variable. For example, in case of attack time, $\mathrm{r}_{-1}$ would be $0.5 \mathrm{~ms}\left(\mathrm{x}_{-1}\right.$ in coded units) and $\mathrm{r}_{+1}$ would be $30 \mathrm{~ms}\left(\mathrm{x}_{+1}\right.$ in coded unit) as per our experimental design.

Also, it is recommended that for any future work using Artemis 11.2 the total dead time in the impulse file should be 3 s to maintain the consistency with the analysis.

As this project is entirely based on the recently developed objective metric for perceived annoyance, it is extremely important to use same algorithms to compute fundamental psychoacoustic metrics. They are:

Loudness: DIN 45631/A1 time varying loudness calculated from 1/3 octave band levels generated by $6^{\text {th }}$ order filter using Artemis $11.2[23,24,28]$

Sharpness: Calculated using Aures method with specific loudness determined with DIN 45631/A1 using Artemis 11.2 [25,28]

Roughness: Calculated with partial roughness algorithm developed by HEAD Acoustics-Artemis 11.2 software. [9,28] 
Loudness based impulsiveness: The loudness based impulsiveness is based on loudness as a function of time [28]. It is given as,

$I_{N}=\frac{1}{M} \sum_{i=1}^{M}\left[\left(N_{i}-N_{b, i}\right)\right]$

where $M$ is the total number of data points in the loudness versus time signal, $N_{i}$ is the magnitude of the original loudness signal at data point $i$ and $N_{b, i}$ is the magnitude of the background loudness signal at data point $i$. The smoothed loudness signal is calculated from a moving average of the original loudness signal [28], as given by

$N_{b}(t)=\left\{\begin{array}{cl}P_{95}\left[N_{0}, \ldots N_{2+i t}\right], & t<0.5 \\ P_{95}\left[N_{i_{t-0.5}}, \ldots, N_{i t+0.5}\right], & 0.5 \leq t \leq T-0.5 \\ P_{95}\left[N_{i}, \ldots t-T, N_{i T}\right], & t>T-0.5\end{array}\right.$

Where $i_{t}$ is the data index corresponding to time $t$, $T$ is the total length of time of original loudness signal, and $P_{95}\left[N_{a}, \ldots, N_{b}\right]$ is the $95^{\text {th }}$ percentile of the ordered loudness data values between indices $a$ and $b$. A MATLAB code developed by Andrew Willemsen is used to calculate the loudness based impulsiveness [28]. Refer to Appendix B.

Based on the above individual psychoacoustic algorithms, following metric for calculating 'perceived annoyance' should be used for obtaining response data for the DOE.

$\vec{A}=27.73+1.24 * I_{N}+0.86 * N_{5} * S_{50}+1.81 * R_{5}$

Equation (8.2.3)

Where $\hat{A}=$ predicted scale value of perceived annoyance (based on 0 to 100 scale from 


$$
\begin{gathered}
\text { jury evaluation experiment) } \\
I_{N}=\text { loudness-based impulsiveness metric } \\
N_{5}=5^{\text {th }} \text { percentile of loudness in units of sone } \\
S_{50}=\text { median of sharpness in units of acum } \\
R_{5}=5^{\text {th }} \text { percentile of roughness in units of asper }
\end{gathered}
$$




\section{9: Future Work}

The scope of this project was to identify the significant physical parameters that could possibly have an effect on the perceived annoyance of a single impulse and to model it mathematically with the help of appropriate DOE. In the future following things can be done:

1) This model is based on 32 annoyance results obtained through Artemis 11.2. The model can be validated by collecting the jury testing responses for these 32 experimental runs.

2) Further testing can be done on some other impulse files as well.

3) The annoyance model can be optimized for desired response. This can be done by fixing couple of the variables in the model depending on the practical constraints and then finding the optimum level for other factors.

4) The research can be extended to multiple impulses to simulate real life conditions. 


\section{0: References}

[1] T. Baird, N. Otto, and W. Bray, "Impulsive Noise of Printers: Measurement Metrics and Their Subjective Correlation," Proc. Noise-con 2005, Minneapolis, MN, (2005).

[2] R. Hellman and E. Zwicker, "Why can a decrease in $\mathrm{dB}(\mathrm{A})$ produce an increase in loudness?," J. Acoustic. Soc. Am., 82(5), 1700-1705, (1987).

[3] J. Parmanen, "A-weighted sound pressure level as a loudness/annoyance indicator for environmental sounds - Could it be improved?," Applied Acoustics, 68, 58-70, (2007).

[4] T. Rossing, Handbook of Acoustics, Springer.

[5] H. Fastl and E. Zwicker, Psychoacoustics: Facts and Models, Springer-Verlag, Berlin, Germany (2007).

[6] R. Sottek and K. Genuit, "Models of signal processing in human hearing," Int. J. Electron. Commun., 59, 157-165, (2005).

[7] H. Fastl, "Psychoacoustic basis of sound quality evaluation and sound engineering," Proc. International Congress of Sound and Vibration 13, Vienna, Austria, (2006).

[8] HEAD Acoustics, "Psychoacoustic Analyses I: Loudness and Sharpness," HEAD Application Note, (2009), Accessed June 2009, <http://www.headacoustics.de/ downloads/eng/application_notes/Psychoacoustic_Analyses_I_03_09e.pdf>. 
[9] HEAD Acoustics, "Psychoacoustic Analyses II: Roughness, fluctuation strength, and tonality," HEAD Application Note, (2008), Accessed June 2009, $<$ http://www.headacoustics.de/downloads/eng/application_notes/Psychoacoustic_ Analyses_I_03_09e.pdf>.

[10] K. Noumura and J. Yoshida, "Perception Modeling and Quantification of Sound Quality in Cabin," Proc. SAE 2003 Noise and Vibration Conference, Traverse City, MI, (2003).

[11] W. Ellermeier, A. Zeitler, H. Fastl, "Predicting annoyance judgments from psychoacoustic metrics: Identifiable versus neutralized sounds," Proc. Inter-noise 2004, Prague, Czech Republic, (2004).

[12] R. Sottek and K. Genuit, "Sound quality evaluation of fan noise based on hearingrelated parameters," Proc. Fan Noise 2007, Lyon, France, (2007).

[13] E. Parizet, E. Guyader, and V. Nosulenko, “Analysis of car door closing sound quality," Applied Acoustics, 69, 12-22, (2008).

[14] D. Västfjäll, M.-A. Gulbol, M. Kleiner, and T. Gärling, “Affective evaluations of and reactions to exterior and interior vehicle auditory quality," Journal of Sound and Vibration, 255(3), 501-518, (2002).

[15] A. Nykänen and A. Sirkka, "Specification of component sound quality applied to automobile power windows," Applied Acoustics, 70, 813-820, (2009).

[16] A. Zeitler and P. Zeller, "Psychoacoustic Modeling of Sound Attributes", Proc. 2006 SAE World Congress, 2006-01-0098, Detroit, MI, (2006). 
[17] F. Rossi and A. Nicolini, "Squeaking noise psychoacoustic evaluation for car passengers," Proc. International Congress on Sound and Vibration 15, Daejeon, Korea, (2008).

[18] N. Otto and G. Wakefield, "A Subjective Evaluation and Analysis of Automotive Starter Sounds," Noise Control Eng. J., 41(3), 377-382, (1993).

[19] E. Altinsoy, G. Kanka, and H. T. Belek, "A comparative study on the sound quality of wet and dry type vacuum cleaners," Proc. International Congress on Sound and Vibration 6, Copenhagen, Denmark, (1999).

[20] I. Sobhi and P. Ladegaard, "Design of Combination Metrics for Two Household Appliances," Proc. International Congress on Sound and Vibration 6, Copenhagen, Denmark, (1999).

[21] W. Aures, "Der sensorische Wohlklang als Funktion psychoakustischer Empfindungsgrößen,” Acustica, 59, 282-290, (1985).

[22] International Organization for Standardization, Acoustics - Methods for calculating loudness level, ISO 532:1975, Geneva, Switzerland, (1975).

[23] Deutsche Institut für Normung e. V., Berechnung des Lautstärkepegels und der Lautheit aus dem Geräuschspektrum - Verfahren nach E. Zwicker, DIN 45631, (1990).

[24] Deutsche Institut für Normung e. V., Berechnung des Lautstärkepegels und der Lautheit aus dem Geräuschspektrum - Verfahren nach E. Zwicker - Änderung 1, DIN 45631/A1, (2007).

[25] G. von Bismarck, "Sharpness as an attribute of the timbre of steady sounds," Acustica, 30, 159-172, (1974). 
[26] W. Aures, "Berechnungsverfahren für sensorischen Wohlklang beliebiger Schallsignale," Acustica, 59, 130-141, (1985).

[27] E. Terhardt, G. Stoll, M. Seewann, "Algorithms for extraction of pitch and pitch salience from complex tonal signals," J. Acoust. Soc. Am., 71(3), 679-688, (1982).

[28] A. Willemsen, "Objective Metric for Assessingthe Perceived Annoyance of Impulsive Sounds," Masters Degree Thesis, Houghton, MI, (2009).

[29] HEAD Acoustics, "Functions of ATP 10," HEAD Application Note, (2008),

[30] R. Devor, T. Chang, J. Sutherland, Statistical Quality Design and Control Contemporary concepts and Methods, Second Edition,(2007).

[31] U. Widmann, "A psychoacoustic annoyance concept for application in sound quality," Proc. Noise-con 97, University Park, PA, (1997).

[32] T. H. Pedersen, "Objective method for measuring the prominence of impulsive sounds and for adjustment of $\mathrm{L}_{\mathrm{Aeq}}$," Proc. Inter-noise 2001, The Hague, The Netherlands (2001).

[33] S. Amman, M. Blommer, and J. Greenberg, "An auditory model for the prediction of detection thresholds of impulsive sound events," Proc. Noise-con 2000, Newport Beach, CA, (2000).

[34] M. Blommer, A. Eden, and S. Amman, "Sound Quality Metric Development and Application for Impulsive Engine Noise," Proc. SAE 2005 Noise and Vibration Conference, Traverse City, MI, (2005). 
[35] R. Sottek, P. Vranken, and G. Busch, "A Model for Calculation of Impulsiveness," Proc. DAGA 1995, (1995).

[36] International Organization for Standardization, Acoustics - Measurement of Airborne Noise Emitted by Information Technology and Telecommunications Equipment, ISO 7779:1999, Geneva, Switzerland , (1999).

[37] NORDTEST, Acoustics: Prominence of Impulsive Sounds for Adjustment of $L_{\text {Aeq }}$, NORDTEST Method NT ACOU 112, (2002).

[38] S. Dfi Dell, K. Pearsonsm, M. Grignetti and D. Green, "Noisiness of Impulsive Sounds", Bolt Beraneka and Newman Incorporated, Canoga Park, California (1991).

[39] I. Boullet, J. Parizeau and S. Meunier, "Temporal summation of loudness as a function of frequency and temporal pattern", The 33rd International Congress and Exposition on Noise Control Engineering, Prague (1991).

[40] M. D. Rao and H. A. Evensen, MEEM4704 Acoustics and Noise Control Course Notes, Michigan Technological University, Houghton, MI, (2005).

[41] Steven Smith, The Scientist and Engineer's Guide to Digital Signal Processing 


\section{Appendix A}

\section{A1: Calculation Matrix for $2^{5}$ Full Factorial Design}

Table 16: Calculation Matrix for $2^{5}$ Full Factorial Design

\begin{tabular}{|c|c|c|c|c|c|c|c|c|c|c|c|c|c|c|c|c|c|c|c|c|c|c|c|c|c|c|c|c|c|c|c|c|}
\hline 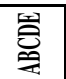 & 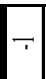 & -1 & - & 7 & -1 & $\rightarrow$ & $T$ & $1-1$ & - & $T$ & $T$ & - & $T$ & -1 & - & 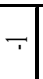 & - & $-T$ & $-T$ & - & - & - & - & $-T$ & - & & - & - & & -1 & - & - \\
\hline 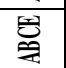 & - & 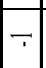 & - & $\because$ & -7 & - & -7 & -1 & 7 & -1 & 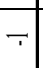 & -1 & -1 & -1 & - & 7 & -1 & -1 & -7 & - & -1 & -1 & -1 & -7 & - & -1 & -1 & -7 & -1 & - & -1 & - \\
\hline 됭 & -1 & $T$ & $T$ & - & - & $T$ & $T$ & - & $T$ & - & -1 & $-T$ & $T$ & - & - & $T$ & -7 & - & - & $-T$ & $T$ & - & - & $T$ & - & 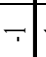 & $T$ & - & -1 & $T$ & $T$ & - \\
\hline 岂 & - & -7 & $T$ & - & $-T$ & - & - & $-T$ & -1 & $-T$ & $\rightarrow$ & - & $T$ & - & - & -1 & $-T$ & - & - & -7. & -1 & -7 & 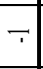 & -1 & -7. & - & -1 & -1 & -1 & 7 & -1 & - \\
\hline 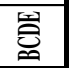 & -1 & $\because$ & -7 & -1 & -7 & - & -1 & -7 & -1 & -1 & -1 & $T$ & - & $T$ & -7 & -1 & -1 & -7 & $T$ & -1 & 7 & -1 & - & $\rightarrow$ & 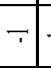 & -1 & -1 & $T$ & -1 & $T$ & $-T$ & - \\
\hline ర్లి & - & -1 & 7 & $\rightarrow$ & -7 & $\rightarrow$ & -1 & -1 & -7 & 7 & - & -1 & -1 & -1 & 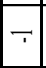 & 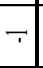 & -1 & -1 & - & -1 & - & -1 & $T$ & -7 & - & - & $-T$ & $-T$ & -1 & -7 & -1 & - \\
\hline ह & -7 & -1 & - & 7 & -1 & $T$ & -1 & -1 & $-7 \mid$ & -1 & -1 & -1 & - & -1 & 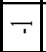 & -1 & -1 & -1 & - & -7 & -1 & -7 & $T$ & - & 7 & -1 & -1 & 7 & -1 & $T$ & -1 & - \\
\hline 天ิ & -7 & - & - & -7 & -1 & - & -1 & -7 & -1 & -1 & $\rightarrow$ & - & -1 & -1 & -7 & -1 & $-T$ & -1 & - & -7 & $T$ & -1 & -1 & $-T$ & - & $\rightarrow$ & -1 & - & -1 & 7 & -1 & - \\
\hline 舁 & $\neg$ & -1 & 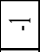 & -1 & -1 & $T$ & -1 & $T$ & -1 & $T$ & -1 & -7 & 7 & -1 & 7 & -1 & $-7 \mid$ & -1 & -1 & -1 & -1 & $-7 \mid$ & -1 & $T$ & - & $\rightarrow$ & - & $-T$ & $\rightarrow$ & - & 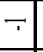 & - \\
\hline ర్ల్ & $\cdot$ & $\rightarrow$ & - & -1 & -1 & - & -1 & $T$ & -1 & -1 & $\rightarrow$ & -7 & -7 & -1 & - & - & -7 & -1 & - & - & -1 & -1 & $\neg$ & 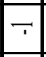 & - & -1 & -1 & - & -1 & $T$ & -1 & - \\
\hline 等 & -7 & - & - & -7 & -7 & - & -1 & $T$ & -7 & -1 & -1 & -1 & $T$ & -1 & -1 & $\rightarrow$ & -1 & -7 & -7 & -1 & -1 & -7 & $\neg$ & -1 & - & 7 & -7 & - & -1 & $T$ & 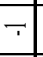 & - \\
\hline st & $T$ & - & $T$ & -1 & -1 & 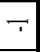 & -1 & $\neg \mid$ & $T$ & -1 & $\rightarrow$ & - & -1 & $T$ & - & 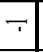 & -1 & -1 & - & -7 & $T$ & -1 & 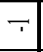 & - & - & 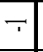 & - & -7 & 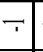 & 一 & 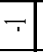 & - \\
\hline ర్లి & $T$ & $T$ & - & -1 & -1 & - & -1 & 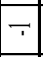 & $T$ & $T$ & -1 & -1 & - & - & $T$ & TI & - & - & 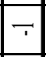 & $T$ & 7 & -7 & - & - & - & -1 & 7 & 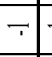 & 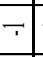 & 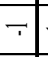 & -1 & - \\
\hline 票 & $\neg$ & - & -7 & -1 & 7 & - & -7 & -1 & -1 & 7 & -1 & -7 & -1 & -7 & - & -7 & -1 & $-T$ & - & -7 & -1 & -7 & - & $T$ & $\neg$ & -1 & $T$ & - & $\rightarrow$ & - & 7 & - \\
\hline శ్ & $-T$ & - & - & -1 & -1 & $T$ & -1 & - & -1 & - & -7 & -7 & - & -1 & -7 & $-T$ & - & - & $-T$ & - & - & -1 & $T$ & -7 & $\rightarrow$ & $T$ & - & - & -1 & - & -1 & - \\
\hline 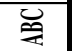 & 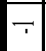 & -1 & $T$ & $T$ & -1 & - & -1 & - & -1 & -1 & - & - & $\tau$ & 7 & 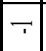 & $-T$ & - & - & - & - & $T$ & -7 & $T$ & -7 & 7 & 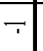 & $T$ & 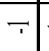 & -1 & - & -1 & - \\
\hline 原 & 二 & $T$ & $\tau$ & - & -1 & $T$ & $T$ & - & - & $T$ & $T$ & - & - & $T$ & 7 & - & - & $T$ & 7 & -1 & - & 7 & $T$ & - & - & 7 & $\div$ & - & -1 & $T$ & 7 & - \\
\hline 穵 & - & 7 & 二 & 7 & 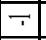 & - & 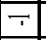 & - & - & 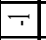 & - & 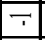 & 7 & - & 7 & - & - & 7 & - & \begin{tabular}{|l|} 
\\
\end{tabular} & 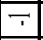 & - & 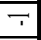 & - & 二 & 7 & - & 7 & 7 & - & 7 & - \\
\hline 已 & - & - & 7 & 7 & $T$ & 7 & - & 二 & - & - & 7 & \begin{tabular}{|l|} 
\\
\end{tabular} & 7 & $T$ & - & - & - & - & 7 & \begin{tabular}{|l|} 
\\
\end{tabular} & 7 & 7 & - & - & - & 7 & 7 & 7 & 7 & $T$ & -1 & - \\
\hline 瓷 & - & 7 & - & 7 & - & 7 & - & $T$ & 7 & - & 7 & - & 7 & - & 7 & - & - & $T$ & - & \begin{tabular}{|l|} 
\\
\end{tabular} & - & 7 & - & 7 & 7 & 7 & -7 & - & 7 & - & 7 & - \\
\hline อิ & - & - & 7 & 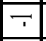 & -1 & - & 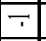 & 7 & 7 & 7 & 二 & - & 7 & 7 & - & - & - & 二 & 7 & \begin{tabular}{|l|} 
\\
\end{tabular} & - & - & $T$ & 7 & 7 & 7 & - & - & 7 & 7 & -1 & - \\
\hline$\overline{\mathscr{e}}$ & - & -1 & - & -1 & 7 & 7 & 7 & 7 & 7 & 7 & 7 & 7 & - & -1 & -1 & -1 & -1 & - & -1 & -1 & 7 & 7 & 7 & 7 & 7 & 7 & 7 & 7 & -1 & - & -1 & - \\
\hline 空 & 二 & 7 & - & 7 & -1 & 7 & -1 & 7 & -1 & 7 & - & 7 & - & 7 & -1 & 7 & 7 & - & 7 & - & 7 & -1 & 7 & -1 & 7 & - & 7 & - & 7 & - & 7 & - \\
\hline 穴 & - & -1 & 7 & 7 & -7 & - & 7 & 7 & - & -1 & 7 & 7 & 二 & - & 7 & 7 & -7 & 7 & - & 二 & 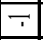 & 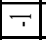 & - & - & 7 & 7 & -1 & 二 & 7 & 7 & $=$ & 二 \\
\hline 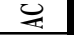 & - & -1 & - & -1 & $T$ & $T$ & 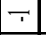 & 7 & - & -1 & - & - & 7 & $T$ & 7 & $T$ & $T$ & 7 & 7 & 7 & -1 & -1 & - & - & 7 & $T$ & 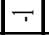 & 7 & -1 & - & - & - \\
\hline$\approx$ & - & -1 & - & -1 & -1 & - & -1 & 一 & 7 & 7 & 7 & 7 & 7 & 7 & 7 & 7 & 7 & 7 & 7 & 7 & 7 & 7 & 7 & 7 & - & - & -1 & - & -1 & - & - & - \\
\hline 도 & 7 & -1 & 7 & -1 & 7 & - & 7 & 二 & 7 & -1 & 7 & -1 & 7 & -1 & 7 & -1 & 7 & - & 7 & - & 7 & -1 & 7 & - & 7 & - & 7 & - & 7 & 二 & 7 & $=$ \\
\hline e & $T$ & 7 & - & -1 & 7 & 7 & -1 & - & 7 & 7 & - & - & $T$ & 7 & -1 & -1 & 7 & 7 & -1 & -1 & 7 & 7 & - & - & $\bar{T}$ & 7 & -1 & - & 7 & 7 & -1 & - \\
\hline U & $T$ & 7 & 7 & $T$ & -1 & - & -1 & - & 7 & \begin{tabular}{|l|} 
\\
\end{tabular} & 7 & 7 & - & -1 & - & - & 7 & 7 & 7 & 7 & - & -1 & - & - & 7 & 7 & 7 & 7 & -1 & -1 & -1 & - \\
\hline$\infty$ & $T$ & 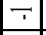 & 7 & 7 & 7 & $T$ & 7 & 7 & - & - & - & - & - & - & - & - & 7 & 7 & 7 & $T$ & $\div$ & 7 & 7 & 7 & -1 & - & - & -1 & - & -1 & - & - \\
\hline$\pi$ & $T$ & 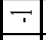 & 7 & 7 & $T$ & 7 & $T$ & 7 & 7 & 7 & 7 & 7 & $T$ & 7 & 7 & $T$ & - & - & 7 & -1 & - & -1 & - & - & -1 & - & - & -1 & -1 & -1 & -1 & - \\
\hline 镸 & $\square$ & - & - & - & - & - & - & & - & 1 & - & - & $\square$ & - & - & - & - & - & - & - & - & - & - & - & - & - & - & - & 1 & - & - & - \\
\hline & & & & & & & & & & & & & & & & & & & & $\approx$ & & & & & & & & & & & & $\approx$ \\
\hline
\end{tabular}




\section{A2: Computed Values for Loudness N5, Sharpness S50, Roughness R5, Impulsiveness and Perceived Annoyance}

\section{A) Impulse: 1s dead time filter setting 1}

Table 17: Psychoacoustic Response values for file: 1s dead time filter setting 1

\begin{tabular}{|c|c|c|c|c|c|c|c|c|c|c|c|}
\hline StdOrder & $\mathbf{A}$ & B & $\mathbf{C}$ & D & $\mathbf{E}$ & $\begin{array}{l}\text { Loudness } \\
\text { N5(sone) }\end{array}$ & $\begin{array}{l}\text { Sharpness } \\
\text { S50(acum) }\end{array}$ & $\begin{array}{c}\text { Roughness } \\
\text { R5(asper) }\end{array}$ & \begin{tabular}{|l|} 
Impuls \\
iveness
\end{tabular} & $\begin{array}{c}\text { Annoy } \\
\text { ance }\end{array}$ & $\begin{array}{c}\text { Annoyance } \\
\text { Rating }\end{array}$ \\
\hline 1 & -1 & -1 & -1 & -1 & -1 & 1.85 & 0.62 & 0.19 & 0.32 & 29.45 & 29.45 \\
\hline 2 & -1 & -1 & -1 & -1 & 1 & 2.92 & 0.92 & 0.39 & 0.51 & 31.37 & 31.37 \\
\hline 3 & -1 & -1 & -1 & 1 & -1 & 5.66 & 0.62 & 1.91 & 1.01 & 35.46 & 35.46 \\
\hline 4 & -1 & -1 & -1 & 1 & 1 & 9.84 & 0.93 & 5.47 & 1.74 & 47.64 & 47.64 \\
\hline 5 & -1 & -1 & 1 & -1 & -1 & 7.27 & 0.61 & 3.04 & 1.09 & 38.42 & 38.42 \\
\hline 6 & -1 & -1 & 1 & -1 & 1 & 8.12 & 0.92 & 3.09 & 1.28 & 41.33 & 41.33 \\
\hline 7 & -1 & -1 & 1 & 1 & -1 & 8.49 & 0.62 & 3.44 & 1.54 & 40.36 & 40.36 \\
\hline 8 & -1 & -1 & 1 & 1 & 1 & 13.21 & 0.93 & 6.94 & 2.26 & 53.64 & 53.64 \\
\hline 9 & -1 & 1 & -1 & -1 & -1 & 14.66 & 0.80 & 1.44 & 3.85 & 45.16 & 45.16 \\
\hline 10 & -1 & 1 & -1 & -1 & 1 & 22.05 & 1.77 & 2.63 & 5.27 & 72.68 & 72.68 \\
\hline 11 & -1 & 1 & -1 & 1 & -1 & 14.87 & 0.80 & 1.58 & 3.74 & 45.45 & 45.45 \\
\hline 12 & -1 & 1 & -1 & 1 & 1 & 22.94 & 1.78 & 4.28 & 5.38 & 77.23 & 77.23 \\
\hline 13 & -1 & 1 & 1 & -1 & -1 & 16.28 & 0.80 & 1.92 & 4.12 & 47.46 & 47.46 \\
\hline 14 & -1 & 1 & 1 & -1 & 1 & 22.88 & 1.77 & 3.10 & 5.54 & 75.06 & 75.06 \\
\hline 15 & -1 & 1 & 1 & 1 & -1 & 16.54 & 0.80 & 2.11 & 3.99 & 47.82 & 47.82 \\
\hline 16 & -1 & 1 & 1 & 1 & 1 & 24.46 & 1.77 & 4.85 & 5.61 & 80.80 & 80.80 \\
\hline 17 & 1 & -1 & -1 & -1 & -1 & 7.19 & 0.60 & 1.94 & 1.12 & 36.36 & 36.36 \\
\hline 18 & 1 & -1 & -1 & -1 & 1 & 10.53 & 1.08 & 10.26 & 1.70 & 58.18 & 58.18 \\
\hline 19 & 1 & -1 & -1 & 1 & -1 & 21.33 & 0.61 & 6.36 & 3.82 & 55.08 & 55.08 \\
\hline 20 & 1 & -1 & -1 & 1 & 1 & 34.74 & 1.09 & 18.16 & 6.30 & 100.82 & 100.00 \\
\hline 21 & 1 & -1 & 1 & -1 & -1 & 27.88 & 0.59 & 10.06 & 4.18 & 65.31 & 65.31 \\
\hline 22 & 1 & -1 & 1 & -1 & 1 & 30.57 & 1.06 & 12.60 & 4.75 & 84.39 & 84.39 \\
\hline 23 & 1 & -1 & 1 & 1 & -1 & 31.02 & 0.60 & 10.24 & 5.78 & 69.40 & 69.40 \\
\hline 24 & 1 & -1 & 1 & 1 & 1 & 46.93 & 1.07 & 21.79 & 8.23 & 120.63 & 100.00 \\
\hline 25 & 1 & 1 & -1 & -1 & -1 & 15.60 & 0.80 & 1.64 & 4.04 & 46.42 & 46.42 \\
\hline 26 & 1 & 1 & -1 & -1 & 1 & 23.41 & 1.78 & 8.43 & 5.71 & 85.93 & 85.93 \\
\hline 27 & 1 & 1 & -1 & 1 & -1 & 24.66 & 0.80 & 5.36 & 5.38 & 60.98 & 60.98 \\
\hline 28 & 1 & 1 & -1 & 1 & 1 & 41.36 & 1.78 & 14.58 & 8.47 & 127.79 & 100.00 \\
\hline 29 & 1 & 1 & 1 & -1 & -1 & 32.38 & 0.80 & 6.05 & 6.38 & 68.73 & 68.73 \\
\hline 30 & 1 & 1 & 1 & -1 & 1 & 39.82 & 1.77 & 11.66 & 8.02 & 119.24 & 100.00 \\
\hline 31 & 1 & 1 & 1 & 1 & -1 & 35.78 & 0.80 & 8.27 & 7.08 & 75.97 & 75.97 \\
\hline 32 & 1 & 1 & 1 & 1 & 1 & 52.06 & 1.77 & 17.49 & 10.11 & 151.31 & 100.00 \\
\hline
\end{tabular}




\section{B) Impulse: 1s dead time filter setting 2}

Table 18: Psychoacoustic Response values for file: $1 \mathrm{~s}$ dead time filter setting 2

\begin{tabular}{|c|c|c|c|c|c|c|c|c|c|c|c|}
\hline StdOrder & A & B & C & D & $\mathbf{E}$ & $\begin{array}{l}\text { Loudness } \\
\text { N5(sone) }\end{array}$ & $\begin{array}{l}\text { Sharpness } \\
\text { S50(acum) }\end{array}$ & \begin{tabular}{|l|} 
Roughness \\
R5(asper)
\end{tabular} & \begin{tabular}{|c|} 
Impuls \\
iveness
\end{tabular} & $\begin{array}{c}\text { Annoy } \\
\text { ance }\end{array}$ & $\begin{array}{c}\text { Annoyance } \\
\text { Rating }\end{array}$ \\
\hline 1 & -1 & -1 & -1 & -1 & -1 & 1.85 & 0.62 & 0.19 & \begin{tabular}{|l|} 
\\
\end{tabular} & 29.45 & 29.45 \\
\hline 2 & -1 & -1 & -1 & -1 & 1 & 3.08 & 0.92 & 1.17 & 0.54 & 32.96 & 32.96 \\
\hline 3 & -1 & -1 & -1 & $\overline{1}$ & -1 & 5.66 & 0.62 & 1.91 & 1.01 & 35.46 & 35.46 \\
\hline 4 & -1 & -1 & -1 & 1 & 1 & 9.95 & 0.93 & 5.75 & 1.77 & 48.30 & 48.30 \\
\hline 5 & -1 & -1 & 1 & -1 & -1 & 7.27 & 0.61 & 3.04 & 1.09 & 38.42 & 38.42 \\
\hline 6 & -1 & -1 & 1 & -1 & 1 & 8.25 & 0.93 & 3.24 & 1.31 & 41.78 & 41.78 \\
\hline 7 & -1 & -1 & 1 & 1 & -1 & 8.49 & 0.62 & 3.44 & 1.54 & 40.36 & 40.36 \\
\hline 8 & -1 & -1 & 1 & 1 & 1 & 13.30 & 0.93 & 7.12 & 2.29 & 54.12 & 54.12 \\
\hline 9 & -1 & 1 & -1 & -1 & -1 & 14.66 & 0.80 & 1.44 & 3.85 & 45.16 & 45.16 \\
\hline 10 & -1 & 1 & -1 & -1 & 1 & 22.64 & 2.03 & 3.77 & 5.40 & 80.81 & 80.81 \\
\hline 11 & -1 & 1 & -1 & 1 & -1 & 14.87 & 0.80 & 1.58 & 3.74 & 45.45 & 45.45 \\
\hline 12 & -1 & 1 & -1 & 1 & 1 & 23.46 & 2.03 & 5.40 & 5.50 & 85.34 & 85.34 \\
\hline 13 & -1 & 1 & 1 & -1 & -1 & 16.28 & 0.80 & 1.92 & 4.12 & 47.46 & 47.46 \\
\hline 14 & -1 & 1 & 1 & -1 & 1 & 23.48 & 2.02 & 4.14 & 5.67 & 83.15 & 83.15 \\
\hline 15 & -1 & 1 & 1 & 1 & -1 & 16.54 & 0.80 & 2.11 & 3.99 & 47.82 & 47.82 \\
\hline 16 & -1 & 1 & 1 & 1 & 1 & 25.04 & 2.03 & 5.79 & 5.73 & 89.01 & 89.01 \\
\hline 17 & 1 & -1 & -1 & -1 & -1 & 7.19 & 0.60 & 1.94 & 1.12 & 36.36 & 36.36 \\
\hline 18 & 1 & -1 & -1 & -1 & 1 & 11.06 & 1.75 & 15.29 & 1.82 & 74.27 & 74.27 \\
\hline 19 & 1 & -1 & -1 & 1 & -1 & 21.33 & 0.61 & 6.36 & 3.82 & 55.08 & 55.08 \\
\hline 20 & 1 & -1 & -1 & 1 & 1 & 35.01 & 1.75 & 21.00 & 6.38 & 126.34 & 100.00 \\
\hline 21 & 1 & -1 & 1 & -1 & -1 & 27.88 & 0.59 & 10.06 & 4.18 & 65.31 & 65.31 \\
\hline 22 & 1 & -1 & 1 & -1 & 1 & 31.00 & 1.71 & 17.01 & 4.85 & 110.19 & 100.00 \\
\hline 23 & 1 & -1 & 1 & 1 & -1 & 31.02 & 0.60 & 10.24 & 5.78 & 69.40 & 69.40 \\
\hline 24 & 1 & -1 & 1 & 1 & 1 & 47.17 & 1.74 & 23.74 & 8.31 & 151.62 & 100.00 \\
\hline 25 & 1 & 1 & -1 & -1 & -1 & 15.60 & 0.80 & 1.64 & 4.04 & 46.42 & 46.42 \\
\hline 26 & 1 & 1 & -1 & -1 & 1 & 24.38 & 2.04 & 12.87 & 5.90 & 101.05 & 100.00 \\
\hline 27 & 1 & 1 & -1 & 1 & -1 & 24.66 & 0.80 & 5.36 & 5.38 & 60.98 & 60.98 \\
\hline 28 & 1 & 1 & -1 & 1 & 1 & 41.87 & 2.03 & 19.31 & 8.61 & 146.49 & 100.00 \\
\hline 29 & 1 & 1 & 1 & -1 & -1 & 32.38 & 0.80 & 6.05 & 6.38 & 68.73 & 68.73 \\
\hline 30 & 1 & 1 & 1 & -1 & 1 & 40.56 & 2.02 & 15.85 & 8.20 & 137.18 & 100.00 \\
\hline 31 & 1 & 1 & 1 & 1 & -1 & 35.78 & 0.80 & 8.27 & 7.08 & 75.97 & 75.97 \\
\hline 32 & 1 & 1 & 1 & 1 & 1 & 52.52 & 2.03 & 21.48 & 10.24 & 170.98 & 100.00 \\
\hline
\end{tabular}




\section{C) Impulse: 3s dead time filter setting 2}

Table 19: Psychoacoustic Response values for file: $3 \mathrm{~s}$ dead time filter setting 2

\begin{tabular}{|c|c|c|c|c|c|c|c|c|c|c|c|}
\hline StdOrder & $\mathbf{A}$ & B & $\mathbf{C}$ & D & $\mathbf{E}$ & $\begin{array}{l}\text { Loudness } \\
\text { N5(sone) }\end{array}$ & $\begin{array}{l}\text { Sharpness } \\
\text { S50(acum) }\end{array}$ & $\begin{array}{c}\text { Roughness } \\
\text { R5(asper) }\end{array}$ & \begin{tabular}{|l|} 
Impuls \\
iveness
\end{tabular} & $\begin{array}{c}\text { Annoy } \\
\text { ance }\end{array}$ & $\begin{array}{c}\text { Annoyance } \\
\text { Rating }\end{array}$ \\
\hline 1 & -1 & -1 & -1 & -1 & -1 & 0.76 & 0.63 & 0.09 & 0.14 & 28.47 & 28.47 \\
\hline 2 & -1 & -1 & -1 & -1 & 1 & 1.20 & 0.92 & 0.55 & 0.22 & 29.95 & 29.95 \\
\hline 3 & -1 & -1 & -1 & 1 & -1 & 3.57 & 0.63 & 1.59 & 0.42 & 33.05 & 33.05 \\
\hline 4 & -1 & -1 & -1 & 1 & 1 & 5.11 & 0.92 & 4.49 & 0.72 & 40.82 & 40.82 \\
\hline 5 & -1 & -1 & 1 & -1 & -1 & 2.25 & 0.63 & 2.33 & 0.41 & 33.66 & 33.66 \\
\hline 6 & -1 & -1 & 1 & -1 & 1 & 2.68 & 0.92 & 2.69 & 0.49 & 35.34 & 35.34 \\
\hline 7 & -1 & -1 & 1 & 1 & -1 & 4.88 & 0.63 & 3.11 & 0.63 & 36.77 & 36.77 \\
\hline 8 & -1 & -1 & 1 & 1 & 1 & 6.17 & 0.92 & 5.68 & 0.93 & 44.08 & 44.08 \\
\hline 9 & -1 & 1 & -1 & -1 & -1 & 14.59 & 0.80 & 1.44 & 1.70 & 42.48 & 42.48 \\
\hline 10 & -1 & 1 & -1 & -1 & 1 & 21.91 & 2.03 & 3.29 & 2.34 & 74.80 & 74.80 \\
\hline 11 & -1 & 1 & -1 & 1 & -1 & 14.64 & 0.80 & 1.48 & 2.54 & 43.64 & 43.64 \\
\hline 12 & -1 & 1 & -1 & 1 & 1 & 22.30 & 2.03 & 4.75 & 3.88 & 80.07 & 80.07 \\
\hline 13 & -1 & 1 & 1 & -1 & -1 & 14.85 & 0.80 & 1.80 & 1.80 & 43.42 & 43.42 \\
\hline 14 & -1 & 1 & 1 & -1 & 1 & 22.27 & 2.03 & 3.67 & 2.44 & 76.23 & 76.23 \\
\hline 15 & -1 & 1 & 1 & 1 & -1 & 15.00 & 0.80 & 1.92 & 3.03 & 45.28 & 45.28 \\
\hline 16 & -1 & 1 & 1 & 1 & 1 & 22.82 & 2.03 & 5.01 & 4.51 & 82.19 & 82.19 \\
\hline 17 & 1 & -1 & -1 & -1 & -1 & 2.90 & 0.61 & 1.59 & 0.40 & 32.63 & 32.63 \\
\hline 18 & 1 & -1 & -1 & -1 & 1 & 4.04 & 1.75 & 10.00 & 0.65 & 52.72 & 52.72 \\
\hline 19 & 1 & -1 & -1 & 1 & -1 & 13.64 & 0.61 & 5.98 & 1.42 & 47.48 & 47.48 \\
\hline 20 & 1 & -1 & -1 & 1 & 1 & 19.31 & 1.76 & 19.88 & 2.36 & 95.81 & 95.81 \\
\hline 21 & 1 & -1 & 1 & -1 & -1 & 9.21 & 0.61 & 8.51 & 1.46 & 49.77 & 49.77 \\
\hline 22 & 1 & -1 & 1 & -1 & 1 & 10.27 & 1.75 & 13.84 & 1.70 & 70.36 & 70.36 \\
\hline 23 & 1 & -1 & 1 & 1 & -1 & 18.32 & 0.61 & 9.58 & 2.16 & 57.33 & 57.33 \\
\hline 24 & 1 & -1 & 1 & 1 & 1 & 23.38 & 1.75 & 22.47 & 3.11 & 107.53 & 100.00 \\
\hline 25 & 1 & 1 & -1 & -1 & -1 & 14.78 & 0.80 & 1.51 & 1.77 & 42.83 & 42.83 \\
\hline 26 & 1 & 1 & -1 & -1 & 1 & 22.52 & 2.03 & 11.19 & 2.51 & 90.39 & 90.39 \\
\hline 27 & 1 & 1 & -1 & 1 & -1 & 19.04 & 0.80 & 4.63 & 3.13 & 53.09 & 53.09 \\
\hline 28 & 1 & 1 & -1 & 1 & 1 & 28.76 & 2.03 & 17.23 & 5.00 & 115.30 & 100.00 \\
\hline 29 & 1 & 1 & 1 & -1 & -1 & 18.73 & 0.80 & 5.44 & 2.58 & 53.66 & 53.66 \\
\hline 30 & 1 & 1 & 1 & -1 & 1 & 25.83 & 2.03 & 13.89 & 3.32 & 102.02 & 100.00 \\
\hline 31 & 1 & 1 & 1 & 1 & -1 & 22.90 & 0.80 & 7.44 & 4.15 & 62.09 & 62.09 \\
\hline 32 & 1 & 1 & 1 & 1 & 1 & 32.35 & 2.03 & 19.27 & 6.14 & 126.67 & 100.00 \\
\hline
\end{tabular}




\section{A3: Coefficients for Loudness N5, Sharpness S50, Roughness R5, Impulsiveness and Perceived Annoyance Mathematical Model}

\section{A) Impulse: 1s dead time filter setting 1}

Table 20: Coefficients for Significant Factors in Predicted Model for annoyance, loudness, roughness, sharpness and impulsiveness for file: 1s dead time filter setting 1

\begin{tabular}{|c|c|c|c|c|c|c|}
\hline $\begin{array}{c}\text { Mathematical } \\
\text { Model }\end{array}$ & & $\begin{array}{l}\text { Perceived } \\
\text { Annoyance }\end{array}$ & $\begin{array}{l}\text { Loudness } \\
\text { N5(sone) }\end{array}$ & \begin{tabular}{|l} 
Sharpness \\
S50(acum)
\end{tabular} & $\begin{array}{l}\text { Roughness } \\
\text { R5(asper) }\end{array}$ & Impulsiveness \\
\hline \multirow{32}{*}{ 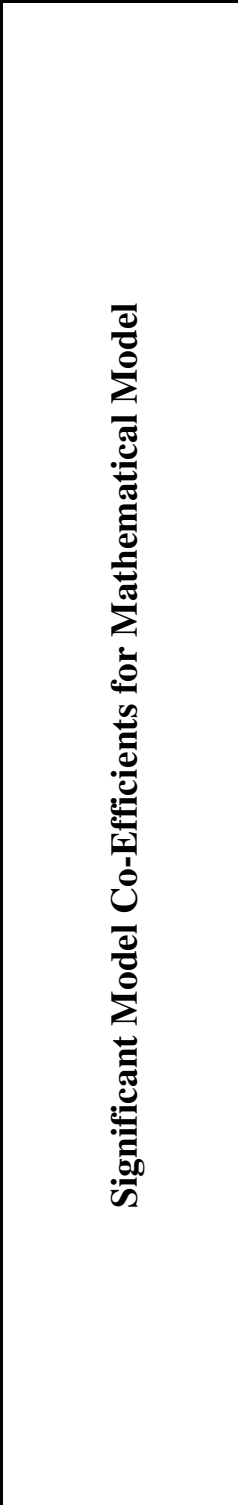 } & Mean & 63.00 & 21.48 & 1.04 & 6.60 & 4.32 \\
\hline & A & 12.42 & 8.23 & 0.02 & 3.70 & 1.37 \\
\hline & $\mathrm{B}$ & 7.60 & 4.76 & 0.24 & -0.64 & 1.47 \\
\hline & $\mathrm{C}$ & 5.04 & 4.38 & $\mathrm{NS}$ & 1.31 & 0.68 \\
\hline & $\mathrm{D}$ & 5.11 & 3.76 & NS & 1.70 & 0.71 \\
\hline & $E$ & 12.51 & 3.89 & 0.34 & 2.50 & 0.73 \\
\hline & $\mathrm{AB}$ & -3.27 & -1.33 & -0.02 & -0.48 & -0.26 \\
\hline & $\mathrm{AC}$ & $\mathrm{NS}$ & 2.97 & $\mathrm{NS}$ & 0.65 & 0.45 \\
\hline & $\mathrm{AD}$ & NS & 2.52 & NS & 0.78 & 0.50 \\
\hline & $\mathrm{AE}$ & NS & 1.34 & 0.02 & 1.56 & 0.24 \\
\hline & $\mathrm{BC}$ & $\mathrm{NS}$ & $\mathrm{NS}$ & $\mathrm{NS}$ & $\mathrm{NS}$ & -0.11 \\
\hline & $\mathrm{BD}$ & NS & -0.92 & NS & NS & -0.28 \\
\hline & $\mathrm{BE}$ & 3.34 & 1.00 & 0.15 & NS & 0.24 \\
\hline & $\mathrm{CD}$ & $\mathrm{NS}$ & -1.06 & $\mathrm{NS}$ & $\mathrm{NS}$ & -0.13 \\
\hline & $\mathrm{CE}$ & NS & $\mathrm{NS}$ & $\mathrm{NS}$ & NS & $\mathrm{NS}$ \\
\hline & $\overline{\mathrm{DE}}$ & NS & 1.56 & NS & 0.89 & 0.25 \\
\hline & $\mathrm{ABC}$ & NS & $\mathrm{NS}$ & NS & $\mathrm{NS}$ & $\mathrm{NS}$ \\
\hline & ABD & NS & NS & NS & NS & NS \\
\hline & $\mathrm{ABE}$ & -2.26 & $\mathrm{NS}$ & -0.02 & $\mathrm{NS}$ & $\mathrm{NS}$ \\
\hline & $\mathrm{ACD}$ & NS & -0.83 & NS & NS & NS \\
\hline & ACE & NS & $\mathrm{NS}$ & NS & $\mathrm{NS}$ & $\mathrm{NS}$ \\
\hline & ADE & NS & $\mathrm{NS}$ & NS & NS & NS \\
\hline & $\mathrm{BCD}$ & $\mathrm{NS}$ & $\mathrm{NS}$ & $\mathrm{NS}$ & $\mathrm{NS}$ & NS \\
\hline & $\mathrm{BCE}$ & NS & NS & $\mathrm{NS}$ & $\mathrm{NS}$ & $\mathrm{NS}$ \\
\hline & BDE & NS & NS & $\mathrm{NS}$ & $\mathrm{NS}$ & NS \\
\hline & $\mathrm{CDE}$ & $\mathrm{NS}$ & $\mathrm{NS}$ & $\mathrm{NS}$ & NS & $\mathrm{NS}$ \\
\hline & ABCD & NS & NS & NS & NS & NS \\
\hline & BCDE & NS & NS & NS & NS & NS \\
\hline & ACDE & $\mathrm{NS}$ & NS & $\mathrm{NS}$ & $\mathrm{NS}$ & $\mathrm{NS}$ \\
\hline & ABDE & $\mathrm{NS}$ & NS & NS & NS & NS \\
\hline & ABCE & NS & NS & NS & NS & NS \\
\hline & ABCDE & NS & NS & NS & NS & NS \\
\hline
\end{tabular}




\section{B) Impulse: 1s dead time filter setting 2}

Table 21: Coefficients for Significant Factors in Predicted Model for annoyance, loudness, roughness, sharpness and impulsiveness for file: $1 \mathrm{~s}$ dead time filter setting 2

\begin{tabular}{|c|c|c|c|c|c|c|}
\hline $\begin{array}{c}\text { Mathematical } \\
\text { Model }\end{array}$ & & $\begin{array}{c}\text { Perceived } \\
\text { Annoyance }\end{array}$ & $\begin{array}{l}\text { Loudness } \\
\text { N5(sone) }\end{array}$ & \begin{tabular}{|l} 
Sharpness \\
S50(acum)
\end{tabular} & $\begin{array}{c}\text { Roughness } \\
\text { R5(asper) }\end{array}$ & Impulsiveness \\
\hline \multirow{32}{*}{ 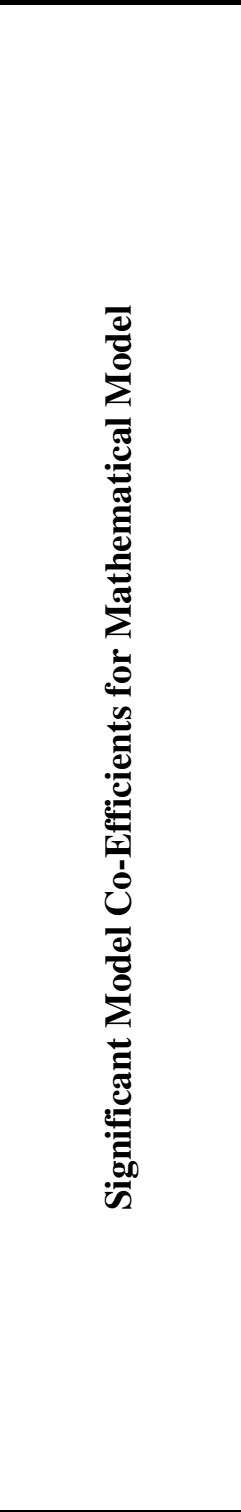 } & Mean & 65.55 & 21.70 & 1.19 & 7.77 & 4.37 \\
\hline & $\mathrm{A}$ & 12.73 & 8.27 & 0.10 & 4.51 & 1.38 \\
\hline & $\mathrm{B}$ & 7.97 & 4.85 & 0.22 & -0.45 & 1.49 \\
\hline & $\mathrm{C}$ & 4.55 & 4.37 & NS & 1.20 & 0.67 \\
\hline & $\bar{D}$ & 3.66 & 3.72 & NS & 1.54 & 0.70 \\
\hline & $\bar{E}$ & 15.06 & 4.10 & 0.49 & 3.67 & 0.78 \\
\hline & $\overline{\mathrm{AB}}$ & -4.74 & -1.34 & -0.10 & -0.47 & -0.27 \\
\hline & $\mathrm{AC}$ & $\mathrm{NS}$ & 2.96 & $\mathrm{NS}$ & 0.60 & 0.45 \\
\hline & $\mathrm{AD}$ & NS & 2.48 & NS & 0.65 & 0.50 \\
\hline & $\overline{\mathrm{AE}}$ & 3.44 & 1.38 & 0.10 & 2.37 & 0.25 \\
\hline & $\mathrm{BC}$ & $\mathrm{NS}$ & $\mathrm{NS}$ & $\mathrm{NS}$ & 0.00 & -0.11 \\
\hline & $\mathrm{BD}$ & NS & -0.93 & NS & 0.00 & -0.28 \\
\hline & $\overline{\mathrm{BE}}$ & 3.71 & 1.10 & 0.13 & $\mathrm{NS}$ & 0.26 \\
\hline & $\mathrm{CD}$ & $\mathrm{NS}$ & -1.05 & $\mathrm{NS}$ & NS & -0.13 \\
\hline & $\mathrm{CE}$ & $\mathrm{NS}$ & $\mathrm{NS}$ & $\mathrm{NS}$ & $\mathrm{NS}$ & $\mathrm{NS}$ \\
\hline & $\mathrm{DE}$ & $\mathrm{NS}$ & 1.52 & $\mathrm{NS}$ & 0.73 & 0.25 \\
\hline & $\mathrm{ABC}$ & NS & $\mathrm{NS}$ & NS & NS & $\mathrm{NS}$ \\
\hline & $\mathrm{ABD}$ & NS & NS & NS & NS & NS \\
\hline & $\mathrm{ABE}$ & -3.72 & NS & -0.10 & NS & NS \\
\hline & $\mathrm{ACD}$ & NS & -0.82 & NS & NS & NS \\
\hline & ACE & $\mathrm{NS}$ & $\mathrm{NS}$ & $\mathrm{NS}$ & $\mathrm{NS}$ & $\mathrm{NS}$ \\
\hline & ADE & NS & NS & NS & NS & NS \\
\hline & $\mathrm{BCD}$ & NS & NS & $\mathrm{NS}$ & NS & NS \\
\hline & BCE & NS & $\mathrm{NS}$ & $\mathrm{NS}$ & $\mathrm{NS}$ & NS \\
\hline & BDE & NS & NS & NS & NS & NS \\
\hline & $\overline{\mathrm{CDE}}$ & $\mathrm{NS}$ & NS & $\mathrm{NS}$ & NS & NS \\
\hline & ABCD & $\mathrm{NS}$ & NS & NS & NS & NS \\
\hline & BCDE & NS & NS & NS & NS & NS \\
\hline & $\mathrm{ACDE}$ & NS & NS & NS & $\mathrm{NS}$ & NS \\
\hline & ABDE & $\mathrm{NS}$ & $\mathrm{NS}$ & $\mathrm{NS}$ & $\mathrm{NS}$ & $\mathrm{NS}$ \\
\hline & ABCE & $\mathrm{NS}$ & $\mathrm{NS}$ & $\mathrm{NS}$ & $\mathrm{NS}$ & $\mathrm{NS}$ \\
\hline & ABCDE & NS & NS & NS & NS & NS \\
\hline
\end{tabular}




\section{C) Impulse: 3s dead time filter setting 2}

Table 22: Coefficients for Significant Factors in Predicted Model for annoyance, loudness, roughness, sharpness and impulsiveness for file: $3 \mathrm{~s}$ dead time filter setting 2

\begin{tabular}{|c|c|c|c|c|c|c|}
\hline $\begin{array}{c}\text { Mathematical } \\
\text { Model }\end{array}$ & & $\begin{array}{c}\text { Perceived } \\
\text { Annoyance }\end{array}$ & $\begin{array}{l}\text { Loudness } \\
\text { N5(sone) }\end{array}$ & $\begin{array}{l}\text { Sharpness } \\
\text { S50(acum) }\end{array}$ & $\begin{array}{l}\text { Roughness } \\
\text { R5(asper) }\end{array}$ & Impulsiveness \\
\hline \multirow{32}{*}{ 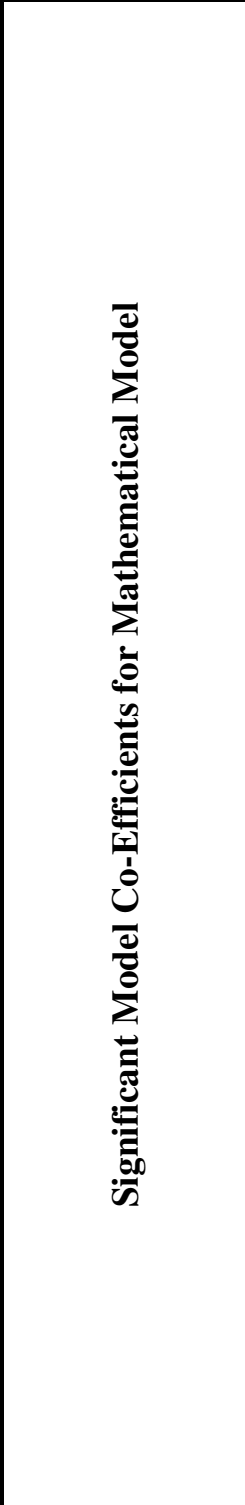 } & Mean & 58.70 & 14.41 & 1.20 & 6.76 & 2.13 \\
\hline & $\mathrm{A}$ & 10.56 & 3.47 & 0.10 & 4.02 & 0.49 \\
\hline & B & 9.43 & 6.42 & 0.22 & 0.00 & 1.05 \\
\hline & $\mathrm{C}$ & 3.19 & 1.34 & NS & 1.16 & 0.30 \\
\hline & $\mathrm{D}$ & 5.16 & 2.61 & NS & 1.65 & 0.63 \\
\hline & $E$ & 14.60 & 2.53 & 0.49 & 3.11 & 0.39 \\
\hline & $\mathrm{AB}$ & -3.44 & -1.18 & -0.10 & -0.44 & -0.09 \\
\hline & $\mathrm{AC}$ & $\mathrm{NS}$ & 0.91 & $\mathrm{NS}$ & 0.62 & 0.16 \\
\hline & $\mathrm{AD}$ & 2.56 & 1.73 & $\mathrm{NS}$ & 0.88 & 0.19 \\
\hline & $\mathrm{AE}$ & 4.80 & 0.41 & 0.11 & 2.08 & 0.09 \\
\hline & $\mathrm{BC}$ & NS & $\mathrm{NS}$ & $\mathrm{NS}$ & -0.35 & $\mathrm{NS}$ \\
\hline & $\mathrm{BD}$ & -2.50 & -1.21 & NS & -0.43 & 0.24 \\
\hline & $\mathrm{BE}$ & 5.23 & 1.49 & 0.13 & $\mathrm{NS}$ & 0.20 \\
\hline & $\mathrm{CD}$ & NS & NS & NS & $\mathrm{NS}$ & NS \\
\hline & $\mathrm{CE}$ & NS & $\mathrm{NS}$ & $\mathrm{NS}$ & $\mathrm{NS}$ & $\mathrm{NS}$ \\
\hline & $\overline{D E}$ & NS & 0.49 & NS & 0.83 & 0.18 \\
\hline & $\mathrm{ABC}$ & NS & $\mathrm{NS}$ & NS & $\mathrm{NS}$ & $\mathrm{NS}$ \\
\hline & $\mathrm{ABD}$ & $\mathrm{NS}$ & -0.48 & NS & NS & NS \\
\hline & $\mathrm{ABE}$ & -2.29 & $\mathrm{NS}$ & -0.11 & $\mathrm{NS}$ & $\mathrm{NS}$ \\
\hline & $\mathrm{ACD}$ & $\mathrm{NS}$ & NS & $\mathrm{NS}$ & $\mathrm{NS}$ & NS \\
\hline & $\mathrm{ACE}$ & NS & NS & NS & NS & NS \\
\hline & $\mathrm{ADE}$ & NS & NS & NS & NS & NS \\
\hline & BCD & NS & NS & $\mathrm{NS}$ & NS & NS \\
\hline & $\mathrm{BCE}$ & NS & NS & NS & NS & $\mathrm{NS}$ \\
\hline & $\mathrm{BDE}$ & $\mathrm{NS}$ & $\mathrm{NS}$ & $\mathrm{NS}$ & $\mathrm{NS}$ & NS \\
\hline & $\mathrm{CDE}$ & $\mathrm{NS}$ & $\mathrm{NS}$ & NS & NS & $\mathrm{NS}$ \\
\hline & ABCD & NS & NS & NS & NS & NS \\
\hline & $\mathrm{BCDE}$ & $\mathrm{NS}$ & $\mathrm{NS}$ & NS & NS & NS \\
\hline & $\mathrm{ACDE}$ & $\mathrm{NS}$ & $\mathrm{NS}$ & $\mathrm{NS}$ & $\mathrm{NS}$ & $\mathrm{NS}$ \\
\hline & $\mathrm{ABDE}$ & NS & $\mathrm{NS}$ & NS & NS & $\mathrm{NS}$ \\
\hline & ABCE & NS & $\mathrm{NS}$ & NS & NS & $\mathrm{NS}$ \\
\hline & $\mathrm{ABCDE}$ & NS & NS & NS & NS & $\mathrm{NS}$ \\
\hline
\end{tabular}




\section{Appendix B}

\section{Matlab Code for Loudness Based Impulsiveness Metric [_]}

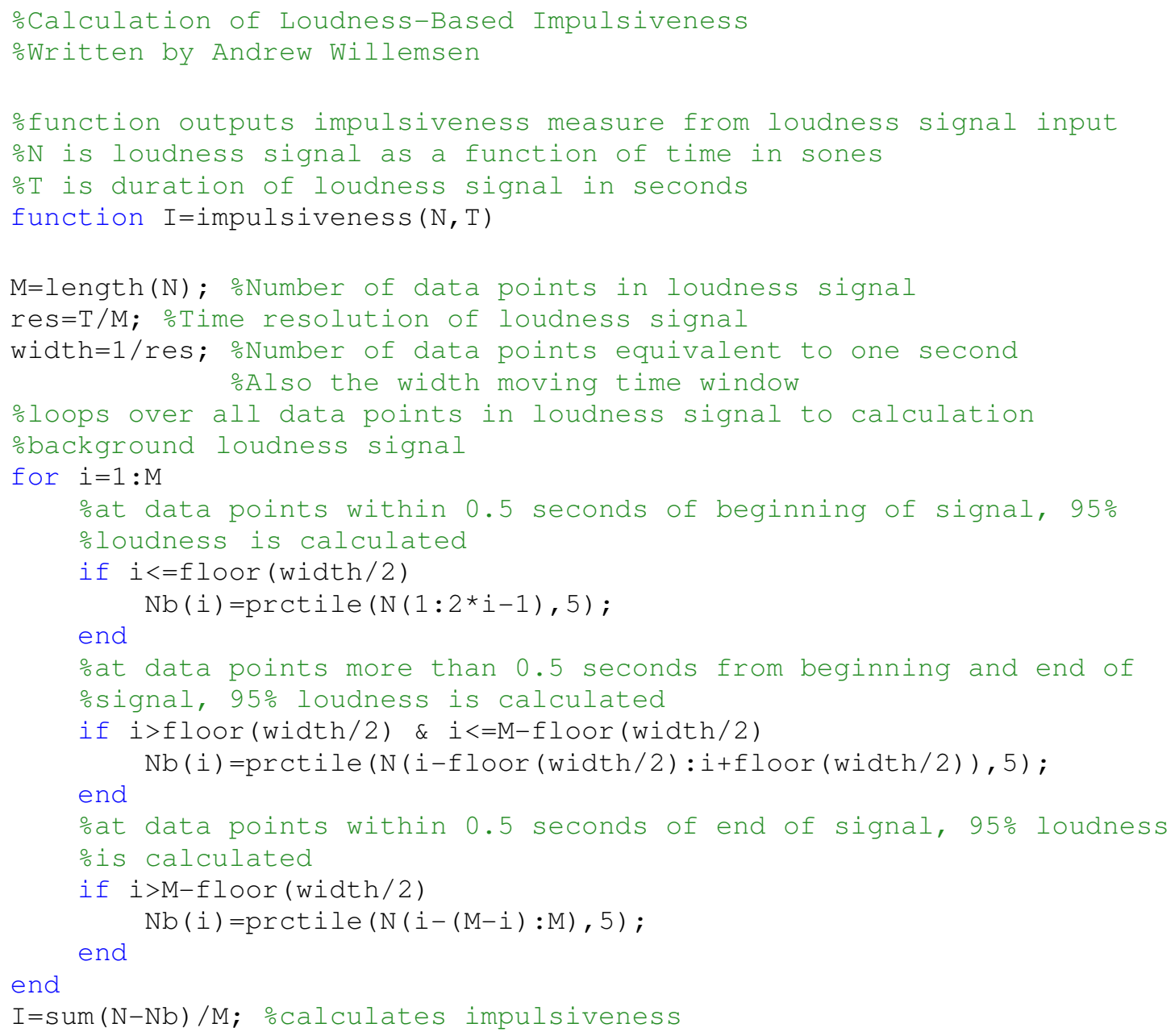




\section{Appendix C}

\section{Permission for using Copyright Material}

May $24^{\text {th }} 2010$

Dear Andrew Willemsen:

I am completing a master's dissertation at Michigan Technological University entitled

"Mathematical Model for Perceived Annoyance of Impulsive Sound In Terms Of Physical

Factors." I would like your permission to reprint in my dissertation excerpts from the following:

"Objective Metric for Assessing the Perceived Annoyance of Impulsive Sounds."

The excerpts to be reproduced are:

1) Loudness Based Impulsiveness Metric Description and MATLAB Algorithm

2) Objective metric for perceived annoyance

The requested permission extends to any future revisions and editions of my dissertation, including non-exclusive world rights in all languages, and to the prospective publication of my dissertation by UMI. These rights will in no way restrict republication of the material in any other form by you or by others authorized by you. Your signing of this letter will also confirm that you own the copyright to the above-described material.

If these arrangements meet with your approval, please sign this letter where indicated below and return it to me in the enclosed return envelope. Thank you very much.

Sincerely,

Gayatri Kadlaskar

PERMISSION GRANTED FOR THE

USE REQUESTED ABOVE:

andrear vallons

[Andrew Willemsen]

Date: May $24^{\text {th }} 2010$ 